This content is unavailable. Please consult the figure list for further details.

This content is unavailable. Please consult the figure list for further details.

This content is unavailable. Please consult the figure list for further details.
This content is unavailable. Please consult the figure list for further details.

This content is unavailable. Please consult the figure list for further details.

This content is unavailable. Please consult the figure list for further details.

\title{
Spectres of M.I.A
}

\author{
JEYAPRIYA FOSTER
}


For அம்மா and அப்பா,

And MIA ம் இ அ / எம் ஐ எ 
Remember the fighters remember the dead. But the survivors are the key $[\ldots]$ as our voices are buried in stacks and stacks of claims cases and missing people's reports. - M.I.A 


\section{ABSTRACT}

M.I.A, born Mathangi Arulpragasam, is a British Sri Lankan Tamil artistactivist whose acronymised stage persona refers to the military term Missing in Action. Set against hegemonic readings which privilege postcolonial, feminist, or transnational categories of analyses, my original contribution to knowledge is to locate M.I.A's work in the political contexts in which they are produced. I thereby foreground the hidden Tamil erasures of the Sri Lankan civil war (1983-2009) that traverse the artist's productions. The historicisation of M.I.A's politics of haunting is not only a research gap, but central in understanding the artist's texts. Using hauntology as a framework and close textual analysis as a method, this thesis constitutes a Tamil-centric reading of M.I.A's work as well as a nuanced contribution to hauntology studies.

My study identifies the Tamil cemeteries evoked in four songs-“Galang” (2003), "Bucky Done Gun" (2004), "Born Free" (2010), and "Borders" (2015) - inquiring into their visual translations, functions, objectives, and larger political significance. I particularly focus on their visual language that emerge from the collective absence-presences of the war, shared by the Tamil diaspora, of which the artist and I are part. My analyses also extend to probing salient aspects of the lyrics, performance, sound- and sartorial politics.

My textual analyses render the following findings: M.I.A's productions recirculate histories of Tamil erasure as sites of death. They replicate and 
extend the funerary work of the cemeteries of the Liberation Tigers of Tamil Eelam (LTTE)—a Sri Lankan Tamil nationalist, separatist, and militant organisation that fought for an independent state in the north and north east of Sri Lanka. The artist recartographises Tamil cemeteries into ubiquitous popcultural expressions, in which the aesthetic techniques-animated stencils, flags, murals, photo montages, and performative bodies-visibilise and physicalise the materiality of violence enacted upon Tamils. M.I.A's topographies of death rematerialise the architecture of cemeteries as inconspicuous yet omnipresent sites of absence, marking a simultaneous obscuration and ubiquitisation of cemeterial landscapes. These memory locales tend to Tamil graves, expose Tamil truth claims, and let the dead speak with and through the depiction of their brutalised bodies. Urging a responsibility for the (living) dead, they challenge the state's control over ontology and visibility that renders Tamil lives unlivable and absent. 


\section{ACKNOWLEDGEMENTS}

I would like to extend my deepest gratitude to my supervisors Dr Jo Smith and Dr Nicola Hyland for constructive feedback, continued guidance, and patience in the writing of this study, and to little Lula Hyland-Dixon for being such a delight during the meetings. I would like to express my heartfelt thanks to the examination committee, Dr Geoff Stahl, Dr Kirsten Zemke, Dr Suvendrini Perera, and Dr Giacomo Lichtner, for valuable and thought-provoking critique. Thanks to the staff of the School of English, Film, Theatre, Media Studies, and Art History, the Faculty of Graduate Research, and the Architecture and Design Library. I cannot even begin to express my gratititude to Patrick Gareth Foster whose unwavering support sustained me. Nothing would have been possible without அம்மா and அப்பா, "I do not have to walk out of this county now to be safe. My parents did that for me, and that is an act of love too great for me to ever repeat." 1

This thesis was funded in part by the Victoria Doctoral Scholarship and the Victoria Submission Scholarship. Thanks also to the Joint Research Committee.

\footnotetext{
${ }^{1}$ Ganeshananthan, Love Marriage, 289.
} 


\section{CONTENTS}

ABSTRACT II

ACKNOWLEDGEMENTS IV

CONTENTS V

GLOSSARY VII

FIGURES IX

1 RE-ENTER M.I.A 1

1.1 Objectives and Questions 2

1.2 Methodology and Theory 6

1.3 Artist's Reception 8

1.4 Chapter Overview 16

2 TAMIL POLITICS OF DEATH 19

$2.1 \quad$ History 21

2.2 Tamil Memory, Territory, and Cemetery 26

2.3 Tamil Politics of Death 33

2.4 Tamil Memory, Mourning, and Witnessing 37

2.5 Tamil Diaspora and Memory Activism 40

2.6 Summary 42

3 SPECTRAL POLITICS OF DEATH 45

3.1 The Spectre 45

3.2 The State's Destructive Politics of Death 51

3.3 The Spectre's Resistive Politics of Death 54

3.4 The Spectre's Imperative 62

3.5 Spectral Media 69

$3.6 \quad$ Summary 72

4 SPECTRES OF OLIVEECHU 73

4.1 Erasing Copies of Copies 74

4.2 Documenting the Documents: Stencils 80

$4.3 \quad$ Tanks 86 
$4.4 \quad$ Nisa 90

4.5 Tigers 99

4.6 Palm Trees 100

$4.7 \quad$ Summary 109

5 SPECTRES OF MULLIVAIKKAL 113

5.1 Making Die and Unwitnessing 114

5.2 Reinflicting or Witnessing Violence 118

5.3 "Born Free" Artwork 122

5.4 "Born Free" Music Video 125

5.5 Summary 136

6 SPECTRES OF THE SEA 139

6.1 Letting Refugees Die 141

6.2 Spectres of Slave and Refugee Ships 152

6.3 Noah's Ark Illegal as Tidalectic Haunting 155

$6.4 \quad$ Life 162

6.5 Clothing \& Lyrics 166

6.6 Production and Release 174

6.7 Summary 177

$7 \quad$ RE-EXIT MIA 181

8 BIBLIOGRAPHY 193 


\section{GLOSSARY}

EPRLF Eelam People's Revolutionary Liberation Front, Sri Lankan political party and former separatist militant Tamil organisation, 1980-. Breakaway faction of the EROS

EROS Eelam Revolutionary Organisation of Students, 1975-. Former Sri Lankan Tamil militant organisation founded in London, Marxist-leaning and militarily inactive. Co-founded by M.I.A's father Arul Pragasam (nom de guerre Arular). Most members defected to the LTTE in 1990

Freedom Birds Women's wing of the LTTE

GoSL Government of Sri Lanka, implemented a series of repressive policies that effectively constitutes systematic state violence against Tamils since 1956

LTTE Liberation Tigers of Tamil Eelam, 1976-2009. Sri Lankan Tamil nationalist, separatist, and militant organisation that fought for an independent state, Tamil Eelam, in the north and east of Sri Lanka. Founded by Velupillai Prabhakaran, annihilated by the SLA in 2009 which marked the end of the Sri Lankan civil war (1983-2009)

M.I.A Stage name of British-Tamil artist-activist Mathangi Arulpragasam, MBE, born 1975

M.I.A/MIA Denotes the blurring of boundaries dividing M.I.A as an individual stage persona and M.I.A as a collective voice for MIA

MIA Missing in Action, status of a missing combatant during war

NFZ No Fire Zone, established to protect displaced civilians in warzones. The NFZ in Mullivaikkal, Northern Sri Lanka, is also referred to as 'The Cage,' as Tamil civilians were shot by the SLA

Oliveechu Newsletter VHS-tapes and later DVDs released by the LTTE in the 1990s and early 2000s. Literally means 'light range' Sri Lanka Army, deployed against the LTTE and Tamil civilians 
SWAT

Tamil

Tiger
Special Weapons And Tactics, US law enforcement established in 1964.

Employs military equipment and tactics

Sri Lankan Tamil, also called Ceylon Tamil or Eelam Tamil, ethnolinguistic minority in Sri Lanka. Mainly refers to Tamils of the north and east of Sri Lanka. The self-identification of 'Eelam Tamil' often connotes a political stance which repudiates the GoSL

LTTE militant 


\section{FIGURES}

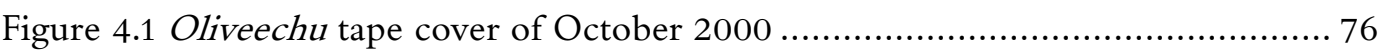

Figure 4.2 Screenshot from "Bucky Done Gun.” M.I.A and tank stencil................... 88

Figure 4.3 Screenshot from "Galang." M.I.A, tank and stealth bomber stencils.......... 89

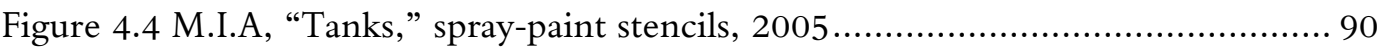

Figure 4.5 M.I.A, "Nisa, Freedom Bird,” spray paint on canvas (animated), 2002 ...... 94

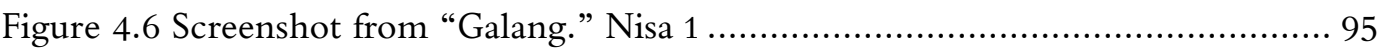

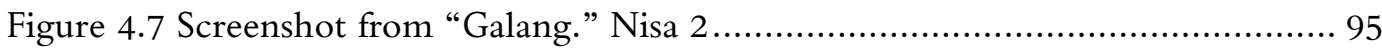

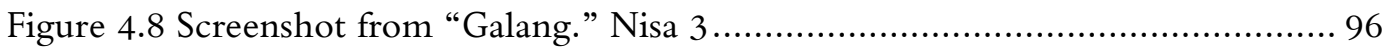

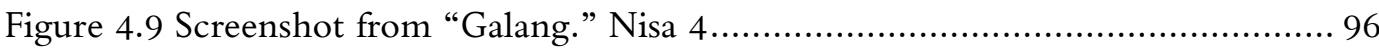

Figure 4.10 Screenshot from "Bucky Done Gun." Nisa and grenade flags ................. 97

Figure 4.11 Screenshot from “Galang.” Animated tiger ..........................................100

Figure 4.12 Screenshot from "Galang." Animated tiger 2 .....................................100

Figure 4.13 M.I.A, “Palm trees,” spray paint on linoleum, 2004 .............................104

Figure 4.14 Screenshot from "Galang." Burning palm trees ....................................105

Figure 4.15 Screenshot from “Galang.” Multiple M.I.A …......................................105

Figure 4.16 Screenshot from "Galang." Palm trees bombed ....................................106

Figure 4.17 Screenshot from "Galang." Palm trees resurrected ...............................106

Figure 4.18 Screenshot from "Galang." Tiger traverses palm trees...........................107

Figure 4.19 Screenshot from “Galang.” M.I.As amidst palm trees ............................107

Figure 4.20 Screenshot from "Galang.” M.I.As and M.I.A ......................................108

Figure 4.21 Screenshot from "Galang." M.I.As, burning palm trees, tanks ...............108

Figure 4.22 Screenshot from "Galang.” M.I.As, burning palm trees, tanks 2 ............109

Figure 5.1 Screenshot from Sri Lanka’s Killing Fields. Witnessing ............................117

Figure 5.2 Title image of Sri Lanka's Killing Fields.............................................121

Figure 5.3 Trophy image of the Mullivaikkal massacre ..........................................122

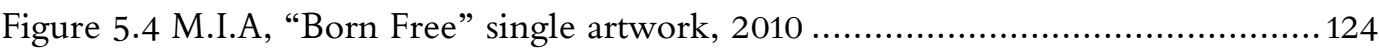

Figure 5.5 M.I.A, "Burqa print," digital print on cotton, 2010................................125 
Figure 5.6 Screenshot from "Born Free.” Mural......................................................131

Figure 5.7 Screenshot from "Born Free.” Execution...............................................132

Figure 5.8 Screenshot from "Born Free.” Oppositional gaze.....................................133

Figure 5.9 Screenshot from "Born Free." Execution of boy ……............................. 135

Figure 5.10 Screenshot from "Born Free.” Dismemberment ....................................136

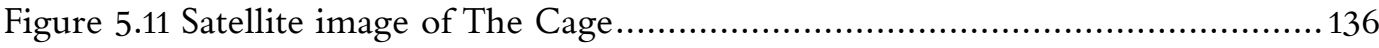

Figure 6.1 Screenshot from "Borders.” M.I.A opening scene ....................................141

Figure 6.2 Time Magazine cover, photograph by Sestini, 2014 ...............................145

Figure 6.3 Marboah, segment of "Echoes and Agreements," 2018 ...........................147

Figure 6.4 Plan of the Slave Ship Brookes......................................................... 152

Figure 6.5 Screenshot from "Borders." Lines of men............................................. 153

Figure 6.6 Screenshot from "Borders." Boat circle ............................................... 153

Figure 6.7 Screenshot from "Borders.” Boat overhead shot ................................... 155

Figure 6.8: "Borders," Time image, and the Brookes .......................................... 155

Figure 6.9 Screenshot from "Borders." Human ship 1 frontal .................................159

Figure 6.10 Screenshot from "Borders." Human ship 2 full shot .............................160

Figure 6.11 Screenshot from "Borders." Title image .................................................162

Figure 6.12 Screenshot from "Borders." Fence climbing....................................... 165

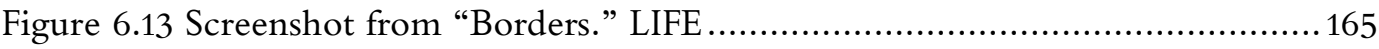

Figure 6.14 M.I.A, “Design for Sum Life painting,” 2007 .......................................166

Figure 6.15 Screenshot from "Borders." Fence of spectres ......................................166

Figure 6.16 Screenshot from "Borders." 'Fly Pirates' ............................................167

Figure 6.17 Screenshot from "Borders." 'Jesus sad' ..............................................169

Figure 6.18 Screenshot from "Borders." Mylar blankets.........................................170

Figure 6.19 Sestini, Syrian refugees on an Italian navy ship ...................................171

Figure 6.20 Screenshot from Matangi / Maya / M.I.A. "Borders" set........................177 
Mathangi (Maya) Arulpragasam, better known by her hip hop persona M.I.A, is a prominent British Sri Lankan Tamil artist-activist. Her auteurism includes musical composition, lyric writing, direction, and visual, set, and costume design. She featured in Time magazine's 100 Most Influential People of 2009 and was nominated for an Academy Award (2008), a Brit Award (2009), and three Grammy Awards (2013, twice in 2009). In 2019, she was appointed a Member of the Order of the British Empire (MBE) for her services to music. Born in West London in 1975 but raised in Jaffna, Northern Sri Lanka, amidst the civil war (1983-2009) until the age of ten, Arulpragasam's childhood was dominated by constant displacements between Sri Lanka and India. In the aftermath of the 1983 anti-Tamil pogrom Black July, her family, excluding her father, returned to London as refugees. After graduating from London's prestigious Saint Martins College with a degree in film, Arulpragasam assumed her stage persona M.I.A and received widespread international attention, becoming the most prominent voice of the Sri Lankan Tamil diaspora.

Despite the multitude of responses to M.I.A's work in western media and academia, most are Eurocentric and monologic. In contrast, the thrust of my study is to speak from a Tamil diasporic positionality as well as speaking back to the absence of Tamil voices in dominant readings of M.I.A's work. Absence is also a fundamental cornerstone of my focus, as 
I draw attention to the erasures in M.I.A's work that distinctly speak to the erasure of Tamil histories of violence. A particular form of haunting emanates from grounding M.I.A's work in the specific political contexts in which they are produced. The Hamletian evocation in the chapter title underlines both the centrality of repetition in haunting and the spectral occurrences that are simultaneously recurrences in M.I.A's work. My study argues M.I.A's output resurrects cemeteries of spectres that fulfil multiple functions of memory, mourning, and witnessing. M.I.A's productions are grounded in the intimate interlinkage of cemetery, memory, and territory in Tamil nationalism. It reflects and extends the workings of Tamil cemeteries. A Tamil politics of death and haunting in reading M.I.A's work is not only a research gap, but pivotal in understanding the political import of the artist's texts.

In the following I outline the objectives, research questions, and metholodogy of my study as well as media and academic narratives on M.I.A to illustrate the significance of this treatise. I employ the notation M.I.A to refer to the artist Mathangi Arulpragasam and MIA to refer to the military status of Missing in Action. I also use Tamil to refer to Sri Lankan Tamil.

\subsection{OBJECTIVES AND QUESTIONS}

M.I.A's work as a subject of inquiry derives not only from her positionality as the most prominent Tamil diasporic artist, but more importantly, from the political import of her work. It perhaps goes without saying that the 
notion of MIA, indicative of a haunting absence, is central to M.I.A's work. It is hence all the more surprising that this focal aspect has not been reflected upon at length before. The Tamil subtexts and histories in M.I.A's work are similarly underresearched.

As I will expound hereafter (Chapter 1.3), the current scholarship on M.I.A disregards the larger visual language and soundpolitics of the artist's productions. It unspecifically maps and thereby de-situates M.I.A's work as postcolonial hybrid, transnational, and feminist, and particularises only 'western'2 references. It thereby obliterates specific Tamil histories and divorces the work's politics from its aesthetics. Set against hegemonic mis/readings that privilege postcolonial feminist categories of analyses, my research objective is to concretise and historicise the erasures and spectres across M.I.A's productions which unearths a cemeterial Tamil politics. In contrast to readings that contextualise the artist in the multiculturality of the Global North, I, to a large extent, ground M.I.A's work in the politicohistorical contexts in which they are produced. I read her work as cemeterial memory locales and specifically situate M.I.A's art activism in the Sri Lankan Tamil struggle for self-determination and genocide recognition.

\footnotetext{
2 Similar to postcolonial historian Chakrabarty's understanding of the terms 'Europe' and 'India,' the notions of 'western,' 'non-western,' and the 'third world' 'are treated here as hyperreal terms in that they refer to certain figures of imagination whose geographical referents remain somewhat indeterminate” (Chakrabarty, 'Postcoloniality', 1.)
} 
My research hypothesis poses M.I.A's artistic output recirculates Tamil sites of death in pursuance of recognising historical wounds. ${ }^{3}$ I am guided by the following research questions: What are the specific cemeterial landscapes evoked in M.I.A's work? How are they visually translated? What are their functions and objectives? What are their significance for Tamil liberational struggles at large? I test my hypothesis through close textual analyses of mainly four songs, "Galang” (Chapter 4), "Bucky Done Gun" (Chapter 4), "Born Free” (Chapter 5), and "Borders" (Chapter 6). M.I.A's diverse repertoire provokes multiple readings, yet my study seeks to trace and historicise the covert and emancipating Tamil politicality of her work which these four songs particularly substantiate. The arrangement of the four case studies follow the songs' release dates (2003, 2004, 2010, 2015). Yet importantly, the chronology of M.I.A's work reflects the multiple erasures and restorations enacted on the (living) dead in the Sri Lankan civil war. My larger account hence exemplarily traces M.I.A's work as renarrativisations of the conflict. Illustrating the Tamil import of M.I.A's work, the selection of the four case studies resonate with key moments of Tamil history. Nonetheless, all selected case studies are major works within M.I.A's oeuvre that received widespread attention yet missed the Tamil politicality to varying degrees and thereby perhaps the crux of the works. I particularly focus on the visual language of the

\footnotetext{
3 Chakrabarty defines historical wounds as "a particular mix of history and memory," in which " $[t]$ o be able to speak [of the wound or to speak in its name]-that is, to speak self-consciously from within a history of having been wounded-is itself a historical phenomenon” (Chakrabarty, 'History', 77.)
} 
music videos, the collective familiar "histories of loss, survival, dislocation and resistance" 4 that traverse M.I.A's work, shared by the Tamil diaspora of which the artist and I are part of. My analyses of the case studies also extend to probing salient aspects of the lyrics, performance, sound- and sartorial politics.

The rationale for my methodology arises from taking M.I.A's evoked Tamil references as points of departure; indeed, they constitute the purport of my study. A close analysis of M.I.A's work cannot be divorced from the historico-political contexts she draws from. To achieve this I employ a wider analytico-theoretical framework that stubbornly harks back to a hauntology firmly situated in Tamil history and politics. In many ways, this study is, to borrow the words of media scientist Pugliese, "constitutive of the process whereby I discursify my subjectivity, and thereby historicise my identity." 5 My historicised reading of M.I.A's diasporic Tamil work is indubitably informed by my own diasporic positionality as a Tamil-German, in which, as cultural studies scholar Suvendrini Perera asserts, "this war is the determining factor of my life [...] this war placed me where I am; as it has most of my family [...] and a million unknown others with whom I share little but this one intractable, brute fate: the war."6

\footnotetext{
4 Kandasamy, 'Home', 55.

5 Pugliese, 'Assimilation', 234.

${ }^{6}$ Perera, 'Missing in Action', 5.
} 
I expound this "brute fate: the war" as cemeterial hauntings in M.I.A's work, and on a wider level, their contribution to a Tamil diaspora politics of memory, mourning, and witnessing. Herein lies the originality of my research: focalising Tamil hauntings in M.I.A's work which is grounded in a Tamil cemeterial politics within a wider Tamil struggle for national liberation. The key contribution of my study lies in revealing M.I.A's political and ideological work through my proximate relationship to Tamil histories. Extending existent feminist, postcolonial, and transnational scholarship on M.I.A's output, I maintain a historicallyinformed Tamil reading is not only a research gap, but central in understanding the artist's work. As such, my study constitutes a historically-informed Tamil reading foregrounding the hidden Tamil erasures in M.I.A's work as well as a nuanced contribution to hauntology studies.

\subsection{METHODOLOGY AND THEORY}

This study is a close textual analysis of selected works of M.I.A. Close textual analysis is a critico-theoretical method that identifies the functions, implications, and the ties between the forms and functions of textual works. The individual case studies of my thesis focus on and analyse predominantly one song at a time, invoking particular historical moments and inquiring into their significance. The rationale for a close textual analysis is to locate M.I.A's work in the contexts in which they are produced and thereby illuminate their Tamil politicality. Each case study entails a description, contextualisation, reception, and a close reading of 
the music video as the primary text. Each chapter can be read on its own, but when brought together, they support the broader claim that M.I.A's work reinscribes a chronology of erased Tamil histories. I unquestionably find myself in a quandary as I declare to excavate a Tamil reading within a Eurocentric framework of hauntology. However, the notion of spectres aptly captures the lingering presences of the past and the subject-position of MIA. Though broadly inflected by poststructuralist and postcolonial discourses, the theoretical framework of my study remains firmly embedded in the Tamil contexts in which the analysed works are produced. This interdisciplinary approach situated in Tamil contexts accounts for the complexity and specificity of the politics of haunting in M.I.A's work. By locating M.I.A's spectres in Tamil history and politics I rethink hauntology beyond Western thought. Haunting enables recurring resistance despite structural effacement across different time-spaces. It questions the primacy of presence, but also lays claims to epistemic and material restitution (I will elucidate this in Chapter 3.4). As previously stated, my study arises out of the myopia of the already undertaken postcolonial, transnational, and feminist research on M.I.A's work, to excavate cemeterial topographies. Acknowledging Tamil historicopolitical contexts and using hauntology as a theoretical framework-to my knowledge a combinatory approach unprecedented in M.I.A scholarship-my close textual analyses pose alternative ways of understanding M.I.A's work. 


\subsection{ARTIST'S RECEPTION}

By laying out the artist's reception, I illustrate the centrality of locating Tamil absences in M.I.A's work. The following review of the current academic and media reception seeks to contextualise and substantiate the rationale of my study which constitutes a study reflective of Tamil politics. Firstly, I make the case that the contestations surrounding M.I.A's biography and output in the dominant media reception delegitimise the artist. These ideological underpinnings not only apply to M.I.A as an individual, but also to the Tamil collectivity at large. In other words, the reception and delegitimisation of M.I.A's individual history and artistic output is inextricably tied to the delegitimisation of Tamil claims for selfdetermination. Secondly, I illustrate the simplification of M.I.A and her work to a generic token of transnationalism, globalisation, postcolonialism, or postcolonial feminism in the academe. This effects the ommission of specific historico-political contexts and non-western intertextualities. I conclude by teasing out reflections that constitute the point of departure and lay the groundwork for my own engagement with M.I.A's work as a cemetery replete with MIA.

\section{The Media Silencing of M.I.A}

Dominant media discourses erase the politicality of M.I.A's work. This is succinctly reflected in Sawyer's description of M.I.A in a Guardian article which limns the artist as an "unsophisticated" "provocateur" and "a drama queen" who "takes up causes [...] without much thought and picks fights 
apparently at random." 7 M.I.A is also subjected to distinct forms of silencing, including sound-political policing, accusations of terrorism, and outright censorship. For instance, M.I.A's song "Paper Planes"8 (2008) was censored by MTV for its gunshot sounds upon its release. A similar sound removal occurred in M.I.A's performance on the David Letterman Show. Music journalist Breihan suggests the sound replacements on both MTV and the talk show underlie racial motives despite the official statements of the respective channels to eliminate the song's purported advocacy of violence. ${ }^{9}$ The censorship illustrates the sound-political policing of perceived post-9/11 'brown' and 'immigrant' threat. ${ }^{10}$ "Paper Planes" satirises western perceptions of migrants and questions definitions of the national self and its racialised others. As M.I.A expounds,

It's about $[\ldots]$ immigrants and how we are seen to be really scary $[\ldots]$. People think it's about robbin' banks or $[\ldots]$ terrorism, but it's not. [...] If $[\ldots]$ you fled

\footnotetext{
7 Sawyer, 'MIA'.

${ }^{8}$ In its refrain, M.I.A raps "All I wanna do is -, and a -, and take your money." The piece (in the places of the hyphens) is undergirded by sounds of three gunshots and an opening cash register. Communication studies scholar Haddad remarks the song "put M.I.A. on the map in US popular culture [...] [and] propell[ed] M.I.A. into mainstream celebrity status” (Haddad, 'Immigration, Authorship, Censorship', 297.)

9 Breihan also suggests Letterman's introduction of M.I.A as an 'acclaimed Sri Lankan rapper,' rather than for instance a British or a British-Tamil artist, serves to highlight M.I.A's foreignness (Breihan, 'M.I.A. and the Double Standard of MTV Censorship'.) ${ }^{10}$ Communication studies scholar Haddad makes a similar point: "It is important to note that the remix of "Paper Planes" in Slumdog Millionaire does not have the loud gunshot sounds in the chorus, thus diminishing its threatening character and rendering it acceptable to accompany an Oscar-winning drama. [...] the song is now coming [...] to be associated with 'safe' internationalism and a palatable foreignness" (Haddad, 'Immigration, Authorship, Censorship', 297.)
} 
a war [...] [i]f you've been exposed to gunfights and violence and bombs and war then I can use those sounds backing my thoughts. ${ }^{11}$

The song's soundscape, as M.I.A insists, reflects the omnipresence of violence in refugee realities. The gun sounds of "Paper Planes" are policed not only because they issue from a perceived immigrant but also from a perceived terrorist. Towards the end and in the aftermath of the civil war in Sri Lanka in 2009-which coincides with the release and success of "Paper Planes" in 2008-M.I.A as well as Tamil diaspora activists drew attention to human rights abuses against Tamils perpetrated by the Government of Sri Lanka (GoSL) and appealed to the international community for an immediate intervention. Yet, they were dismissed as sympathisers of the Liberation Tigers of Tamil Eelam (LTTE) whose annihilation by the GoSL marked the end of the war and whom western nation-states (following the GoSL) classify as a terrorist organisation. M.I.A is denounced as "a cheerleader for 'terrorists" in Sri Lanka and (non-independent) Sri Lankan media ceased broadcasting her music since 2009. ${ }^{12}$ Denying systematic, state-sanctioned acts of genocide against Tamils, Sri Lanka's Foreign Secretary advised M.I.A to "stay with what she's good at, which is music, not politics."13

M.I.A's positionality as a transnational Tamil actor is of larger political significance, to the extent that the British public relations and reputation

\footnotetext{
${ }^{11}$ M.I.A quoted in Touré, 'M.I.A. Goes to War'.

12 Ramesh, 'MIA Accused'. 'Star Rapper'.

13 Palitha Kohona in Smiley, 'My Conversations with M.I.A.'
} 
management company Bell Pottinger created propaganda campaigns on behalf of and funded by the GoSL to brush off accusations of human rights violations and to specifically target M.I.A, "because I was the most visible face of this war outside of Sri Lanka,"14 the "most famous member of the Tamil diaspora." 15 Acculately aware of the silencing of Tamils (including herself), M.I.A illuminates the strategic-ideological underpinning of the 'Tamil equals Tiger equals Terrorist' formula of Sri Lankan and Western mediascapes that effectively silences the Tamil community at large,

Due to the propaganda, when you think Tamil, you automatically think Tiger [...] There's only 4000 Tamil Tiger soldiers and if you want you can wipe them out in a day [...] Using [the LTTE as a pretext] we're managing to wipe out the whole Tamil population [...] If you're a terrorist organisation, you don't have a right to speak, that is passed on to the Tamil civilians [...] [who] don't have a right to speak or the right to live. ${ }^{16}$

It is, as I will continue to argue, precisely in this context that M.I.A's artistic output opposes the state's politics of death by rematerialising Tamil sites of death.

\section{The Academic Generalisation of M.I.A}

To situate my own approach, I sketch dominant, well-meaning yet problematic academic readings. The scholarship on M.I.A is limited to a small number of journal articles or monograph chapters, all of which

\footnotetext{
${ }^{14}$ Arulpragasam, 'Vicki Leekx', 170.

15 Mackey, 'Outside Sri Lanka, Tamil Diaspora Not Ready to Surrender'. (Deliberately) misidentified as a Tiger, her father Arul Pragasam (Arular) was instead involved with the Eelam Revolutionary Organisation of Students (EROS) (Arulpragasam, 'Arular', 16.) ${ }^{16}$ M.I.A quoted in PBS interview on Smiley, M.I.A Tells of Sri Lanka Genocide.
} 
uniformly gravitate towards solemnising the artist. The respective analyses are located in cultural, media, postcolonial and feminist studies of/in the Global North and tend to make generic statements on the hybridity, feminist postcoloniality, or transnationality of M.I.A's work. Women's studies scholar Weems reads M.I.A as a 'Third World' 'refugee rebel girl' and a symbol of transnational feminism and (later) 'refugee chic' who poses brown bodies as sites of gender and sexual politics. ${ }^{17}$ Atluri, also a women's studies scholar, reads M.I.A's work as a "form of racialized feminine defiance." 18 Communications studies scholar Haddad argues M.I.A, despite attempts to "contain her excessive female ethnicity," subverts dominant representations of women of colour in popular US culture. ${ }^{19}$ Performance scholar Chambers-Letson asserts performativity in M.I.A's work negotiates "the violence necessary in a reparative diasporic, revolutionary project.”20 English postcolonial literary scholar Emig reads M.I.A's lyrical self-and current Asian-British pop music in general-as a

\footnotetext{
17 Weems, 'M.I.A.', 57. Weems reiterates this point in the article "Border Crossing" that also foregrounds M.I.A's song "10 Dollar" whilst introducing the notion of border crossing (Weems, 'Border Crossing', 179.) Weems maintains to understand the term 'Third World girls' similar to (what she claims) feminist postcolonial scholar Mohanty's notion of 'Third World women,' not as (in the words of Weems) "prediscursive essentialist lived experience[s]," but as a designation of political solidarity (Weems, 181.) This is surprising, for Mohanty critiques the very use of the term 'third world woman' and disputes the homogenisation and assumed oppression in the production of the "poor, uneducated tradition-bound" 'third world woman' against the self-representation of the emancipated and educated western woman (Mohanty, 'Feminist Postcolonial Theory', 53.)

18 Atluri, 'Like PLO I Don't Surrender', 189.

19 Haddad, 'Immigration, Authorship, Censorship', 298.

${ }^{20}$ Chambers-Letson, 'Reparative Feminisms', 178.
} 
"displaced and homesick child" with "naive and childlike fears of being left behind." ${ }^{21}$ Drawing on postcolonial and cultural studies, Eckstein claims M.I.A confronts immigrant alienation with third world revolution. ${ }^{22}$ Media scholar Creech views M.I.A as "an ideal site for the textual study of globalized identity" 23 and argues the artist and her music form hybrid globalised media. Hip hop scholar Rollefson points out that M.I.A's music-which, according to him, draws on black Atlantic musics, West African traditional musics, New York hip hop, London grime, and South Asian classical musics- "stands as a testament to the inherent hybridity of these musics." 24

Within the majority of scholarly reception I observe the following: the debate clearly circulates in western and Eurocentric framings of media, cultural, hybrid, postcolonial, performative, and feminist studies. The mentioned studies downscale M.I.A's work to a response to the limitations of white feminism, patriarchy, and neocolonialism. ${ }^{25}$ Yet neither the agents of the 'third world' nor M.I.A are exclusively concerned with writing back discourses, or, in the words of postcolonial critic Dabashi, "we are no longer talking to the dead interlocutor code-named

\footnotetext{
21 Emig, 'Missing in Act(i)On', 274-75.

22 Eckstein, 'Sound Matters', 449.

23 Creech, 'Refugee Status', 267.

24 Rollefson, Flip the Script, 136-37.

25 For instance Weems expounds, "girlhood studies have been dominated by the voices [...] which center on White, middle-class, Western/Northern, heterosexual young women” (Weems, ‘M.I.A.', 58. Weems, 'Border Crossing', 185.)
} 
'Europe,' or 'the West." 26 The scholarship on M.I.A also fails to engage with non-western intertextualities. ${ }^{27}$ Only references from 'the west' are noted, to cite Chakrabarty, the authors "produce their work in relative ignorance of non-Western histories," and are "under no obligation here to be able to name with any authority and specificity the 'Indian' (read: non-western) allusions."28 Furthermore, ignoring geopolitical differences, the studies transform M.I.A into an epitome of unspecific 'brown' 'migrant' 'desi' 'subaltern' resistance. ${ }^{29}$ It is noteworthy the existent scholarship tends to tokenise the artist, make generic observations, and obfuscate specific histories, even those that thematise M.I.A's Tamil background. Indeed, I neither deny nor dismiss feminist or postcolonial implications of M.I.A's work, yet rather insist on its deeply-rooted Tamil politics. M.I.A's work not only rests on Tamil contexts (particularly the 'academic void' of a historicised Tamil politics of death), but more

\footnotetext{
${ }^{26}$ Dabashi, Can Non-Europeans Think?, 29.

27 Weems acknowledges a reference to the film Full Metal Jacket (1987) in M.I.A's song "10 Dollar," yet remains ignorant of the well-known Tamil nursery rhyme with which the song commences. She also mistranslates 'chinna girl' as 'female villager' and 'village virgin,' (Weems, 'M.I.A.', 72. Weems, 'Border Crossing', 186, 192.) though 'chinna' simply means 'small' or 'little,' and hence refers to 'little girl.' She also claims the Arabic characters in M.I.A's "Galang" CD cover constitute "a Tamil folk aesthetic" (Weems, 'Refuting "Refugee Chic"', 123.)

${ }^{28}$ Chakrabarty, 'Postcoloniality', 2-3.

${ }^{29}$ Weems recognises the necessity of grasping the effect of globalisation in their specific locales, yet refers to a totalising South Asian block of 'Desi young women,' the desi 'community,' and the 'worldwide Desi population (Weems, 'M.I.A.', 58. Weems, 'Refuting "Refugee Chic"', 116, 128.) Meaning 'country' or 'land,' this contested Sanskrit term refers to (North) Indians whilst it also often claims Bangladeshis, Pakistanis, Sri Lankans, and their respective diasporas.
} 
importantly, the latter are key in understanding her work and its larger political significance.

In their respective case studies of M.I.A's "Born Free"-which depicts the graphic slaughter of red-headed men by US American law enforcement units and to which Chapter 5 is dedicated—cultural studies scholar Perera and postcolonial Marxist scholar Hutnyk respectively lead the way for my own engagement with M.I.A's work. Concerned with securocractic technologies that enable seeing but still render violence invisible, Perera's poignantly self-reflective article on the end of the war in Sri Lanka cites M.I.A's "Born Free" "bring[s] to the surface the nightmare images and subterranean histories of war, massacre and displacement." 30 Where Perera foreshadows an extra-ontological quality of M.I.A's work, Hutnyk emphasises its Scheherazadian story-telling praxis. He shines a light on M.I.A as "the new Scheherazade for our times" whose work is "poetry after Guantanamo." 31 Yet he also points out the limitations of M.I.A's outcry: the medial muting or censorship of the artist (as sketched earlier) that turns "the storyteller into a detainee" and the futility of speech lacking political power. ${ }^{32}$ My own analysis extends this line of scholarship and provides 'hidden histories.' By recording M.I.A's resistive sites of death, my own study, in this regard, is a cemeterial story-telling. I am ultimately interested in what I understand to be M.I.A's reinscriptions of

\footnotetext{
30 Perera, 'Missing in Action', 19.

${ }^{31}$ Hutnyk, 'Poetry', 555, 557, 569; Hutnyk, Pantomime Terror, 137.

32 Hutnyk, 'Poetry', 570, 567.
} 
Tamil cemeteries. Of prime import in M.I.A's work (and, by extension, in my own study) is not 'talking back to the centre' ('western' media or academia), but talking against silencing (living and dead) Tamils and the responsibility to our dead.

Similar to the previously cited German scholars Eckstein and Emig, I too write from a disciplinary standpoint of German literary Anglophone postcolonial studies. My own Tamil diasporic positionality and my proximate relationship to Tamil histories inflect my reading of M.I.A's diasporic Tamil art, enabling a simultaneous interior and exterior subjectposition.

\subsection{CHAPTER OVERVIEW}

In this study, I argue M.I.A resurrects Tamil cemeteries, the demolished cemeteries of the LTTE (based on "Galang" in Chapter 4), the cemetery of the Mullivaikkal massacre (based on "Born Free" in Chapter 5), and the refugee cemetery of the sea (based on "Borders" in Chapter 6). These cemeteries pursue the work of memory, mourning, and witnessing. In Chapter 2, I discuss the politics of Tamil cemeteries, arguing they assert memorial and onto-territorial claims, that is, the right to remember, mourn, be, and be there. I demonstrate the state's denial of Tamil cemeteries denies Tamil memory, mourning, and witnessing. My reading of M.I.A's work-my argument that M.I.A resurrects cemeteries of spectres-draws from this. Drawing from the work of Derrida and Agamben, Chapter 3 probes the notion of the spectre and the politics of 
death. I juxtapose the state's destructive politics of death with the spectre's resistive politics of death. My objective here is to develop a terminological and an argumentative groundwork for my subsequent analyses of M.I.A's work, namely, M.I.A's spectres pursue a resistive politics of death, specifically the work of memory, mourning, and witnessing. In Chapter 4, I argue the music video of "Galang" and "Bucky Done Gun" resurrect the cemetery of the tapes of the LTTE called Oliveechu, which in turn, iterate (the work of) LTTE cemeteries. M.I.A translates the images of the tapes into stencils that replicate the workings of LTTE cemeteries, asserting the right to remember, mourn, to be, and be there. They iterate Tamil absences and contest the Sri Lankan state's demolition of LTTE cemeteries and the illegalisation of the Oliveechu tapes by western nationstates. In Chapter 5, I argue the music video of "Born Free" and the artwork "Born Free" resurrect the cemetery of the Mullivaikkal massacre. M.I.A reproduces and translates a soldier's trophy image of the Mullivaikkal massacre-which evinced the Sri Lankan state's ultimate power and subjugation over Tamils-into a 'ginger genocide' to witness the unwitnessed event. In Chapter 6, I contend M.I.A's "Borders" resurrects the refugee cemetery of the sea. The music video's eminent mise-en-scènes draw on and transform dominant images of refugee and slave ships to oppose unwitnessing refugee deaths and expose that to let refugees die is to make refugees die. Chapter 7 provides a résumé and reflects on the relevance of M.I.A's work at large. 
The thesis does not primarily address the obvious lens of interpretationthe music of M.I.A. It focusses on visual aspects of M.I.A's work (e.g. stencil, performance art, and mise-en-scène) to make an original contribution and to answer the research questions. The specific theoretical framework and the visual focus provide an original perspective on the subject and readings which musical analyses alone do not provide.

This treatise is not an extension of the philosophical discourse on haunting in general or Derrida's hauntology in particular, but a concrete and historicised reading which reveals the hidden politics of a selection of M.I.A's work. Though drawing from postcolonial, feminist, and transnational theories, it rejects the authoritative top-down approaches emerging from these fields to prioritise a Tamil bottom-up approach. Certainly, the limit of my study is its scope, yet the selected case studies radically rethink M.I.A's work from a global, postcolonial, and feminist praxis to Tamil grave-tending, which, fundamentally is key in understanding its larger import. 


\section{Tamil Politics OF Death}

Tamil cemeteries have a bearing upon memory and the landscape. My study argues that M.I.A's work revisualises Tamil sites of death to pursue a particular politics of death. To be specific, M.I.A's cemeteries replicate the raison d'être of LTTE cemeteries (a key argument of Chapter 4). Informed by the research on Tamil politics of largely Tamil political and social scientists, this chapter seeks to address the historical context critical in understanding the political import of M.I.A's work which lies in opposing Tamil erasures.

The following historical outline is by no means exhaustive. 33 It neither sets out to minimise the atrocities committed by the LTTE nor glorify its ideologies. Rather, my aim is to provide contexts that specifically speak to my research questions and that derive from the concrete connections between M.I.A's work and the LTTE. 34 The occasional collapse of the

\footnotetext{
33 I acknowledge the complexity of the war and the multiplicity of Tamil and Tamil diasporic narratives. The works of University Teachers for Human Rights affiliated with the University of Jaffna is an example of a corpus I had to exclude (University Teachers for Human Rights, The Politics of Destruction; University Teachers for Human Rights, The Trapped People; University Teachers for Human Rights, A Sovereign Will to SelfDestruct, University Teachers for Human Rights, Land, Human Rights \& The Eastern Predicament, University Teachers for Human Rights, Hoole, and Thiranagama, The Arrogance of Power, University Teachers for Human Rights, Let Them Speak; Hoole and Sosasundaram, The Broken Palmyra.)

34 M.I.A's stencil motifs in "Galang" (Chapter 4) derive from LTTE videos and "Borders" (Chapter 6) was released on the memorial day for fallen Tigers.
} 
distinction between LTTE and Tamil identities in my analysis reflects the strong way M.I.A deliberately conflates the experiences of Tamil militant, civilian, and refugee in her work for critical and political reasons. ${ }^{35}$

In this chapter I explore the Sri Lankan state's destructive politics of death as well as a Tamil resistive and productive counter/politics (the notion of a destructive and productive politics of death will be canvassed in Chapter 3.2 and Chapter 3.3). The conflict in Sri Lanka is partly staged on the dead by means of erasing cemeteries and unseeing violence. The demolition of Tamil cemeteries by the Sri Lankan state sought to erase and delegitimise memorial and territorial claims. In other words, it derealised Tamil claims to remember, to mourn, to be, and to be there. During and in the aftermath of the war in 2009 , the state has been prohibiting (Tamil) memory, mourning, and witnessing to deny justice (I illustrate how memory, mourning, and witnessing constitute and contribute to justice in Chapter 3.4). Tamil diasporic memory activism, reflecting Tamil cemeteries, holds an affinity to memory and landscape. In this study I argue M.I.A's output replicates the work of Tamil

\footnotetext{
35 The rhetoric of a clear-cut distinction between Tamil civilians and Tamil militants is both generated and dismantled in Sri Lankan state and western (Canadian or Australian) media. The GoSL binarise Tamils into Tamils civilians who have no need to flee and Tamil terrorists who flee under the pretext of being refugees (see Ellis, 'The Smugglers' Prey'.) Canadian state media distinguishes between Tamil refugees (equalling 'authentic' civilians) and Tamil Tigers (equalling terrorists). Both discourses maintain yet also collapse the dichotomies of civilian vs militant (respectively fake asylum claimant vs terrorist). M.I.A's work deliberately amalgamates those terms not only to nullify the unsustainable distinctions, but also to point to the larger rationale of vilifying and muting a Tamil collectivity at large.
} 
cemeteries and contributes to Tamil diaspora politics of memory, mourning, and witnessing. This is effected by means of haunting which enables the recurrence of claims for justice. The LTTE cemeteries asserted memorial and territorial claims, whereas M.I.A's work centres on justice for the dead.

\subsection{HISTORY}

The ethno-linguistic majority in Sri Lanka are Sinhala who predominantly follow Buddhism, while Tamils, mainly Hindus and Christians, though a minority in the overall population, constitute a demographic majority in the north and northeast of the island. ${ }^{36}$ After independence from Britain in 1948, the Sinhala-led government enacted a series of repressive policies that effectively constitute systematic state violence against Tamils, to which the latter initially responded with non-violent protests and subsequently with organised militancy. In 1956, the parliament passed the Sinhala Only Act, thereby instituting a policy of official unilingualism which replaced English with Sinhala as the only national language. The language act encapsulates the Tamil "loss of linguistic rights and alienation from the country's educational and professional spaces," 37 and effected a

\footnotetext{
36 Unless other specified I refer to Sri Lankan Tamils as Tamils. In this account I am mainly concerned with Tamils in the north and northeast of the island, leaving out Muslim Tamils and Indian Tamils in Sri Lanka. The former community was expelled from Jaffna and the Nothern Province by the LTTE in 1990. The latter community, also referred to as 'upcountry' Tamils, was disenfranchised, decitizenized, and declared stateless in 1948 by the Ceylon Citizenship Act.

37 Kurian, Narratives, 126.
} 
significant decrease in Tamil representation in the public sector. 38 The anti-Tamil pogroms in 1956 and 1958, sparked in the wake of the language act, were the first island-wide race riots targeting and killing Tamils. The Policy of Standardisation of 1971, officially implemented to 'rectify' ethnic disparities in university enrolment, required a higher score in university entrance exams for Tamils than Sinhala, which denied Tamil admittance to universities and led to the economic marginalisation of Tamil youth. ${ }^{39}$ The Prevention of Terrorism Act of 1979-as response to growing Tamil nationalist grassroot efforts that began to organise into approximately thirty-six Tamil nationalist movements-authorised the "indiscriminate arrests, disappearances, and death[s] of Tamil youth" and established a military rule over Tamils. 40 Understood as the beginning of a systematic cultural genocide, the Jaffna Public Library-which held rare Tamil and Sinhala palmyra-ola-leaf manuscripts—was burnt by the Sinhalese police

\footnotetext{
38 Tamil leaders at the time described the policy as a form of apartheid (DeVotta, 'Ethnolinguistic Nationalism', 124.) Tamil government employees were dismissed from their positions (Sangarasivam, 'Militarizing', 61.) Political scientist DeVotta, referring to the account of eminent Tamil lawyer Ponnambalam, submits, "In 1956, 30 percent of the Ceylon administrative service, 50 percent of the clerical service, 60 percent of engineers and doctors, and 40 percent of the armed forces were Tamil. By 1970 those numbers had plummeted to 5 percent, 5 percent, 10 percent, and 1 percent, respectively" (DeVotta, 'Ethnolinguistic Nationalism', 129. Ponnambalam, Sri Lanka, 142.)

39 Sangarasivam, 'Militarizing', 61. As Wilson remarks, “To add to the damage, 'a district quota system' was put in place in 1972 which amounted to added discrimination against the Ceylon Tamils" (Wilson, Sri Lankan Tamil Nationalism, 102-3.)

${ }^{40}$ Sangarasivam, 'Militarizing', 62. It is important to note that the LTTE annihilated other Tamil organisations, forcibly conscripted child soldiers, and practiced sexual containment of its members.
} 
and organised mobs in 1981.41 This was followed by 'Black July' which refers to a series of anti-Tamil pogroms throughout Sri Lanka in July 1983. More than three thousand Tamils were murdered and thousands more displaced. International relations scholar Sriskanda Rajah states it epitomised state-sanctioned violence and impunity, the confiscation of Tamil lands, the expulsion of Tamils, and the culmination of the state's biopolitical use of the power of death (see Chapter 3.2) to secure the Sinhala Buddhist race. ${ }^{42}$ Any Sinhala Buddhist held the power to kill Tamils and "avenge their 'enemy' race." 43 Black July also signified the (re)emergence of Tamil resistance and nationalism and solidified the belief that "an armed struggle for political independence was no longer the last choice, but inevitable." 44 It established the rise of the Liberation Tigers of Tamil Eelam (LTTE) as the leading Tamil nationalist movement who saw their objective of national self-determination realised in the creation of the state of Eelam, 45 and mobilised women's participation in armed

\footnotetext{
${ }^{41}$ Wilson comments the manuscripts are "a profound symbol of the pre-existing interethnic accommodation" (Wilson, Sri Lankan Tamil Nationalism, 160.)

${ }^{42}$ Sriskanda Rajah, Government, 63. Cheran observes the commemoration of Black July in the Tamil diaspora "was the only event where victimhood takes precedence over valor and pride" (Cheran, The Sixth Genre, 19.)

${ }^{43}$ Sriskanda Rajah, Government, 63. To facilitate Tamil dispossession and elimination, the state supplied lists of Tamil residences and aided in the disposal of the bodies (Sriskanda Rajah, 64.)

${ }^{44}$ Sriskanda Rajah, Government, 65.

45 Hellmann-Rajanayagam, 'The "Groups", 178. The LTTE's stance that the conflict revolves around national self-determination, sociologist Hellmann-Rajanayagam observes, stands in contrast to other Tamil militant movements (such as the ultraleft Marxist groups EPRLF and EROS) who reframe the conflict as a class struggle and justify the state of
} 
resistance. ${ }^{46}$ The repercussions of Black July reached global proportions; its aftermath catalysed a mass refugee exodus to India, Europe, Northern America, and Australia. It caused the emergence of the second wave of the Tamil refugee diaspora, and it brought forth M.I.A and myself as refugees. In 1995, the Sri Lanka Army (SLA) militarised the Tamil north after the Battle of Jaffna, which resulted in a mass displacement and exodus of Tamils. The government take-over also meant the demolition of LTTE cemeteries by the SLA. In the early 2000s, reinforced by $9 / 11$, the LTTE was classified as a terrorist organisation and its video publications Oliveechu were prohibited in the Global North (these events are significant in Chapter 4). During the Peace Process (2002-2006) mediated by Norwegian diplomats, the LTTE rebuilt the demolished cemeteries (2002-2005). The armed conflict between the Sri Lankan military and the LTTE resumed in 2006 and ended with the defeat of the latter in 2009. The Mullivaikkal massacre in May 2009-the indiscriminate slaughter of Tamils by the Sri Lankan military in a designated No Fire Zone (NFZ)-informed the end of the war and

Eelam on grounds of neo-colonial and proletarian suppression of Sri Lankans in general and Tamils in particular (Hellmann-Rajanayagam, 179.) She rationalises the rise of the LTTE on its mass mobilisation based on the ('lower') caste background of its leadership (Hellmann-Rajanayagam, The Tamil Tigers.) Historian Vaitheespara critiques her contention-that the LTTE is the least Marxist-oriented of the militant groups-arguing she downplays the socialist impetus of the movement (Vaitheespara, 'Beyond "Benign"', 447.)

46 Sangarasivam, 'Militarizing', 62. Following Black July, between a fifth and one third of all Tiger cadres were female (Weiss, The Cage, 68.) 
signified war crimes, enforced disappearances, and human rights violation (revisited in Chapter 5). ${ }^{47}$

After the war, the LTTE cemeteries were disestablished again. Under governmental and military surveillance, harassment, and intimidation Tamils are detained and "'de-Tigerised' in massive government camps." 48 Those who flee the country as boat people are criminalised as terrorists in western states (Chapter 6).

The following historical moments (1995, 2009, and 2010) inform my reading of M.I.A's work: the Battle of Jaffna, the demolition of LTTE cemeteries by the SLA, the prohibition of LTTE videos (Chapter 4), the Mullivaikkal massacre (Chapter 5), the MV Sun Sea incident and the concomitant demonisation of Tamil refugees in western nation-states such as Canada and Australia (Chapter 6).

The conflict in Sri Lanka, as I will show in the next section, centres on territoriality and memory. Tamil nationalism-in particular the politics underlying LTTE cemeteries-reflects this. South Asian studies scholar Kanaganayakam reveals Tamil nationalism is historically bound up with

\footnotetext{
47 International politologist Kingsbury suggests the government, pursues 'a policy of genocide or of regional ethnic cleansing' against Tamils (Kingsbury, Sri Lanka, 82.) Kingsbury also maintains the state-sponsored displacement, structural discrimination, the internment camp 'disappearances' of Tamils, presumably murdered by soldiers or police without recourse to trial, suggests a demogracide (Kingsbury, 8-10.)

48 Ellis, 'The Smugglers' Prey'.
} 
Tamil territoriality which "affirmed a collective identity; it implies land, landscape and a particular way of life." 49 This connotes an intricate linkage between Tamil territory and both an individual and collective Tamil identity. Tamil nationalism, by means of centralising cemeteries, not only laid territorial claims, but also fostered remembering and mourning the dead.

\subsection{TAMIL MEMORY, TERRITORY, AND CEMETERY}

Territorial and memorial claims intersect in the conflict in Sri Lanka, Tamil nationalism, and M.I.A's work. ${ }^{50} \mathrm{~A}$ number of research studies emphasise the territorial nature of the conflict. ${ }^{11}$ Sociologists Stokke and Ryntveit remark,

Sinhalese nationalists commonly claim that the undivided island is [their] homeland [...]. Tamil nationalists [...] hold it as unquestionable that the Tamilspeaking people of Sri Lanka constitute a separate nation and that their

49 Kanaganayakam, 'Configuring Spaces', 84.

50 The strife in Sri Lanka is largely grasped as a territorial ethno-nationalist conflict. Other exegeses, beside the territorial and historico-political, emphasise its human rights, internal colonial, class, anti-capitalist or socialist impetus.

51 McDowell accentuates the conflict arose from competing territorial ideologies (McDowell, 'Symbolic Warfare in the Ethnocratic State', 23.) Similarly, for Perera, the war is a contestation of nationalist cartographic imaginations, "the genesis of Sri Lanka's civil war was essentially over the ownership of a map [...] [in which] the Tamil nationalist imagination of Eelam [...] [conflicts with] the Sri Lankan state's and Sinhala nationalists' conception of [the] integral territory of Sri Lanka" (Perera, Warzone Tourism, 171-72.) Yet, Perera's emphasis on affect in the cartographic imagination of Eelam-the notion that Tamils are emotionally invested in their homeland-is problematic (and simplistic): it reduces state discrimination to (cartographic) affect. 
traditional settlement pattern outlines the boundaries of the Tamil homeland, or Tamil Eelam. ${ }^{52}$

The conflict over territory is intimately linked to a conflict over history and memory. Political and cultural scientist Hellmann-Rajanayagam states Tamils'

emphasis on history $[\ldots]$ and use of history, go $[\ldots]$ to prove that they have a right to be there, a right to be. [...] Whoever possesses the history possesses the country, possesses the right to rule, the right to exist. 53

The struggle over history and memory not only concerns the right to exist ('a right to be'), but also the right to exist 'there,' substantiating ontoterritorial claims. Hellman-Rajanayagam propounds for Tamils history bolstered political claims for separate representation and independence. ${ }^{54}$ Remembering the history of oppression justifies the right for Tamil selfdetermination. 55 Tamil memory substantiates claims over Tamil territory and ontology, to the extent that the dispossession from the past is the dispossession from the land and the self. 56

\footnotetext{
${ }^{52}$ Stokke and Ryntveit, 'The Struggle', 288. Manogaran submits Sinhalese leaders oppose "the concept of a traditional Tamil homeland in Sri Lanka because they allege [Tamils] have a homeland in south India [...] [yet] to the Sri Lankan Tamils, Tamil Nadu is an alien state” (Manogaran, 'Colonization', 102-3.)

53 Hellmann - Rajanayagam, 'Tamils and the Meaning of History', 5 emphasis mine.

${ }^{54}$ Hellmann-Rajanayagam, 'The Politics of the Tamil Past', 112, 118.

55 Hellmann-Rajanayagam, 'The "Groups”, 177.

56 This is reflected in Anglophone diasporic Tamil literature, as literary scholar Salgado observes, "the loss of the past is connected to the loss of the land" (Salgado, "Writing Sri Lanka', 14.)
} 
Territoriality and memory not only have a bearing on the Tamil minority, but also the state. Sri Lanka, critical geographers Yiftachel and Ghanem contend, is a Sinhalese ethnocracy. ${ }^{57}$ Ethnocracies, despite the semblance of a democracy, pursue the undemocratic expansion of the dominant ethno-nation. ${ }^{8}$ They promote the "ethnicization of contested territory and power apparatus" and construct minorities as a 'threat' to "the project of 'purifying' ethnic spatial control." ${ }^{59}$ In other words, the ethnocratic state expands the dominant ethno-nation. The ethnicisation of the state apparatus and spatial control can be achieved through biopolitics and thanatopolitics, the politics of life and death (explained in Chapter 3). The racial violence of Black July (Chapter 2.1), says Rajah, is the culmination of the state's use of the power of death as part of its biopolitics to secure the Sinhala Buddhist race and ethnocratic state order. ${ }^{60}$ Any Sinhala Buddhist held the power to kill a Tamil and "avenge their 'enemy' race." ${ }^{11}$ Constituting Tamil lives as disposable and unlivable, Black July enshrined the power of death in the biopolitics of the ethnocratic state. Biopolitics became thanatopolitics as Sinhalese had the power to let die/make die and let live/make live (see Chapter 3.2).

The ethnocratic political structure as a power over life and death can be challenged by memory praxes. McDowell underlines memorialisation as

\footnotetext{
57 Yiftachel and Ghanem, 'Understanding “Ethnocratic” Regimes', 658.

58 Yiftachel and Ghanem, 647, 649.

59 Yiftachel and Ghanem, 647, 649, 652.

${ }^{60}$ Sriskanda Rajah, Government, 63.

${ }^{61}$ Sriskanda Rajah, 63.
} 
a powerful spatial strategy in ethnocracies which redefines categories of victims and perpetrators, challenges hegemonic narratives, legitimises (counter)violence, and constitutes an act of warfare. ${ }^{62}$ Commemorating the dead in particular within ethnocracies is a political act that challenges state power. ${ }^{63} \mathrm{McD}$ owell (amongst others) explicitly cites the memory work of LTTE cemeteries within the Sinhalese ethnocracy. The LTTE established cemetery sites as spaces of commemoration and mourning, literally crossing politics of memory with a politics of death. As Sangarasivam observes, the cemetery sites (called 'memorial parks,' 'Great Heroes cemeteries' or 'places of rest for the Great Heroes') claim territory and memory, they

serve to honor those who committed their lives to the nationalist struggle and died in battle. The physical geography of war memorials has served as a means of claiming space and as an assertion of territorial rights that are intimately connected to national identity. [...] [They] inscribe the presence of the honored dead into the land. [...] This respect for the dead was destroyed by the Sri Lankan military forces upon their occupation of the north in October 1995, when they bulldozed these war memorials, unearthing the dead. 64

McDowell notes this obliteration of the LTTE cemeteries by the SLA in 1995-against which the analysis of Chapter 4 is set-had the adverse affect of mobilising a larger cross-section of 'ordinary' Tamils who “opposed the SLA's actions [...] not just [as] an attack on the LTTE's right

\footnotetext{
${ }^{62}$ McDowell, 'Symbolic Warfare in the Ethnocratic State', 26, 27, 28, 32.

63 McDowell, 34.

${ }^{64}$ Sangarasivam, 'Militarizing', 69.
} 
to acknowledge the dead but as an attack on Tamil space and rights." 65 The collective reconstruction of the LTTE cemeteries between 2002 and 2003 defied the state's control over territory and memory. ${ }^{66}$ Resisting erasure, the LTTE cemeteries not only claimed, but reclaimed territory and memory. McDowell regards the rebuilt cemeteries as "a key part of Tamil identity" that came to represent "the symbolic centres of the new Tamil Eelam." 67 The commemoration of the dead occupies a central position in LTTE nationalism and the envisioned state of Eelam. As the cemetery is 'the symbolic centre' of Eelam, the envisioned state and the birth of the nation is grounded in death. ${ }^{68}$ De-emphasising the finality of death, the name thuyilum illam ('resting' or 'sleeping abodes') for the cemeteries emphasises the lingering presences of the dead.

In the aftermath of the war in 2009 , as sociologist Sasanka Perera notes, the SLA dismantled all LTTE sites claiming 25 LTTE war cemeteries

${ }^{65}$ McDowell, 'Symbolic Warfare in the Ethnocratic State', 31. The demolition of cemeteries are instances of what Bargu calls necropolitical violence. Necropolitical violence, she propounds, is violence that "target[s] the dead bodies of those killed in armed conflict, by way of their mutilation, dismemberment, denuding, desecration," and "the destruction of local cemeteries and other sacred spaces that are designated for [...] [the] commemoration of the dead," in other words, it is "the dishonoring, disciplining, and punishment of the living through the utilization of the dead" (Bargu, 'Another Necropolitics', n.p.)

${ }^{66}$ McDowell, 'Symbolic Warfare in the Ethnocratic State', 29.

67 McDowell, 30.

${ }^{68}$ Foucault, in his rendering on heterotopia, delineates the exterritorialisation of the cemetery from the city centre in eighteenth-century Europe (Foucault, 'Of Other Spaces', 25.) In the Tamil case, the cemetery is central in the nation-building process. 
consisting of 20,400 tombs. ${ }^{69}$ How can these repeated erasures of LTTE cemeteries by the GoSL be read? Historian Roberts, who is termed an apologist for Sinhala nationalism by critics, believes the destruction of the cemeteries deny the LTTE political legitimacy and argues Heroes Day served to legitimise Eelam and mobilised Tamils by blurring the commemoration of militants with civilians. ${ }^{70}$ Perera's take, echoing the government's rationale, is that the cemeteries serve as "a forum to narrate and perform [the LTTE's] obsession with a relentless sense of heroism."71 This downplays the cemeteries' function as a space of remembrance and mourning and obscures the ulterior motives of their demolition: the landscapal erasure of cemeteries erases LTTE presences and delegitimises Tamil memorial and territorial claims.

LTTE cemeteries embody a particular interlinkage of death, memory, and territory. This interlinkage is reflected in M.I.A's productions. LTTE cemeteries are both what Pierre Nora terms lieux de mémoire (sites of memory) and what Abderrezak terms lieux-mouroir (sites of death). ${ }^{72}$ The

69 Perera, Warzone Tourism, 77.

70 Roberts in McDowell, 'Symbolic Warfare in the Ethnocratic State'.

71 Perera, Warzone Tourism, 77.

72 Nora, 'Between Memory and History'. Abderrezak, 'The Mediterranean Seametery and Cementery', 158. They can also be described as what I would refer to as thanatomnemoscapes. In the context of colonial Namibia, Kößler defines mnemoscape as "the representation of past events, and of claims connected to such events, by the built environment. [They are] forms in which memory contents are preserved, reproduced and represented [in the landscape]" (Kössler, Namibia and Germany, 4.) Merging thanatopolitics with mnemoscapes, thanatomnemoscapes can be thought to 
constant erasure and reconstruction of LTTE cemetery evince that the struggle over memory and territory is fought over the dead. Their annihilation-the erasure of the dead or absence itself in the case of missing remains-constitute an assault on the already dead. This annihilation, it is pivotal to note, is met with constant reconstruction. The notion that cemeteries are spaces of constant erasure and resurrection is revisited in Chapter 4 with regard to M.I.A's stencils.

Staged at the cemeteries are the official commemorations events (called 'Great Heroes' Day') for dead LTTE fighters on November 27-an important event informing the release of M.I.A's song “Borders” (Chapter 6). ${ }^{73}$ This day of commemoration and mourning for the LTTE fighters is also known as elucci nal ('Day of Rising'). The word 'rising' emphasises overcoming oppression. ${ }^{74}$ M.I.A evokes the phrase in "Born Free" in a mural which cites the IRA slogan "Our day will come" to threaten with the hauntings of the immanent dead (Chapter 5).

describe a thanatotopic and memorial landscape that challenges the biopoliticality of the state.

73 Regarded a national day for Tamil Eelam, 27 November marks the death of Shankar, the first LTTE member who 'sacrificed' his life for Eelam. This day of commemoration Maveerar Naal (மாவீரர் நாள்) is held annualy for the maveerar, the Great Heroes, fighters who died in battle (see Fuglerud, 'Aesthetics', 76.)

${ }^{74}$ As Fuglerud propounds, "Maveerar Nal is also referred to as elucci nal, 'Day of Edification' or 'Day of Rising' [...] [It is] not only a day of mourning. It is a day of growth, a celebration of what is coming and becoming" (Fuglerud, 81.) In my view, elucci (rising) constitutes a metaphor which expresses the realisation of justice. This metaphor is also employed by Indian Tamil Dalit and socialist groups, referring to the overthrow of oppressive caste and class systems which enables the rising of the Dalits and the proletariat. 


\subsection{TAMIL POLITICS OF DEATH}

As anthropologist Trawick remarks, "[t]he LTTE has sometimes been called a 'cult of the dead." 75 For many, deaths are the reason to join the movement, "combatants have been motivated to join the LTTE because of frustrated anger at the death of loved ones killed by the army."76 Death and the memory of the dead are central to the movement. The LTTE casts its militants as the foundation for the birth of the nation. They are already spectral or MIA, even when alive. As Fuglerud states,

The fighters still alive $[\ldots]$ were 'living dead', dead but not yet died, [...] The sacrifice they had accepted made them into harbingers of life. ${ }^{77}$

Selected for their guerrilla skills and commitment to the Tamil cause, Black Tigers, whose identities are only revealed after their demise, are termed the LTTE's 'elite suicide squad' by critics. ${ }^{78}$ As suicidal discourses are absent within and outside the movement, Sangarasivam deplores the inaccuracy of the label 'suicide bombers' and propounds Black Tigers missilise and militarise their bodies. 79 Hellmann-Rajanayagam emphasises that Black Tigers follow secular-national objectives and apply to 'donate their lives' as tankotai (also referred to as thatkodai in Tamil sociologist and poet Cheran's work), as a gift for "the liberation of the Tamil

\footnotetext{
75 Trawick, 'Reasons for Violence', 177.

76 Trawick, 170.

77 Fuglerud, 'Aesthetics', 78.

78 Roberts, 'Pragmatic Action', 75.

79 Sangarasivam, 'Militarizing', 73.
} 
Motherland," on their own volition. ${ }^{80}$ Cheran remarks this self-giving stands in contrast to suicide (thatkolai). ${ }^{81}$ This distinction between thatkodai (தற்கொடை), which means the 'giving (donating) of life' in the LTTE discourse and the word suicide, the 'taking of life' (தற்கொலை), is significant. It encapsulates the difference between creation and destruction, birth and annihilation, presence and absence. The one fixates on life, the other on death. The notion of death as self-donation in LTTE discourses emphasises the agency and willingness of the militant, but also the productivity of death. ${ }^{82}$

${ }^{80}$ Hellmann-Rajanayagam, 'Female Warriors', 13-14.

${ }^{81}$ Cheran, The Sixth Genre, 19.

${ }^{82}$ The LTTE ideology of uyirāyutam (உயிராயுதம்) further illustrates this. Black Tigers fathom their bodies as uyirāyutam or 'life (as) weapon' (Schalk, 'Historisation', 40.) While äyutam (ஆயுதம்) means 'weapon,' uyir (உயிர்) denotes life. Yet, the meanings and significations of life (uyir) in Tamil are complex and multifaceted. Uyir derives from the verb $\bar{u}-t h u$, which means to blow, or from $u-y i$, which means to breathe; as a verb it designates existence or being (Müller, Anthropological Religion, 203.) Its semantic exceeds mere breath and life; it signifies voice and spoken sound and communicates the inseparability of the body and the soul (Nair, Restoration of Breath, 51-52. Carman and Narayanan, The Tamil Veda, 178.) In short, uyir is that which breathes life, including soul, speech, and consciousness. Premised on subjectivity and agency, uyir entails both an ontological and epistemological state of being and knowing. Life, understood as a material body (ontology) and agentic speech (epistemology), is transformed into a means of resistance. Uyirāyutam conceptualises life (a subject who is and knows) as a human weapon. The weaponisation of life in LTTE discourses signifies resistance to Sinhalese supremacy and Tamil sovereignty. Biopoliticing death, the LTTE's ideology reconstructs thanatopolitics as biopolitics. The biopoliticisation of death means that death here follows a biopolitical logic, it is a death to ensure life. This death signifies the birth of the nation and the lives saved from a thanatopolitical state. 
LTTE fighters, says Hellmann-Rajanayagam, are "honoured not for killing the Tigers' enemies but for their own deaths." 83 In fact, they take "no pride or pleasure in killing." 84 The notion of life in death stems from the notion that " $[\mathrm{t}]$ he worst suffering of all is helpless suffering, the worst death the death from which no other life springs." 85 Trawick maintains this notion, symbolised by a "vegetative, horticultural" imagery, is also the most prevalent theme in Eelam poetry. ${ }^{86}$ Critics often understand this politics of death as suicide fanatism. Criminal justice researcher Van de Voorde submits "religious fanaticism has been a driving force for members of the LTTE and the cult of martyrdom [...] [a] central feature of LTTE terrorism." 87 This, of course, simplifies and dehistoricises the conflict and the history of violence. As Trawick states,

to honour those who have died in battle and to revere their memories is a custom of all civilised nations. [...] The LTTE are not religious fanatics or fundamentalists. Its members practice the religions of their choice. If there is an LTTE religion, it is devotion to Tamil Eelam. ${ }^{88}$

Social anthropologist Fuglerud emphasises that this conception-“dead fighters were not buried, they were 'planted' as seeds, to be reborn," or in generic terms that "new life grows from the battlefield"-preceded the

\footnotetext{
83 Hellmann-Rajanayagam, 'And Heroes Die', 122.

84 Trawick, 'Reasons for Violence', 177.

85 Trawick, 180.

86 Trawick, 155.

87 Van De Voorde, 'Sri Lankan Terrorism', 188.

88 Trawick, 'Reasons for Violence', 178.
} 
LTTE and is not new in Tamil culture. ${ }^{89}$ M.I.A references the image of 'planted as seeds' in "Born Free" to express future hauntings (Chapter 5).

LTTE nationalism centres the dead, yet it is thanatopolitics as biopolitics. In the terms expounded in the following chapter (Chapter 3.3), death in the LTTE is understood as a resistive (productive) thanatopolitics against the destructive thanatopolitics of the state (politics of death). Death in the LTTE is conceptualised as a productive force, it births the nation and brings liberation, even more so for female militants. Freedom Birds are female militants of the LTTE women's cadre. ${ }^{90}$ Sangarasivam notes female militancy as a regenerative form of violence within LTTE discourses. ${ }^{91}$ The demise of the female militant signifies a "sacrifice' for liberation," a choice to break from "traditional feminine roles to inscribe, with her life [...] a new history,"92 to "'give birth' not to a child but to a free nation." 93 It re-semanticises death which is understood to resist the destructive Sinhalese politics of death. Political scientist Silva fathoms the 'self-

\footnotetext{
89 Fuglerud, 'Aesthetics', 80.

90 As birds are a metaphor for freedom, the appellation Freedom Birds is an uncanny double. Discourses on female militancy arborise into victimisation and demonisation narratives. Both depoliticise, deagentise and mute militant women. For instance, Alison rejects the LTTE's self-proclaimed rationale for deploying female cadres that foregrounds the sovereignty of the Tamil nation and women's determination (Alison, 'Cogs in the Wheel?', 42-43.) O'Connor argues that media coverage of LTTE women foreground their victimisation and erase their violence (Stack-O'Connor, 'Lions, Tigers, and Freedom Birds', 49.)

91 Sangarasivam, 'Militarizing', 70.

92 Sangarasivam, 67.

93 Marway, 'Scandalous Subwomen', 228.
} 
sacrifice' of female militants to extend the idea of motherhood to include "a woman who will never be a mother." 94 It transforms thanatopolitics into biopolitics; instead of offering sons (biological reproduction), they offer their own bodies to produce the birth (ideological re-production) of the nation. ${ }^{95}$ Michelsen delineates suicides, as 'the limit condition of resistance,' expose the centrality of death in biopower and subvert sovereignty's monopolistic right over the decision on death. ${ }^{96}$

\subsection{TAMIL MEMORY, MOURNING, AND WITNESSING}

Thousands of [Tamil] civilians had died [...] but there is no memorial for them. ${ }^{97}$ In the previous section I probed the significations of the LTTE cemeteries and their erasure by state actors. The SLA demolished the cemeteries in 1995 (when they militarised the north island), which the LTTE reconstructed in 2002 (when they regained control over the north). In $2008 / 2009$, the cemeteries were (perhaps ultimately) erased. I also noted the cemeteries asserted memorial and onto-territorial claims.

\footnotetext{
94 Mangalika Silva quoted in O'Rourke, 'Female Suicide Terrorism', 711-12.

95 It is a both homicidal and suicidal thanatopraxis, an act of "self-determination as well as self-annihilation" (Butler and Athanasiou, Dispossession, 123-24.)

${ }^{96}$ Michelsen, Politics and Suicide, 131, 138. Michelsen nevertheless cautions that a "revolutionary politics cannot simply offer death against death," the problem of the 'autorealisation of one's death' is "the impossibility of having consciousness of the disappearance of one's consciousness" (Michelsen, 134, 71.) Similarly, other critical voices deny the suicide bomber "full vocalization," (Hutnyk, Pantomime Terror, 59.) condemn the "celebration of suicidal martyrdom," and the equation of death and resistance (Sivamohan, 'Militant Tamil', 142.)

97 Barry, 'Postwar Sri Lanka's Awkward Peace'.
} 
LTTE cemeteries both commemorated and mourned the dead. Political anthropologist Schalk's pivotal article sheds light on memory and mourning praxes in post-war Sri Lanka with particular reference to Mullivaikkal memorial day (May 18), the day on which Tamils commemorate and mourn their dead, while the state glorifies its own soldiers in triumphal ceremonies. ${ }^{98}$ The GoSL interpretes any Tamil memorial observance as an inducement to terrorism, it equates private grieving (tuyaram of the People Movement) and public mourning (tukkam of the Tiger Movement), to ban both and denies the strong attachment to the dead in Tamil culture (" $[\mathrm{t}] \mathrm{o}$ memorialise the dead is a gift of love extended to the departed").99 The GoSL bans both formal mourning (as a combatant) and personal mourning (as a kin) of the 'dead Tamil enemy.' As mourning identifies the GoSL as perpetrators of a series of historical violence, Schalk argues, the GoSL denies the truth of the accusation to delegitimise claims for justice, particularly material restitution (this point is also later made by Parry in more general terms in Chapter 3),

The GoSL may have to pay a large sum to the victims' families [...] [for a series of well-documented 173 massacres from 1956 onwards that together constitute an intended, gradual genocide]. Still worse, the UN may recognise Tamililam

\footnotetext{
98 Schalk's construction of Ilattamils (Eelam Tamils) and government loyalists is binaric but his points are still significant.

${ }^{99}$ Schalk, 'Ilattamils'.
} 
[...]. [The GoSL consequently] silences all criticism [...] by establishing a culture of denial against all accusations. ${ }^{100}$

Schalk contends though the state may prevent public mourning and "sever the connection between the dead and the living in grief-work," it cannot disenfranchise private grieving. ${ }^{101}$ As Schalk indicates, the war continues over memory and mourning, but also by means of (thanato)tourism. ${ }^{102}$ Tamil cemeteries were bulldozed and replaced by tourist sites and army memorials. Set up by the GoSL, the postwar army-

100 Schalk.

${ }^{101}$ Schalk. He argues Tamil mourners in the island and the global diaspora defy the GoSL by silent grieving. The grief-work performs public akavanakkam (அகவணக்கம்), the 'veneration' for the dead to emphasise their humanity, to represent victims, to defy the state. Schalk, like Roberts, points to blurring of People's Movement and Tiger Movement. The deliberate merging and divorce of the Tiger and Tamil (identity) is deliberate and has a bearing on Tamil memory and mourning. As M.I.A expressed (Chapter 1), the criminalisation of the LTTE enables the criminalisation of Tamils as a whole. The Tamil/ Tiger distinction is expressed as 'People Movement' and 'Tiger Movement' in Schalk's research.

102 Death-related sites and tourist activity are referred to as dark tourism, war tourism, thanatourism, (Seaton, 'From Thanatopsis'.) thanatotourism, thanotourism, atrocity or dissonant heritage. As sites of tourist attraction associated with death, disaster or suffering, they (re)construct and interpret past events and affected lives and deaths (Sharpley, 'Dark Tourism', 8, 10.) They not only constitute sites of past horror spectacularised for consumption but pose current sites of historical wounds, traumata, and national contestation. Atrocity heritage is "both a highly marketable combination of education and enjoyment and a powerful instrument for the transference of political or social messages" (Ashworth, 'Holocaust Tourism', 4.) Clark's term trauma tourism foregrounds the iteration of trauma, and the disjuncture between the sacrality of trauma and the profane approach of tourism that seeks to iterate the trauma, "as a culture we will endlessly be drawn back, again and again, to the sites of trauma until the underlying issue is resolved" (Clark, 'Coming to Terms with Trauma Tourism'.) 
run accommodations are morbid unethical tourist sites, and monuments are spaces of leisure and recreation to glorify the army. ${ }^{103}$

Sasanka Perera contends the war, which was televisually mediated and sanitised, did not take place for Sinhalese, and furthermore, necessitated by guilt, the Sinhalese erasing gaze unsaw the inconvenient "pain, death and destruction of the north-east." 104 Sinhalese warzone tourism conveniently erases war experiences of/and Tamils from the collective conscience. ${ }^{105}$ The 'warzone tourist trail' of army memorials propagates the state's narrative and rewrites history by the state. M.I.A's diasporic output is situated against this context of erasing violence and Tamils.

\subsection{TAMIL DIASPORA AND MEMORY ACTIVISM}

Sociologist Jones contends discourses of the Tamil diaspora centre on exile and forced migration. ${ }^{106}$ The Tamil diaspora is, as McDowell terms, an asylum diaspora, ${ }^{107}$ and in Wayland's words,

\footnotetext{
103 Stewart, 'War Tourism in the North of Sri Lanka'.

104 Perera, Warzone Tourism, 70, 74-75.

105 Perera, 126.

${ }^{106}$ Jones, Superdiverse Diaspora, 29. Cheran elucidates exile in the Tamil tradition is "a form of supreme punishment more severe than the death penalty," and "a space of "social death," yet it has become to be viewed as a space of "new possibilities" (Cheran, 'Citizen of Many Worlds', 151-52.)

107 McDowell, A Tamil Asylum Diaspora.
} 
comprised of refugees and exiles who were forced to leave their home country because of [ethnic persecution in an ethnonationalist] conflict rather than because of economic need or the wish to forge a new life abroad. ${ }^{108}$

Like Tamil cemeteries, Tamil diasporic nationalism asserts memorial and territorial claims. As Cheran states, Tamil identity in the diaspora is fashioned by the "systematic and ritualistic organization and transmission of shared memory." 109 Despite differences in their political positionality towards the LTTE, Chandrakanthan claims, "their commitment to the furtherance of Tamil nationalism is the common denominator." 110 Diasporic Tamil nationalism, as Cheran states, "does not revolve around the notion of returning to an idealized home [...] [but] toward the

108 Wayland, 'Ethnonationalist', 408, 417-18.

109 Cheran, The Sixth Genre, 16.

${ }^{110}$ Chandrakanthan, 'Eelam', 170. There are of course other differences beside political positionality. Tamil island identity is fragmented and intersectional, yet scholars have highlighted specific religious, caste or spatial affiliations as constitutional of Tamil identity. For instance, Pfaffenberger points out Tamil identity referred to a caste, not an ethnic identity_-Being 'Tamil' ... was tantamount to being 'Vellalar'”- which was later dissolved by the abolishment of caste in LTTE nationalism (Pfaffenberger, 'Political Construction', 149. Pfaffenberger, 'Introduction: The Sri Lankan Tamils', 20.) Similarly, Wilson states the regional Tamil identities of the Northern and Eastern Provinces merged to form a Tamil consciousness that evolved into a Tamil nationalism that demanded the right of self-determination (Wilson, 'The Colombo Man', 138.) Similar to Tamil island identity, Tamil diasporic identity is fragmented "on the basis of statehood, [...], religion, regionalism and the intersecting subject positions of gender, class, and age or life-state" (Jones, Superdiverse Diaspora, 221.) Nevertheless and importantly, the quoted scholars insinuate the quest for Tamil liberation unites both Tamils in the island and the diaspora. In the words of Wayland, "[m]embers of the Tamil diaspora are linked by a common [unified ethno-national Tamil] identity that is rooted in (1) ethnic persecution in Sri Lanka, (2) the shared trauma of migration [...] ; and (3) economic and social marginalisation in the receiving society" (Wayland, 'Ethnonationalist', 414, 424.) 
possibility of establishing an idealized homeland."111 Media studies scholar Ranganathan claims the Tamil diaspora holds a key role in leading Tamil nationalism and the movement for Tamil rights. ${ }^{112}$ Tamil diasporic memory opposes injustice 'here' and 'there,' or, as historian Kandasamy contends, Tamil diaspora activists use memory to sustain Tamil claims to justice, challenging Sinhala-Buddhist nationalism as well as critiquing their respective country of settlement. ${ }^{113}$ Revisualising spectral cemeteries, M.I.A's work is a form of memory activism.

Art in particular is a potent space of memory activism. Shanaathanan, a Jaffna Tamil artist and scholar, submits Tamil art documents erased spaces and memories and witnesses displacement against political erasure. ${ }^{114}$ It testifies to the personal and collective loss of space and memories, as M.I.A's work does. This is particularly visible in her stencil art work, as discussed in Chapter 4. Yet, her work not only documents, it specifically recirculates histories of Tamil erasure as sites of haunting.

\subsection{SUMMARY}

A key contention of my study is that M.I.A's visual landscape replicates the work of LTTE cemeteries to assert a responsibility for the dead. The LTTE cemeteries asserted memorial and onto-territorial claims, that is,

\footnotetext{
111 Cheran, 'Citizen of Many Worlds', 161.

112 Ranganathan, Eelam Online, 39.

113 Kandasamy, 'Home', 54-55.

114 Shanaathanan, 'Painting', 103. Shanaathanan, 'Commemorating', 416-17, 420.
} 
they remembered and mourned the dead, while also claiming the right to be and the right to be there. The conflict in Sri Lanka as such is staged on the dead by means of erasing cemeteries and unwitnessing acts of genocide. The demolition of cemeteries by the GoSL in 1995 sought to delegitimise Tamil memorial and onto-territorial claims. During and after the end of the war in 2009, the GoSL implemented a politics of denying Tamils the right to remember and mourn their dead as well as witness state violence. M.I.A's work contests these acts of state repression by reinscribing histories of violence enacted on Tamils through haunting as a resistive politics of death. 



\section{3 spectral Politics of Death}

M.I.A's memory locales, my study argues, oppose the state's destructive politics of death by translating particular images of death. The spectral sites of M.I.A's presented work lay claims to justice for the dead. In this chapter I delineate the spectre and I probe the politics of death of both the spectre and the state. I draw from Derrida's theorisation of the spectre and the politics of life and death from Foucault and Agamben, respectively, to juxtapose the destructive politics of death of the state with a resistive politics of death of the spectre. The spectres in M.I.A's work, my analyses will show, follow a resistive politics of death, of memory, mourning, and witnessing against the state's destructive politics of death. For this reason, I probe the imbrication of spectrality with memory, mourning, and witnessing. I end with reflecting upon the problematics and potentialities of spectrality. Acknowledging its limits, I highlight not only the utility, but the imperative and necessity of applying a spectral framework in reading M.I.A's work. This urgency lies, I argue, in iteration as the intricate link between the spectre and the MIA which enables the recurrence of claims of justice.

\subsection{THE SPECTRE}

My notion of spectres and spectrality in M.I.A's work draws from Derrida's reflections on the nature of spectre and his theorisations of hauntology. His notion of spectres eludes the binaries of life and death, as 
do M.I.A's spectres and the concept of MIA in general. Derrida relates the spectre to (a disruption of) ontology, visibility, and temporality. The spectre, says Derrida, displaces ontology, "the discourse on the Being of beings," for it "is neither living nor dead, present nor absent."115 It defies the binaries of being and non-being, and it "is not seen, which is why it remains $[. .$.$] beyond being." 116$ In a first step then, Derrida equates life with presence and death with absence, and then conflates absence (nonbeing) into invisibility. He therefore implies the centrality of visibility for being; in other words, to be is to be seen. In a sense, ontology preconditions visibility, while spectrality centres seeing without being seen. Derrida maintains the spectre is an imagination, a screenless projection of an absence, a surveillor who "first of all sees us [...] even before any apparition."117 The spectre sees without being seen, and it sees prior to its (own) visitation. This visitation by the spectre, which is a return or a recurrence, can signify a 'strict inspection,' a 'violent search' or persecution. ${ }^{118}$

Derrida maintains that haunting, which signifies absence, must be introduced into every concept, such as being and time. ${ }^{119}$ A logic of

\footnotetext{
115 Derrida, Specters of Marx, 63. I acknowledge Sedgwick's rightful statement that attempts to define Derrida's 'concepts' are antithetical to the intent of deconstruction (Sedgwick, Descartes to Derrida, 211.)

116 Derrida, Specters of Marx, 125.

117 Derrida, 125.

118 Derrida, 126.

119 Derrida, 202.
} 
haunting or hauntology, he submits, is "more powerful than an ontology or a thinking of Being." 120 Ontology defies hauntology "only in a movement of exorcism," ${ }^{121}$ that is, ontology seeks to exorcise hauntology.

Legal scholar Davis emphasises that for Derrida the otherness of the spectre must be preserved which marks "the ethical turn of deconstruction."122 Derrida's spectre is, in Davis' words, “a deconstructive figure,"123 a figure of unknowability that defies the epistemic order. ${ }^{124}$ Derrida urges to preserve its unknowability and to listen to the spectre, What seems almost impossible is to speak always of the specter, to speak to the specter, to speak with it, therefore especially to make or to let a spirit speak. [...]

120 Derrida, 10.

121 Derrida, 202.

${ }^{122}$ Davis, 'Hauntology, Spectres and Phantoms', 373.

123 Davis, 376.

124 This stands in contrast to Abraham's phantom, which he defines as follows: "the 'phantom', whatever its form, is nothing but an invention of the living. [...] what haunts are not the dead, but the gaps left within us by the secrets of others. [...] The phantom's periodic and compulsive return [...] works like a ventriloquist, like a stranger within the subject's own mental topography" (Abraham, 'Notes on the Phantom', 171, 173.) In Abraham's conception of the phantom, the dead repose within the living. Abraham argues a transgenerational 'incorporation' occurs if the internalisation of the dead fail (which is necessary for mourning according to Freud), then "the dead are taken into us, [...] they can speak for themselves, they can haunt our body and ventriloquise our speech" (Derrida in McMullen, Ghost Dance.) As such they differ from Derrida's spectre. Davis observes phantoms to lie about the past whilst spectres gesture towards a still unformulated future (Davis, 'Hauntology, Spectres and Phantoms', 379.) Abraham's phantom "prevent $[\mathrm{s}]$ its traumatic and usually shameful secrets from coming to light," it is "a liar; its effects are designed to mislead the haunted subject and to ensure that its secret remains shrouded in mystery" (Derrida in Ghost Dance quoted in Davis, 374.) 
scholars believe that looking is sufficient. Therefore, they are not always in the most competent position to do what is necessary: speak to the specter. ${ }^{125}$

Derrida's spectre constitutes an ethical injunction, it evokes a regard and responsibility toward the dead. He hence implies a relationship between spectrality and a politics of death: the spectre demands ethicality, and its ethical injunction, in the work of M.I.A, is a politics of death that opposes erasure.

Erasure is constitutive in M.I.A's work, the erasure of memories and voices, landscapes and cemeteries, the erasure of absence itself. Multiple scholars state the spectre is not only a replaceable term in Derrida's oeuvre-a ghost, a phantom, a revenant-but also related to his exegeses of under erasure (sous rature) and (archi)trace (trave). ${ }^{126}$ Indeed, hauntology itself underscores erasure. In her acclaimed "Translator's Preface" of Derrida's Of Grammatology, Spivak explains Derrida's sous rature as "under erasure," which

is to write a word, cross it out, and then to print both word and deletion. (Since the word is inaccurate, it is crossed out. Since it is necessary, it remains legible)..$^{127}$

Sous rature hence describes the trace which, says Derrida, is not a presence, it has "no place, for effacement belongs to the very structure of

\footnotetext{
125 Derrida, Specters of Marx, 11.

126 The spectre is also related to différance, pharmakon, and logocentrism (Gere, 'Hauntology', 204. Dubreuil, 'The Presences of Deconstruction', 113. Atkinson, Poetics, 95.) Derrida himself affiliates spectrality intimately with différance and trave (Derrida, 'Deconstruction Engaged', 44.)

127 Spivak, 'Translator's Preface', xvi.
} 
the trace." 128 The trace opposes logocentrism, the priority of speech over writing, and the certainties of metaphysics. It is defined by its effacement which produces its spectrality. ${ }^{129}$ Sedgwick elucidates the trace "indicates that meaning itself is, in a very particular sense always already written before it can be spoken." 130 In Derrida's own words, the spectre is an a priori signification, a trace, as

[The specter] exceeds all the oppositions between visible and invisible [...]: a trace that marks the present with its absence in advance. The spectral logic is de facto a deconstructive logic. It is in [...] haunting that deconstruction finds the place most hospitable to it, at the heart of the living present [...]. Like the work of mourning, in a sense, which produces spectrality, and like all work produces spectrality. ${ }^{131}$

The spectre is sous rature or a trace that (to refer to Marx's term in his famous exordium of The Communist Manifesto) remains inexorcisable.

Derrida notes the spectre "inhabits without residing," its space is elusive, and its time is out-of-joint. ${ }^{132}$ In fact, it is defined by temporal and spatial iteration,

128 Derrida, Speech and Phenomena, 156.

129 As Derrida states, "[Language] conceals and erases itself in its own production [...] the signified always already functions as a signifier. [...] The trace is not only the disappearance of origin - within the discourse that we sustain and according to the path that we follow it means that the origin did not even disappear, that it was never constituted except reciprocally by a non-origin, the trace, which thus becomes the origin of the origin" (Derrida, Of Grammatology, 7, 61.)

${ }^{130}$ Sedgwick, Descartes to Derrida, 207.

131 Derrida, 'Echographies of Television', 117.

132 Derrida, Specters of Marx, 21. 
Repetition and first time, but also repetition and last time, since the singularity of any first time, makes of it also a last time. [...] A question of repetition: a specter is always a revenant. ${ }^{133}$

The spectre is defined by simultaneous identity and alterity. Derrida's concept of différance highlights simultaneous identity and alterity, wherefore it is closely linked to the spectre. ${ }^{134}$ It is perhaps precisely due to the spectre's elusive time and space that Derrida insists on the need to concretise its historicity. ${ }^{135}$ The spectre as well as différance, in Chia and

133 Derrida, 10-11.

134 The temporality and spatiality of the spectre is inextricably linked to and reflected by Derrida's concept of différance. Derrida's defines différance as encapsulating both difference and deferral. It coalesces a difference, signifying a temporal and spatial movement, and a deferral, the repetition of the same. The verb différer ('to differ') in French, "[o]n the one hand $[\ldots]$ indicates difference as distinction, inequality, or discernibility; on the other, it expresses the interposition of delay, the interval of a spacing and temporalizing that puts off until 'later'" (Derrida, 'Différance', 279.) It thereby corresponds to the different and the deferred (Derrida, 279.) The verb carries temporalizing, that is "the action of postponing until later," and spacing (interval or distance), "the sense of not being identical, of being other" (Derrida, 283.) It signifies both non-identity and the order of the same, and "this sameness which is not identical" Derrida terms, "by the silent writing of its a," différance (Derrida, 279.) This marked difference "remains inaudible;" it "remains silent, secret, and discreet, like a tomb" (Derrida, 280-81.) As a recurrence with a difference (Derrida, Specters of Marx, 43-44.), the spectre personifies différance as a deferred iteration. It interrupts history, presence, and temporality; its haunting exposes the contretemps, the out-of-joint-ness of time. In the French language both différance and hauntology are characterised by an inaudibility to their counterparts, différance-différence and ontologie-hontologie. Différance is an order that "resists philosophy's founding opposition between the sensible and the intelligible" (Derrida, 'Différance', 281.) Both resist ontology which is at the heart of Western production, as " $[\mathrm{t}]$ he history of metaphysics, like the history of the West, $[\ldots]$ is $[\ldots]$ being as presence." (Derrida, 'Sign', 249.) Anderson rephrases différance as 'a discourse on hauntology' which interrupts history understood as presence by the possibility of delayed arrival or deferral (Anderson, Derrida, 102.)

135 Derrida, Specters of Marx, 126. 
Kallinikos' words, are "more like an absence that haunts the world of conventional presences.”136 They serve a purpose.

Jameson translates absence/presence as spectrality/ontology and past/presence, "a world cleansed of spectrality is precisely ontology itself, a world of pure presence, [...] of things without a past." 137 The repudiation of hauntology is the repudiation of a past. Erasing the spectre is erasing history and the violence of/in the past. The erasure of absence, the erasure of hauntology itself, is most palpable in the demolition of LTTE cemeteries (Chapter 2.3), as the GoSL dismantled cemeteries containing MIA (empty graves). M.I.A's artistic productions, in a way, contest the erasure (demolition) of absence (MIA) by physicalising cemeterial sites that actuate Tamil hauntings.

\subsection{The State's Destructive Politics of Death}

My recurring key assertion drawing from case studies of M.I.A's work is its resurrection of cemeteries, of politically erased subjects, spectres who pursue a particular politics of death. It is hence critical to consider the preconditions of spectrality, the politics of life and death itself: the power to take life, make life, let live, make live. These, Foucault expounds, are grounded in sovereign- and biopower. He states the power of sovereignity, the traditional mode of power, is the power to take life and

\footnotetext{
136 Chia and Kallinikos, 'Organized Worlds', 146.

137 Jameson, 'Ghostly Demarcations', 58. It is noteworthy that by implication Jameson equates ontology with presence and hauntology with (a) past.
} 
let live. ${ }^{138}$ In contrast, biopower is the power of regularisation, the power to make live and let die, a productive power that can also let die when "racism intervenes." 139 Most important in capitalist societies, says Foucault, is biopolitics, the governmental mode of regulating populations (life) through biopower. ${ }^{140}$ It is a 'new technology of power' which "derive[s] its knowledge from, and define[s] its power's field of intervention in terms of, the birth rate, the mortality rate, various biological disabilities, and the effects of the environment."141

While Foucault foregrounds two modalities of the power of life and death, Agamben describes two modalities of life itself. Agamben posits that since antiquity Western history is understood through separating bare life $(z o \vec{e})$ from politically recognised life (bios). The Greeks, he illuminates, employed two terms for 'life,' zoe, "the simple fact of living common to all living beings (animals, men, or gods)," and bios, the "way of living proper to an individual or a group." 142 Bios is "politically qualified life," while zoē constitutes the "mere fact of living," bare and hence killable. ${ }^{143}$ In contrast to Foucault who frames biopolitics as productive, Agamben

\footnotetext{
138 Foucault, Society, 247.

139 Foucault, 247, 254.

140 Foucault, 'La Naissance'; quoted in Hardt and Negri, Empire, 27.

141 Foucault, Society, 245, 243.

142 Agamben, Homo Sacer, 9.

143 Agamben, 9, 42, 10, 12. Deutscher rightfully points out the concept of bare life is unspecific and unconsiderate of the different ways and levels of vulnerability in which subjects become bare life (Deutscher, Foucault's Futures, 9.)
} 
conceives of biopolitical power as lethal.144 Agamben even nullifies the distinction between a productive and destructive biopolitics.

Biopolitics, 'the politics of and over life' or 'the promotion of human life' can become thanatopolitics, 'the politics of and over death' or 'the violent production of human deaths.' 145 Foucault maintains biopolitics becomes biopower only in the pursuit of optimising life, ${ }^{146}$ yet, Agamben insists biopolitics-in both totalitarian and democratic states-is indistinguishable from thanatopolitics, "the decision on life becomes a decision on death, and biopolitics can turn into thanatopolitics, this line no longer appears today as a stable border dividing two clearly distinct zones." 147 In other words, biopolitics can become thanatopolitics, genocidal, an 'indirect murder,' pursued not in an exertion of sovereign power but as part of biopolitics. ${ }^{148}$ It instrumentalises death to establish

\footnotetext{
${ }^{144}$ It is important to note that Agamben's biopolitical power draws on Schmitt's state of exception which becomes the rule (Murray, 'Thanatopolitics', 204.)

145 Jemima, 'Thanatopolitics or Biopolitics?', 110. Debrix, Global Powers, 9.

146 Foucault, Society, 246.

147 Agamben, Homo Sacer, 72 emphasis mine.

148 Deutscher, Foucault's Futures, 103. Deutscher emphasises that Mbembe's concept of necropolitics reinterprets biopolitics as thanatopolitics which distributes indirect forms of death (Deutscher, 7.) Linking sovereignity and the exposure to death, Mbembe defines necropolitics as "forms of subjugation of life to the power of death" (Mbembe, 'Necropolitics', 39.) The logic of necropolitics and necropower is the "maximum destruction of persons and the creation of death-worlds," conferring the status of the living dead to vast populations (Mbembe, 40.) Sovereignity controls mortality and dictates "who may live and who must die" (Mbembe, 11-12.) Mbembe views the 'contemporary colonial occupation of Palestine' as a concatenation of 'disciplinary, biopolitical, and necropolitical' powers, in which "the colonial state derives its
} 
an economy of life and death. ${ }^{149}$ The life produced in thanatopolitics, Vatter notes, is "a zoe entirely separate from a bios, a life destined to die, a life that has death inscribed into it from the very beginning." 150 Thanatopolitics generates bare, killable, unlived and unlivable lives; lives that are both simultaneously let die and make die. The preceding contentions-that the state's biopolitics is thanatopolitics, that its production of qualified life (bios) is indivisible with the production of killable life $(z o \vec{e})$, that, in short, let die is make die-constitute a major critique in M.I.A's work, particularly in "Born Free" (Chapter 5) and "Borders" (Chapter 6).

\subsection{The Spectre's Resistive Politics of Death}

The thanatopolitics of the state, as outlined before, is ultimately the control over life and death itself. Its destructive logic can be resisted. Ethicist Murray envisions a resistive politics of death, a thanatopolitics that

fundamental claim of sovereignity and legitimacy from the authority of its own particular narrative of history and identity" (Mbembe, 27, 29.) (This concatenation of powers, the exclusivist claim on territory, history, and memory, indubitably applies to the Sri Lankan state as well.) Nevertheless, it is crucial to distinguish between thanatopolitics and necropolitics. The operational logic of Mbembe's necropolitics is destruction which produces the 'living dead.' Necropolitics, as Deutscher insists, rejects Foucault's characterisation of biopolitics as managing death to the ends of life, it instead manages populations by means of death, stimulating and proliferating disorder, chaos, and insecurity (Deutscher, Foucault's Futures, 103.)

149 Dillon, Biopolitics of Security, 152.

150 Vatter, 'Eternal Life and Biopower', 218. 
opposes the state's control over life and death. ${ }^{151}$ This resistive politics of death calls for "a responsibility, a calling, a regard for the dead." 152 Murray maintains, deaths such as political suicides, "meaningfully subvert biopolitical logic through thanatopolitics." 153 Death in LTTE discourses, as seen in Chapter 2, reflect this reading. In M.I.A's work, my study reveals, a resistive thanatopolitics of the spectre opposes the destructive thanatopolitics of the state. The outlined politics of death not only mirrors the LTTE's understanding of death as a productive force opposing the destructive thanatopolitics of the state, it also pursues similar interests. To distinguish the state's destructive politics from the spectre's resistive politics, I will henceforth label the politics of the state as biopolitics and the politics of the spectre as thanatopolitics. That is, biopolitics refers to the biopolitics-turned-thanatopolitics of the state and thanatopolitics refers to the thanatopolitics-turned-biopolitics of the spectre. The resistive thanatopolitics of M.I.A's spectres are concerned with memory, mourning, and witnessing. M.I.A's spectres connote erasure (that is the erasure by the state), yet their resistive politics contest (their own) erasure.

151 This resistive thanatopolitics is similar to what some scholars term spectropolitics. Making a clear connection between the spectre and memory (and a politics of justice), Blanco and Peeren define spectropolitics as "a politics of or for specters" that commemorates historical injustices, the cultural-specific circumstances for their emergence and the concomitant disempowerment, social erasure, marginalisation, and precarity (Blanco and Peeren, 'Conceptualizing Spectralities', 19.) Cuder submits spectropolitics constitutes "an alternative means to articulate trauma" (Cuder, 'More than Words', 76.)

152 Murray, 'Thanatopolitics', 206.

153 Murray, 205. 
They do so by memory, mourning, and witnessing, acts the government denies.

\section{Memory and Territory}

In the previous chapter I illuminated the memorial and onto-territorial claims of LTTE cemeteries. Some forms of haunting, as a resistive politics of death, not only contest the state's power over life and death, but also its claims over memory and territory.

Political scientist Auchter suggests (the hauntings of) memorials as materialised sites of memory (or memorial territories) contest the 'pure ontology' the state enforces and blur the lines it creates between life and death. ${ }^{154}$ Human geographers Jones, Robinson and Turner suggest states use absencing and presencing as political tools of narrative and territorial control.155 In other words, the political making of absence and presence, of spectrality and ontology, are means of politico-territorial control, the very same binary (of absence and presence) spectres challenge. Auchter

\footnotetext{
154 Auchter, Haunting, 5, 10-11, 20. Similar to Auchter's line of argumentation, postcolonial scholar Laouyene submits diasporas query the notion of the state's 'pure' 'unified' ontology. He specifically states Canadian national discourses are "haunted by the spectre of Aboriginal and diasporic others-a haunting that renders problematic the construction of a cohesive national identity" (Laouyene, 'Canadian Gothic', 127.) The diaspora can be viewed as a spectral entity disputing the ontologies of the state. Explicitly mirroring this account, Turcette and Rando conceptualise the diaspora as "a 'moving centre,' of [unfinished and spectral] people" and "a spectral, contradictory, fraught, and constantly changing zone of contact and possibility" (Turcotte and Rando, 'Diasporic Spectrality', 2, 10.)

${ }^{155}$ Jones, Robinson, and Turner, 'Between Absence and Presence', 257-58.
} 
and (by implication only) Jones et al., link hauntology to memory and territoriality. Haunting, like LTTE cemeteries, opposes the memorial and territorial claims of the state, a claim my study asserts. The haunting of M.I.A's spectres, I propose, effectuate the same, haunting, for instance, flags as national sites in Chapter 4.

M.I.A's resurrected cemeteries haunt to iterate erased memories. As illustrated in the previous chapter, the Sri Lankan state institutes a policy of reconciliation and simultaneous denial of memory, mourning, and witnessing. In the following I illustrate that haunting enables memory, mourning, and witnessing, which in turn, claim justice.

\section{Memory and Justice}

To reconcile is to restore, to return to a status quo ante..$^{156}$

Memory is tied to justice, to the extent that memory preconditions justice. In Newman's words, "without remembrance we cannot live justly."157 Memory studies scholar Assmann describes the reciprocal influence of past and present with haunting, "The present is 'haunted' by the past and the past is $[\ldots]$ reconstructed by the present. ${ }^{158}$

\footnotetext{
156 Mamdani, 'The Truth', 182.

157 Newman, 'Suffering from Reminiscences', 112.

${ }_{158}$ Assmann's concept of mnemohistory-which is "concerned not with the past as such, but only with the past as it is remembered"-reflects the inextricable link between (present) memory and (past) history (Assmann, Moses the Egyptian, 8-9.) Similarly, Derrida sees memories/ remembering as transforming the present and the future, "To speak [...] of 'memory,' [...] was also to speak of the future" (Derrida, Memoires, 58, 93.)
} 
As shown in the previous chapter, LTTE cemeteries as sites of death assert territorial and memorial claims. Memory politics is particularly concerned with recognising violence and claims for justice. Postcolonial critic Parry raises the question whether memory or reconciliation institute justice. ${ }^{159}$ She locates justice in memory, as memory recognises violence, whereas reconciliation obfuscates violence. ${ }^{160}$ Reconciliation, the call to forget or overcome the past, she says, is institutionalised forgetfulness which implies exculpation or acquittal. ${ }^{161}$ Perpetrators institute reconciliation to discount violence, refuse remembrance, and relinquish responsibility. Parry invokes Benjamin's historical memory “as the fight for the oppressed past" and the "battle to disclose the dead victims' moral claims." 162 The iteration of memory invokes repetitive witnessing. The work of mourning opposes entrenched present injustices. ${ }^{163}$

\footnotetext{
159 Similarly, philosophers Honneth and Fraser consider the question whether recognition or redistribution is integral in achieving justice. Honneth answers recognition alone, while Fraser advocates cultural recognition must be accompanied by material redistribution (Fraser and Honneth, Redistribution or Recognition?)

160 English literature scholar McGonegal critiques Parry argument that reconciliation prevents justice. Failing to explicate the conditions for forgiveness, McGonegal (unconvincingly) submits forgiveness "restore[s] agency to victims whose subjectivity has been de-authorized" (McGonegal, Imagining Justice, 38-39.)

${ }_{161}$ Parry, 'Reconciliation and Remembrance', 86-87. Remembering and forgetting are instruments of power in which forgetting means, "those who implemented or were complicity [sic] with violence, terror and institutionalized injustice are absolved of their actions $[\ldots]$ and are allowed to feign ignorance of their own histories. Whose interests, we must ask, are served by an officially instituted memory-loss?” (Parry, 88.)

162 Parry, 'Reconciliation and Remembrance', 91.

163 Parry, 93.
} 


\section{Mourning and Justice}

Similar to Parry's understanding of memory, Butler's mournability recognises violence and life that matter, or in Agamben's terms, qualified life. M.I.A's cemeteries of spectres not only haunt, they also mourn. Both ontology and spectrality have a bearing upon mournability. For Derrida, mourning "consists always in attempting to ontologize remains, to make them present, in the first place by identifying the bodily remains and by localizing the dead."164 In other words, mourning identifies and presences the dead. For Butler, "grievability is a presupposition for the life that matters,"165 Ungrievable lives are unrecognised lives, "subjects who are living, but not yet regarded as "lives." 166 She states mournability presupposes grievability, ${ }^{167}$ ungrievable lives are unlived and hence unmournable, as, "[a]n ungrievable life is one that cannot be mourned because it has never lived, that is, it has never counted as a life at all."168 Butler's notion of grievability is governed by frames as they "generate specific ontologies of the subject." 169 This implies the frame constitutes ontology and spectral subjects are outside the frame and hence

\footnotetext{
164 Derrida, Specters of Marx, 9.

165 Butler, Frames of War, 14. This argument recurs in her work, for instance in "specific lives cannot be apprehended as injured or lost if they are not first apprehended as living" (Butler, 1.)

166 Butler, Frames of War, 31-32.

167 In general, grief refers to an internal (private) expression of loss, while mourning denotes the external (public) expression of loss. Grief hence precedes mourning.

168 Butler, Frames of War, 38.

169 Butler, 3-4.
} 
unrecognised as life. The bounds of the frame governs ontology and spectrality and the recognition and repudiation of life. ${ }^{170}$ To be grievable is to be inside the frame. Or, in Agamben's terms, to be inside (grievable) is to be qualified life (bios); to be outside (ungrievable), is to be bare life (zoe). However, reiteration as well as haunting resist the (ontologising) frame,

Subjects are constituted through norms which, in their reiteration, produce and shift the terms through which subjects are recognized. ${ }^{171}$

In M.I.A's work, reiteration is spectral haunting/ recurrence. Enabled by a medium, Butler explicitly poses haunting as a way to resist ontology and to confirm grievability,

To confirm that a life was $[\ldots]$ is to underscore that a life is a grievable life. $[\ldots]$ If we are not haunted, $[\ldots]$ there has been no life that was lost. But if we are $[\ldots]$ 'haunted' by a photograph, it is because the photograph [...] outliv[es] the life it documents; it establishes in advance the time in which that loss will be acknowledged as a loss. [...] grievability as the precondition of life $[\ldots]$ is discovered retrospectively through the temporality [of] the photograph. ${ }^{172}$

Subjects that are outside the frame, hence spectral and unmournable, can resist by haunting. Particular media such as photographs enable haunting

\footnotetext{
${ }^{170}$ Yet, Butler insists, "the point would not be to locate what is 'in' or 'outside' the frame, but what vacillates between those two locations, and what [...] becomes encrypted in the frame itself" (Butler, 75.) As I particularly illustrate in Chapter 5 and Chapter 6, M.I.A's "Born Free" and "Borders" depict what vacillates between the interiority and exteriority of the frame, namely, the seeing and unseeing (the make die and let die), the witnessing and unwitnessing of refugee and Tamil deaths.

${ }^{171}$ Butler, 3-4.

172 Butler, 97-98.
} 
and instate grievability and mournability. ${ }^{173}$ I illustrate that M.I.A's resurrection of cemeteries of spectres not only enable haunting, but more importantly, instate mournability. The medium she deploys is visual art in the broadest sense, music videos that convert LTTE images of MIA into stencils (Chapter 4), that transposes a trophy image of the Mullivaikkal massacre into 'a ginger genocide' (Chapter 5), that translate dominant refugee photographs of Mediterranean sea deaths into human sculptures (Chapter 6). Resisting the ontologising frame, M.I.A's resurrected cemeteries of spectres demand the recognition of life and mournability.

\section{Witnessing and Justice}

in the non-place of the Voice stands not writing, but the witness. ${ }^{174}$

Trauma researcher Laub remarks bearing witness to trauma includes its listener who "comes to be a participant and co-owner of the traumatic event." 175 The hearer enables witnessing as "the absence of an addressable other $[\ldots]$ [who can] affirm and recognize their realness, annihilates the story." 176 For Laub then, there is no (past) injury and trauma without the

\footnotetext{
${ }^{173}$ It is important to note Butler's quote suggests the agency of the haunted to either accept or refuse haunting.

174 Agamben, Remnants, 130.

175 Laub, 'Bearing Witness', 57.

176 Laub, 68. The testimony enables witnessing, Laub says, it is "the process by which the narrator (the survivor) reclaims his position as a witness" (Laub, 'An Event', 85.) He also famously posits the impossibility of witnessing the Holocaust, "the very circumstance of being inside the event made unthinkable the very notion that a witness could exist, that is, someone who could step outside of the coercively totalitarian and dehumanizing frame of reference in which the event was taking place [...] One might say that there
} 
witness. In other words, (to use Butler's terminology), injury can only be realised with the witness. The presence of a witness realises injury and enables mournability. The listener is at the same time a witness to the trauma witness and a witness to himself. 177

Witnessing centres the narrative of victims, the violence they are subjected to. M.I.A's work calls for witnessing; it asserts a responsibility for the dead. Witnessing is a pivotal work of M.I.A's cemeteries of spectres, they oppose the unseeing of refugee sea deaths (Chapter 6) and the unwitnessing of the Mullivaikkal massacre (Chapter 5). The call for witnessing opposes the unseeing and derealisation of violence, the denial of mournability (and life).

\subsection{THE SPECTRE's IMPERATIVE}

As a framework hauntology renders as many deficiencies as potentialities. ${ }^{178}$ To begin with, I claim to ground M.I.A's work in Tamil contexts and epistemologies, yet ground and subscribe to Western frameworks. Hauntology, situated contiguously in spectrality and deconstruction, critiques the primacy of presence in western theory. Yet,

\footnotetext{
was, thus, historically no witness to the Holocaust either from outside or from inside the event" (Laub, 81.) Being inside the dehumanising frame disables witnessing, wherefore the Holocaust was an "event that produced no witnesses," (Laub, 80.) it created "a world in which one could not bear witness to oneself' (Laub, 'Bearing Witness', 66.)

177 Laub, 'Bearing Witness', 58.

178 As Derrida and most scholars I have cited, I use the terms spectrality and hauntology synonymously.
} 
most markedly feminist, Marxist, and postcolonial critics point to its limits, in particular its elusiveness, apoliticality, eurocentrism, phallocentrism, and capitalism-blindness. ${ }^{179}$

Hauntology encounters representational limitations. The spectre's invisibility is equated to unrepresentability. Representation, in turn, is coupled with agency and speech. ${ }^{180}$ Lacking both representation and speech, it follows the spectre is ineffective as a tool of resistance. Luckhurst, who coined the term spectral turn, cautions against "the generalized structure of haunting [which] is symptomatically blind to its generative loci." ${ }^{181}$ The ahistoricity of the spectre renders it possibly ineffective.

Materialist critiques pronounce that hauntology runs the risk of derealising subjects and their material experiences of violence, doubly so

179 Even though, regarding class ignorance, the main thrust of Derrida's Spectres of Marx is to proclaim the enduring relevance of Marx and Marxism.

180 Spivak, for instance, sees representation as two-fold: political/agentic representation (e.g. speech) and non-agentic re-presentation (e.g. art). In her exegesis of the subaltern, she refers to Marx's distinction between two types of representation in The Eighteenth Brumaire of Louis Bonaparte, namely, vertreten ('represent' in the first sense) and darstellen ('re-present' in the second sense), which is "the contrast, say, between a proxy and a portrait" (Spivak, 'Can the Subaltern Speak?', 276.) Vertreten presupposes consciousness, political subjectivity, and agency. The spectre is thus devoid of representation in both senses, of artistic representation (Darstellung) and political representation (Vertretung).

${ }^{181}$ Luckhurst, 'The Contemporary', 528. 
for erased victims of state violence. If presence is equated with materiality, hauntology inevitably obscures material inequalities. ${ }^{182}$

Feminist critiques draw attention to the absence of women in hauntology. For Derrida, the spectre is a phallocentric concept, "the arch-specter, is a father." 183 Spivak incriminates "the ghost of Marx that Derrida is most haunted by returns to the bosom of Abraham" as "woman is nowhere" in Marx and "she is nowhere in Specters of Marx." 184 If the spectre is absence or lack, woman constitute a double absence.

Postcolonial critiques point to the Eurocentrisms of western theorieseven those that question their own primacy of presence. To be precise, they indicate hauntology disregards (the intersectionality of) asymmetric race, class, and gender hierarchies of power. Chow points out ethical claims made on behalf of deconstruction rely on otherness as the limit of western thought. ${ }^{185}$ Hauntology, understood as alterity, only serves as a counter-point to ontology (the western self). Critical theory's claim to alterity, its ontological dependence on otherness, Chow maintains, marks

\footnotetext{
${ }^{182}$ Spivak observes deconstruction and hauntology disregards "the connection between industrial capitalism, colonialism, so-called postindustrial capitalism, neocolonialism, electronified capitalism, and the current financialization of the globe, with the attendant phenomena of migrancy and ecological disaster" (Spivak, 'Ghostwriting', 68.)

183 Derrida, Specters of Marx, 137, 221.

184 Spivak, 'Ghostwriting', 66.

${ }^{185}$ She states, "In the hands of poststructuralist theorists, who tend to dismiss positions of otherness defined in positive, phenomenological terms, the claim to otherness becomes a claim to the capacity for subverting established signs of social power by putting such signs 'under erasure."' (Chow, Ethics after Idealism, xvi-ii.)
} 
a form of elitism, "a special kind of aristocracy," and a process which “operates by demanding [...] 'deconstruct the best you can - but continue to center on the West." "186 It hence remains a western-centric praxis with the sole purpose of affirming the western self. Morton points out theories of spectrality "are cognitively unable to address the agency and embodied knowledge of particular disenfranchised groups.”187 In other words, they deagentise marginalised communities.

Of particular import for my study is the critique that hauntology, particularly in contexts of violence, runs the risk of romanticising spectres and ventriloquising the dead.

Yet, despite these drawbacks of hauntology, it is crucial to note that spectres acutely reflect MIA. Despite lacking representation (as outlined above), spectres lend themselves to embody erasure. That is, because of their unrepresentability they suitably depict erasure. Spectres, as international relations scholar Auchter remarks, aptly represent the invisibility of the "victims of a totalitarian thanatopolitics." 188 Leeder similarly pronounces the spectre signifies the persistence of memory and history in the 'living present,' it is

\footnotetext{
186 Chow, xviii.

187 Morton, 'Postcolonialism and Spectrality', 616.

188 Auchter, Haunting, 56.
} 
a potent representation of and figure of resistance for those who are unseen and unacknowledged, reduced to a spectral half-presence by dominant culture and official history. ${ }^{189}$

The spectre's temporality is particularly most resistive for subjects that are politically erased. The in Spivak's words “uncontrollable, sporadic, and unanticipatable periodicity of haunting"190 interrupts temporality and the biopolitical order of the nation when the erased pasts return to haunt the present. Haunting embodies the spirit of Parry's understanding of memory, that of "remaining unreconciled to the past (histories of injustice).”191 The power of hauntology as a tactic over ontology is hence its iterability. Returning from the past and insistently remaining in the present, the spectre as "a cipher of iteration," Buse and Stott state, challenges the rigid chronology of temporality and historicism, ${ }^{192}$ to conjure justice and responsibility. As such, the spectre is a transruption. Transruptions, says African-American studies scholar Hesse, unsettle repressive hegemonic practices and discourses, and in the lack of effective resolutions, refuse repression by 'apparitional' recurrence. ${ }^{193}$

Haunting requires witnessing. Luckhurst reminds that the grammatical voice of haunting is passive, "[y] ou do not haunt; you do not actively

\footnotetext{
189 Leeder, 'Cinematic Ghosts', 1.

190 Spivak, 'Ghostwriting', 70.

191 Parry, Postcolonial Studies, 193.

192 Buse and Stott, 'Ghosts', 11.

193 In contrast, he says, interruption denotes a singular event, whereas disruption an ultimate event. Barnor, with recourse to Williams, divides transruptions into residual and emergent (Hesse, 'Introduction', 17-18.)
} 
ghost; rather, you come to be haunted by another," "you are subjected to haunting, you are not the subject of haunting."194 Haunting stipulates a willingness to be haunted, it requires witnessing.

Indeed, hauntology is not an arbitrary framework to read M.I.A's work. Rather, haunting is at the heart of her work, evinced even in the act of her self-naming M.I.A.

\section{The Spectrality of MIA}

MIA is a military acronym for Missing in Action and refers to missing combatants in war. They refer to unrecovered bodies or unidentified remains. They hence connote absence or an ontological uncertainty. Political scientist Edkins argues MIA pose a challenge to the state as they are "names without bodies,"

[when people go missing after wars and after or during migration, the] states' authority in the control of their population-and the authority of the state itself as political form-is challenged. [...] [MIA interrupt] the everyday processes of death, mourning, and commemoration. ${ }^{195}$

MIA are neither living nor dead, like spectres, and they also contest the state's control over life and death. They occupy an elusive time-space. MIA pose a challenge not only to state control, but also to state

\footnotetext{
194 Luckhurst, 'Ghosts', 51. The spectre's unidentifiability and unlocalisability is most visible in the German language (Derrida, Specters of Marx, 169-70.) In "The Uncanny," Freud writes "es spukt," which Derrida translates as "it haunts, it ghosts, it specters," it carries the "atmosphere of anonymous threat" (Derrida, 169-70.)

195 Edkins, 'Missing Migrants', 360.
} 
memory. ${ }^{196}$ In M.I.A's work, MIA or spectres are politically erased subjects, Tamil militants MIA (Chapter 4), victims of state massacres (Chapter 5), and refugee bodies (Chapter 6). Edkins suggests missing migrants are MIA and double erasures: when migrant bodies-those already missing-meet their deaths, "they become unidentified decedents—bodies without names-undocumented dead who are doubly disappeared."197 Yet, she urges not to identify them,

a focus on identification and reparations could obscure the larger factors that led to these people going missing [...] [and] it can lead to closure. ${ }^{198}$

Identification then, (like reconciliation as Parry argues,) is closure. Closure means the end to a lingering presence. Haunting opposes closure by recurrence. In the context of Argentina's war (briefly explored in the next subsection), historians Bevernage and Aerts argue that the mothers of the disappeared kept the past, their children's disappearance, an actuality by rejecting closure and resisting against the metaphor of death ('Because death is final'). ${ }^{199}$ They observe, disappearance, in contrast to 'ordinary' death, $[\ldots]$ never 'passes' $[\ldots][$ As the ghosts] could potentially haunt the country $[\ldots]$ the junta leaders $[\ldots]$ [spoke] about the dead. ${ }^{200}$

\footnotetext{
196 Edkins, 362.

197 Edkins, 362.

198 Edkins, 379.

199 Bevernage and Aerts, 'Haunting Pasts', 393-94, 405. It should be noted that mourning for the Madres means substantiating or confirming the dead, a practice they hence eschew. In M.I.A's work, memory, mourning, and witnessing oppose political erasure and the destructive thanatopolitics of the state.

200 Bevernage and Aerts, 396.
} 
The disappeared are not only MIA, but potential haunting and dangerous spectres. The declaration of the death of the disappeared and MIA to establish finality illustrates the spectre's resistive power. In 2020, the current president of Sri Lanka, similarly to the junta leaders in Argentina, declared the missing of the civil war dead. ${ }^{201}$ The disappeared are the key to enable justice claims. Highlighting the individual and collective significance of disappeared bodies for legal justice, literary scholar Nayar expounds the ramifications of their absence,

The disappeared are unavailable for legal, humanitarian and historical purposes [...]. They cannot be 'claimed' as evidence for prosecuting those responsible for the disappearances $[\ldots]$. They are unavailable for families and communities to achieve closure for their dead. ${ }^{202}$

M.I.A, as my case studies illustrate, re-visualises these disappeared bodies as spectres to actualise claims for justice.

\subsection{SPECTRAL Media}

Each of my case studies draws from a respective photograph: photographs of dead soldiers in LTTE videos (Chapter 4), a soldier's trophy image of the Mullivaikkal massacre (Chapter 5), a TIME photograph of a refugee boat (Chapter 6). Conjuncted with death, absence, and haunting, photography, theorists argue, enables memory, mourning, and witnessing. Photography theorist Dubois describes photography as a timeless death and an image of death, an "a-chronic death" and a

\footnotetext{
201 'Sri Lanka Civil War: Rajapaksa Says Thousands Missing Are Dead'. 202 Nayar, Human Rights and Literature, 114-15.
} 
"thanatography." 203 Film critic Bazin maintains it hides "a mummy complex" and embalms the living body against death by preserving its image. ${ }^{204}$ For literary theorist Barthes, photographers are "agents of Death.”205 As photographs affirm a past presence, he concludes, they are 'absence-as-presence.' 206 Yet, simultaneously, they arrest, anaesthetise, and immobilise time. ${ }^{207}$ They are a Tableau Vivant, a "made-up face beneath which we see the dead." ${ }^{208}$ As "the return of the dead," they embody iterations, simulacra, spectres. ${ }^{209}$ Yet, Barthes insists, these spectres lack agency; photographs musealise, de-subjectivise, and dispossess the self. 210 Besides death, photography is conjoined with (its) truth value. Art historian Diack remarks, “[a]rguably, more than any other medium, photography was $[\ldots]$ invested with $[\ldots]$ the topos of photography as truth." ${ }^{211}$ Despite postmodern critiques of truth values ascribed to photography (what photographer and critic Sekula calls the "myth of photographic truth" 212 ), it remains a cornerstone in evincing (war) crimes (this aspect is significant in Chapter 5). For instance, during Argentina’s Dirty War (1976-1983), government officials sought to destroy the photographs of the victims. Performance studies scholar Taylor

\footnotetext{
203 Dubois, L'Acte photographique; van Gelder and Westgeest, Photography Theory, 106.

204 Bazin, 'The Ontology of the Photographic Image', 4.

205 Barthes, Camera Lucida, 92, 9.

206 Barthes, 106.

207 Barthes, 57, 91.

208 Barthes, 32.

209 Barthes, 9, 14.

${ }^{210}$ Barthes, 13-14.

${ }^{211}$ Diack, 'Clouded Judgment', 225.

${ }^{212}$ Sekula, 'On the Invention of Photographic Meaning', 86.
} 
understands the erasure of documentary evidence as an attempt to erase "traces of the life itself." 213 Photographs document the (past) presence of the victims. The victims' mothers, termed 'Las Madres de la Plaza de Mayo,' protested the disappearances of their children with scaled up photographs as a form of evidence. They thus "turned their bodies into archives, preserving and displaying the images that had been targeted for erasure." 214 Taylor contends photographs witness erasures and percepticides, which she defines as the general population's partial blinding, killing or sensory numbing. ${ }^{215}$ Sociologist Sosa remarks the Madre "became one of the main ambassadors of the new era of memory." 216 Closely linked to the notion of evidence and witnessing inherent in photography is vulnerability, grievability, and mournability. For critic and filmmaker Sontag, photographs are memento mori, and " $[\mathrm{t}] \mathrm{o}$ take a photograph is to participate in another person's (or thing's) mortality, vulnerability, mutability." 217 Photographs, she remarks, "haunt us." 218 Butler extends this line of thought and states photographs not only enable haunting but also instate grievability and mournability. ${ }^{219}$

\footnotetext{
213 Taylor, The Archive and the Repertoire, 177.

214 Taylor, 177-78.

215 Taylor, Disappearing Acts, 123-24.

216 Sosa, Queering Acts of Mourning, 88.

217 Sontag, On Photography, 15.

${ }^{218}$ Sontag, Regarding the Pain of Others, 89.

219 Butler, Frames of War, 97-98.
} 


\subsection{SUMMARY}

My recurring key assertion poses the revisualisation of Tamil cemeteries in M.I.A's output, the spectral recurrences of politically erased subjects who pursue a particular politics of death. The precondition of spectrality is the politics of life and death itself: the power to take life, make life, let live, make live. Biopolitics, 'the politics of and over life' can become thanatopolitics, 'the politics of and over death,' that is, the promotion of life can simultaneously signify the promotion of death. Hauntology contests political erasure and the state's power over life and death. Some forms of haunting, as a resistive politics of death, not only contest state violence, but also its claims over memory and territory. Haunting, like LTTE cemeteries, opposes the memorial and territorial claims of the state, a claim emerging from the analyses of my case studies. Haunting also enables memory work, mournability, and witnessing-political acts that recognise violence and claims for justice. The medium of photography particularly reflects the enabling potentials of haunting. M.I.A's work materialises disappeared bodies as spectres to actualise claims for justice by translating spectral media, photography in particular. Spectres acutely reflect MIA and lend themselves to embody erasure. As "ciphers of iteration," they conjure recurring ethical injunctions. 


\section{Spectres of Oliveechu}

We know about the war, I said. As a child, we used to receive newsletters about it. Unofficial publications, because no one would publish anything official. ${ }^{220}$

The traces of the war in Sri Lanka or what American-Tamil novelist Ganeshananthan refers to as 'unofficial publications' traverse Tamil diasporic lives and M.I.A's early visual art. They dissimulate in M.I.A's bright pop art stencils which depict Tamil subjects, symbols, and landscapes. Recurring motifs are palm trees, tanks, and women's faces. They originate from re-photographed images of LTTE videos tapes.

In the previous chapter I illustrated the ethical injunctions of haunting. Haunting, like LTTE cemeteries, enables the work of memory and mourning. In this chapter, I identify M.I.A's stencils as sites of haunting that enable remembering and mourning Tamil subjects and landscapes. I demonstrate that LTTE tapes replicate the functions of LTTE cemeteries, asserting memorial and onto-territorial claims (Chapter 2.2). In other words, the tapes are cemeteries that mediatise LTTE cemeteries. M.I.A's artwork translates the images of the LTTE tapes into stencils, thereby reiterating the cemeterial claims in a medium sous rature. They also visualise both the deconstruction of the LTTE cemeteries by the army in 1995 and their reconstruction (Chapter 2.1). As I stated in Chapter 2, the

${ }^{220}$ Ganeshananthan, Love Marriage, 47. 
conflict is staged on the dead, by means of erasing and resurrecting cemeteries. M.I.A's stencils resurrect the Oliveechu images and thereby LTTE cemeteries. LTTE cemeteries claim territory (stencils, in general, also claim public space, critique the state, and are under erasure) and remember and mourn (as do photographs). By displaying the dead of the month, the Oliveechu tapes resurrect LTTE cemeteries. The Oliveechu tapes themselves are under erasure, as they are criminalised in western nation-states. They are nationalist documents, too, mobilising diaspora (memory) activism. M.I.A's stencils resurrect a cemetery, commemorate and claim space (by the use of LTTE images and stencil). They are spectres that haunt and oppose the state (by the inscription onto flags and by use of stencil). LTTE cemeteries were destroyed by the SLA in 1995 and the LTTE videos were criminalised by western nation-states in the early 2000 s (post-9/11), the time when M.I.A produced the stencils. Stencils hence constitute traces of 'unofficial newsletters,' images sous rature, and an archive of absence.

\subsection{ERASING COPIES OF COPIES}

M.I.A's early artworks emerge from resistance to racism, classism, elitism, and Weltfremdheit-unworldliness or worldly alienation—in British art and academic landscapes that, in her own words, "missed the whole point of (art) representing society." ${ }^{221}$ Instead, they archive tapes of a distant war. From the mid-1990s onwards the LTTE released video tapes called

${ }^{221}$ M.I.A. in Loveridge, 'Foreword', 6. 
Oliveechu (Figure 4.1). They were addressed to, copied, and circulated amongst the Sri Lankan Tamil diaspora, and contained war reportage and photographs of the fallen LTTE rebels, so, M.I.A reflects, "parents could go buy the tapes at the local grocery store to see if their kids were on there that month." 222 M.I.A was particularly haunted by images of rebel girls, frozen "between life and death; combat and murky silhouettes of rockets being launched through palm trees; tanks and camouflaged uniforms." 223 Notably, these are the images that find recurrence in her work. She re-photographed, re-scaled, and spray-painted the images of militants and MIA from the LTTE videos on cheap canvasses or cardboards. 224

\footnotetext{
222 Arulpragasam, 'Arular', 16.

223 Loveridge, 'Foreword', 11.

${ }^{224}$ Loveridge, 11; Arulpragasam, 'Arular', 16.
} 


\section{This content is unavailable. Please consult the figure list for further details.}

Figure 4.1 Oliveechu tape cover of October 2000

The cover text itself emphasises commemoration; it reads, 'Recovering from tragedy Remembering twelve Black Tigers - The 13 year anniversary memorial of the first female tiger Lt. Malathi’. 
The 'original' media of M.I.A's art are videoised LTTE newsletters, recopied en masse to be distributed to Tamil communities in Western cities. Hence even M.I.A.'s source media is a glitchy 'copy of a copy,' 225 a pixelated and fragmented iteration. As the videos' document absence, M.I.A stencils of the MIAs of the month constitute an iteration and ontologisation of absence. Even the album's name Arular arises from a personal and collective absence,

Arular comes from my father's code name [...] in the Tamil resistance movement. [...] My mum always used to say, "He was so useless. All he ever gave you was his name." So I turned it around, turned nothing into something. ${ }^{226}$

As a name, Arular connotes a paternal absence, but also a documentary absence of war memories. Hence the album Arular presences M.I.A's absent father and a deliberately obliterated history of oppression and violence. The term MIA is a conceptual and material space of absence, too. For M.I.A it refers to a missing personal and collective identity; it signifies M.I.A's own missing cousin ${ }^{227}$ and a missing Tamil "youth culture" 228 at large.

\footnotetext{
225 Loveridge, 'Foreword', 11.

226 Arulpragasam, 'Arular', 16.

227 "M.I.A. came because of my missing cousin. [...] he was M.I.A. (Missing in Action) in Sri Lanka. We were the same age, went to the same schools growing up." (Arulpragasam, 'Introduction', 13.) Cousin or sibling (including twin) narratives as tropes of sameness and difference can be found in diasporic Tamil fiction as well, e.g. Sivanandan, When Memory Dies; Ganeshananthan, Love Marriage.

228 "a whole youth culture there had gone missing" M.I.A. quoted in Orlov, 'Interview with M.I.A.'
} 
In the aftermath of $9 / 11$, Western nation-states classified the LTTE as a terrorist organisation and censored the LTTE videos. As M.I.A reflects, ${ }^{229}$ Soon, these tapes were considered a terrorist material and were destroyed. Not only were the people in the videos dead, but their images were destroyed-along with their identities and memories. To the future and the world, they didn't exist. I wanted to document the documents. I hid one tape in my mum's attic, and in the end, termites ate it. I was happy that there was a record of what this looked like. ${ }^{230}$

The prohibition of the LTTE tapes mute memories of Tamil resistance, and absences (erases) absences (MIA), again. M.I.A's stencils therefore document and archive images sous rature (under erasure). They oppose the illegalisation of Tamil rebel videos in the Global North and the memoricide campaign by the Sri Lankan state against dissident Tamil voices. They protest the uncertain state and the possible decease of the MIA. They document death (MIA) against death (censorship). They form an archive of absence.

Indeed, I also watched this archive of absence and witnessed acts of archivisation. My parents obtained parcels of the Oliveechu editions, along with the most recent available Indian Tamil films, from a Tamil shop in Frankfurt. M.I.A's visual landscape was immediately familiar to me, they evoke images I glimpsed at in my childhood, images many

\footnotetext{
229 As Wayland states, "Britain has been the most important site of the LTTE's overseas political activity. Until anti-terrorism legislation passed in Britain on 28 February 2001 banning the LTTE, the Tigers' international secretariat had been located in London" (Wayland, 'Ethnonationalist', 419.) 230 Arulpragasam, 'Arular', 18 emphasis mine.
} 
diaspora Tamils shared. These were images my parents re-taped, too, to retain a copy, to 'document the documents.' An imagined community ${ }^{231}$ was sustained by means of tape images. This imagined community not only beheld the images, they also shared memories and commemoration. M.I.A observes, when you go MIA [in Sri Lanka,] [...] [y]ou don't have a funeral[,] [y]ou don't see a body, you don't get an official government letter, so this person never dies. ${ }^{232}$

Tamil MIAs are characterised by corporeal and documentational absence. At the same time, they remain in an eidolic state, neither living nor dead, as their absence occurs only in the moment of state certification, which Tamil families are denied, as any governmental acknowledgement of Tamil deaths implicates the state's complicity in the production thereof. Against this backdrop of bureaucratic power, the Oliveechu tapes provide a form of death notice. Circulating images of the dead, the LTTE videos contribute to a burial-memorial practice. The tape segments of fading-in the MIAs of the month is a practice of commemoration.

The Oliveechu tapes are transient yet iterable obituaries that perform rituals of funeral. They also mobilise diaspora activism and remembrance. While the LTTE videos function as obituary that commemorate dead fighters and MIA, M.I.A's stencils haunt throughout Arular. The

\footnotetext{
${ }^{231}$ I am evoking Anderson, Imagined Communities.

232 Arulpragasam, 'Introduction', 13.
} 
Oliveechu tapes iterate the LTTE cemetery, while M.I.A's stencils, as I will show, iterate the Oliveechu cemetery.

\subsection{DOCUMENTING THE DOCUMENTS: STENCILS}

M.I.A's debut album Arular was released in 2005 and included the songs "Galang" (2003) and "Bucky Done Gun" (2005). The corresponding music videos were directed by Ruben Fleischer and Anthony Mandler respectively.

Both songs feature M.I.A's own stencil artworks. The music video of "Galang" is pervaded with stencils, derived from or inspired by the Oliveechu videos, some of which are animated, relocated, magnified, and iterated. The stencils locationally vacillate between Jaffna and London, juxtaposing the annihilation of Jaffna's palm tree landscapes with the destitution of London's council houses; persecuted Tamil militants with racially profiled youths; violence (tanks, police cars, stealth bombers) with

resistance (militants, tigers, palm trees). They foreground the violence of both settings: A state that kills its people and kindles the landscape (symbolised by tanks and trees ablaze), another that invades foreign countries and ghettoises its migrants (symbolised by stealth bombers striking Muslim women, police cars pursuing hooded youths, and fenced buildings). Amidst rapid stencil overlaps and disorienting editing, the only remaining constant is M.I.A's steady gaze into the camera and her jerky impromptu movements. The music video of "Bucky Done Gun," on the other hand, recurs several stencils of "Galang” and alternates between the 
militarised sites of an underground club space and a fenced-in seashore war zone. The club setting spotlights M.I.A against a tank stencil, whereas the seashore displays stencil prints of a Tamil militant and grenades on flags.

Noted for their "paramilitary graf art," "revolutionary chic" fashion, "nonsensical rapping" and "sex-funk gibberish," 233 the reception of “Galang” and "Bucky Done Gun” prevalently paternalises, patronises, and infantilises the artist and, by extension, devalorises the songs. Music magazine critics describe "Galang," for instance, as a "nursery-rhyme swing," 234 to which, M.I.A "performs a silly little-girl dance" against "graffitied third-world signifiers." 235 Similarly, music journalist Hermes describes the song "Bucky Done Gun" as an "ode to revolution and rough sex," a "'let's fuck' anthem," and a "ghetto groove."236 Postcolonial sound studies scholar Maier echoes this construal, pronouncing the song's aesthetics "is completely decontextualized from the lyrical content and instead focuses on stereotyped connotations of the gloomy ghetto and shallow sexiness." 237 In marked contrast to Hermes' and Meier's impressions, I illustrate and emphasise the politicality of the song's stencil aesthetics which evokes spectres of the Sri Lankan war, or specifically, the

\footnotetext{
${ }^{233}$ Hermes, 'Artist of the Year', 58. Binelli, 'M.I.A'. Trilling, 'New World Order'. 'M.I.A. Arular. XL/Interscope', 65.

${ }^{234}$ Hermes, 'Artist of the Year', 57.

235 Fleischer, 'The 50 Best Music Videos of the Aughts'.

${ }^{236}$ Hermes, 'Artist of the Year', 5, 56-58.

237 Maier, Transcultural Sound Practices, 134.
} 
Oliveechu tapes. The 'graffitied third-world signifiers' and M.I.A's 'silly little-girl dance' in "Galang," likewise, pursue a resistive politics of memory and mourning against state violence.

Even though my main focus revolves around M.I.A's use of stencils, the songs' politicality also lies in the lyrics and the sartorial politics of the music video. For instance, the music video of "Bucky Done Gun" foregrounds M.I.A's lip-synching opened mouth and a mic to reflect the lyrical insistence to speak: the lyrical persona not only demands to speak ('make a sound'), but also to be listened to ('quieten down'). Violence is all-pervasive and articulated by a cacophony of sounds (and images). It is against these sounds that the lyrical persona speaks,

They're coming through the window

They're coming through the door

They're busting down the big wall

And sounding the horn

The drums, trumpets and horns in the song mimic a war soundscape. The war is experienced auditively as 'coming' footsteps, 'busting' walls, and the sound of the horn, but so is resistance, too, by 'making a sound.' The lyrical call to 'quieten down' demands the end of war (sounds), yet also implies the unhearing or perhaps drowning of subaltern speech in hegemonic cacophonies. "Bucky Done Gun" is a favela funk (or funk carioca) song-a hip hop derivative from Rio de Janeiro in which the favela constitutes a key spatial referent-and draws an analogy between the violence of Brazil's favelas and Jaffna by sound and image. 
The so-called 'nursery-rhymes' of "Galang" in fact mock state conformity. A stencil background in the music video iterates the word 'how' in Tamil (எப்படி, vernacularised எப்பிடி). Linguist Canagarajah explains it is the Tamil equivalent of the Guyanese patois gwan, "a common conversation opener in Tamil, an utterance someone would use in a phone call from London to Jaffna. Galang is a Jamaican creole word meaning variously 'go along,' 'behave yourself,' or simply 'be cool.' The rap urges listeners to face oppressive conditions with ease."238 Yet, I take the view "Galang" urges to do the opposite of 'galang' (to 'go along'). Its following lines replicate authoritarian dictates and simultaneously castigate the conformity thereof,

$$
\begin{aligned}
& \text { They say rivers gonna run though } \\
& \text { Work is gonna save you } \\
& \text { Pray and you will pull through } \\
& \text { Suck a dick'll help you }
\end{aligned}
$$

The call to 'galang' hence critiques the upholding of the status quo by mimicking what 'they say'. M.I.A herself subverts the 'galang.' The first line of "Galang", "London calling, speak the slang now" refers to the song "London Calling" by The Clash, which itself refers to the announcements broadcast by the BBC World Service during World War II. It hence refers to imperial interpellation of the centre (empire) to the margins (colonies). M.I.A mimics and subverts the centre's interpellation that once transformed colonial subjects into mimic wo/men. Yet, the asymmetric power relations between centre and margin remain, as the hooded

\footnotetext{
${ }^{238}$ Canagarajah, Translingual Practice, 3.
} 
Londoner (reflected in the lyrics and video) is subjected to persecution, ghettoisation, and racial profiling. The song's music video more distinctly intervenes the 'galang' by stencil art.

Music magazine writer Wheaton states M.I.A's choice of the "superficial, ephemeral medium" of graffiti-stencils runs the risk of exoticising and depoliticising "distant struggles" into "all spectacle." 239 Yet, M.I.A's stencils do not depoliticise 'distant struggles,' and the stencil's ephemerality is deliberate. Indeed, I submit M.I.A's stencils resurrect LTTE cemeteries and replicate their memorial and onto-territorial claims (Chapter 2.2). The artforms M.I.A draws from-stencil and photography-are, as such, tied to iteration and spectrality. Earlier (Chapter 3.5) I made the case that photography enables memory, mourning, and witnessing.

In the following I illustrate stencil art claims space, contests the state, and embodies erasure (sous rature). Stencilling enables the repeated production of the same image, and the term stencil refers to both the 'original copy' as well as the reproduced image. It is, by definition, an iteration and alteration of the same and hence an instance of différance (Chapter 3.1). Councils, considering unauthorised stencils as defacement, vandalism or property damage, commission their removal from public spaces. Like LTTE videos, stencil art is an illegalised expression. It is

239 Wheaton, 'London Calling', 43-44. 
transient, palimpsestual, with erasure inscribed into its inception. Its characteristics of recurrence (iteration) and erasure, of graffitiing and graffiticide, imbue stencils with a spectral, absent-present quality. Stencil artist and cataloguer Howze theorises stencils as self-produced "informal documents of citizenship." 240 Similarly, media scholar Truman sets forth stencils subvert "recognizable icons, symbols, and phrases" by mimicking the authoritative typography of official documents. ${ }^{241}$ Both Howze and Truman locate stencil praxes as performative acts within and against national discourses. As such, stencils, as digital cultures theorist Carrington and architectural historian Chattopadhyay respectively propound, inscribe self-narratives onto cityscapes and challenge the privileged materiality of public spaces. ${ }^{242}$ Despite the often elitist status of stencil writers as "white, male, and art-school educated," Howze insists stencils express the disenfranchised and contest citizenship from urban "hiding place[s]." 243 The national contestation in M.I.A's stencils revolve around the resurrection of the LTTE cemetery by means of Oliveechu images, a resistive thanatopolitics against the state's destructive thanatopolitics (Chapter 3.2 and Chapter 3.3).

\footnotetext{
${ }^{240}$ Howze, Stencil Nation, 8.

241 Truman, 'The (In)Visible Artist', 3.

${ }^{242}$ Carrington, 'I Write, Therefore I Am', 419. Chattopadhyay, 'Making Place', 64-65.

243 Howze, Stencil Nation, 120, 8. Stencil writers are spectral (non-)citizens of sorts, or, in homage to Bhabha, a DisStencilNation (Bhabha, 'DissemiNation'.)
} 


\subsection{TANKS}

In "Bucky Done Gun," M.I.A notably wears a military uniform against a stencil tank image in the club space (Figure 4.2), which also recurs in "Galang" (Figure 4.3). M.I.A explains the song was inspired by "that sort of insanity" ascribed to Gaddafi, who "every time he's got a photo opportunity, he gets [his] backdrop out and stands in front it."244

The club space, scholars voiced, reconstitutes and renegotiates urban, working-class, and gender identities. In "Bucky Done Gun," the club space stages the thanatopolitics of the state. It is militarised by means of M.I.A's textile politics (which also facilitate gender inversion) and the tank stencil background. M.I.A's mocking demeanour in Figure 4.2 implies the uniform is a sartorial persiflage, a mimicry of the clichéd male third world dictator. It mocks the likes of Gaddafi, who western media describes as a "sartorial exhibitionist," a "desert chieftain in rich and vivid robes," a "tinpot dictator decked out in purple like a Roman emperor."245 Dismissed as irrational, bizarre, and vain, Gaddafi is an ambivalent figure: anti-imperialist and authoritarian, a human rights abuser and a fashion icon. ${ }^{246}$ Yet, as postcolonial critic Mbembe propounds, the vestiary pomposity of power can be inverted in the postcolony, "The real inversion takes place when, in their desire for a certain majesty, the masses join in the madness and clothe themselves in cheap imitations of power to

\footnotetext{
244 M.I.A quoted in Nand, 'Brown By Ashlene'.

245 Parris, 'Absolute Power', 37.

246 Parris, 37.
} 
reproduce its epistemology, and when power, in its violent quest for grandeur, makes vulgarity and wrongdoing its main mode of existence." 247 In a similar vein, M.I.A derides the obscene of power by enacting a dictator in a sartorial mimicry. Her carnivalesque parody undermines what Mbembe terms 'officialdom' "by turning it all into an object of ridicule."248 It contests state's necropolitics that produces what Mbembe refers to as 'the living dead' who "live in death, be already dead, while being-there."249

In a step further than Gaddafi, M.I.A not only brought, but also created her own tank stencil backdrop that evokes the army tanks of the SLA (Figure 4.4). As journalist Subramanian recites a Tamil witness account on the militarisation of Jaffna,

Tanks groaned through the slender roads [of Jaffna]. Floods of armed soldiers took over the town. 'You would see one of these soldiers, and you would naturally start to think: "He is Sinhalese, I am Tamil. He has a tank, I have nothing. He doesn't have to show his ID card at checkpoints, I do. If he blocks the road, I must turn back." ${ }^{250}$

The tank metonymises the Sinhalese Buddhist state's war machinery and its destructive thanatopolitics. The state's power over life and death is abstracted into an image of military technology. The presence of the state's tank is in marked contrast to Tamil absence or having 'nothing.'

\footnotetext{
247 Mbembe, On the Postcolony, 133.

248 Mbembe, 103-4.

249 Mbembe, 201.

250 Subramanian, This Divided Island, 134.
} 
The tank stencils in both "Bucky Done Gun" and "Galang" memorise and iterate the militarisation of Jaffna and the demolition of LTTE cemeteries as historical injustices. 'Hav[ing] nothing' is understood as vulnerability (the exposure to state violence), Tamils, as a killable population, are and have nothing. As a medium of destruction, tanks signify Tamil erasure.

\section{This content is unavailable. Please consult the figure list for further details.}




\section{This content is unavailable.} Please consult the figure list for further details.

Figure 4.3 Screenshot from "Galang." M.I.A, tank and stealth bomber stencils 251

${ }^{251}$ A stealth bomber traverses the tank stencil background. Stealth bombers, like tanks, recur in M.I.A's imagery. A US-technology deployed during the Afghanistan and Iraq wars, stealth bombers capture their targets without detection or capture by 'enemy' radars, enabling the unchecked movement within and invasion of enemy territory. As such, they are an almost unblockable mode of attack. The stealth bombers references in "Galang" invoke them as a strategy of deception (spectresque, as they see without being seen) and a war machinery. The coupling of tanks with stealth bombers connects imperialism and Islamophobia post-9/11 and the dispossession and demonisation of Tamils. It invokes violence imposed on Muslims and Tamils in the name of the 'war on terror' by the US and Sri Lankan state respectively. 


\section{This content is unavailable. Please consult the figure list for further details.}

Figure 4.4 M.I.A, “Tanks,” spray-paint stencils, 2005

\subsection{NISA}

The stencil of a woman's face frequents both "Galang" and "Bucky Done Gun." She 'debuts' in M.I.A's stencil "Nisa, Freedom Bird” (Figure 4.5). This stencil juxtaposes an androgynous portrait-like face on the left side with an image of a jumping tiger on the right. The face is outlined in black spray paint against a white background. A curl protrudes from the woman's short, cropped hair, and she glances to the side with her lips opened. A determined expression rests on her face. Unlike the woman's monochromatic black and frontal positioned face, the tiger is depicted sideways and painted almost lifelike against a red splash. The woman, identified in the caption as 'Nisa, Freedom Bird,' is a LTTE militant, an MIA during the Battle of Jaffna, whose image M.I.A transformed from an Oliveechu tape into a stencil. Already a spectre in the Oliveechu video, 
her stencils haunt M.I.A's works. In an explanatory note to the stencil, M.I.A remarks,

The birth of M.I.A. as a concept stems from these stencil paintings [...] When the war started and all the north territories were invaded, [Nisa, a Freedom Bird, and anti-tank commander] was the first girl stationed at the bridge [called Elephant Pass in Jaffna] to stop the army [...] [In my stencil animation] [s]he explains how she became a freedom fighter and how she was the first person assigned to protect the Elephant Pass [...]. When the Tigers lost the Elephant Pass Bridge in the '90s, the army surrounded [...] and militarized the north. Killing thousands. ${ }^{252}$

The Battle of Jaffna describes a confrontation between the LTTE and the Sri Lankan Army (SLA) fought in 1995 for Jaffna, considered the heart of the Tamil homeland and envisioned the capital for the independent state of Tamil Eelam. After three months of attacks, the army captured the city. The city's militarisation by the army cut off the peninsula from the rest of the Tamil areas and displaced 200,000 Tamil civilians. ${ }^{253}$ The army also demolished LTTE cemeteries (Chapter 2.2). As sociologist Sasanka Perera states, "many tombs in these [LTTE] cemeteries did not contain the remains of those who had died in combat but were affectively [sic] markers." 254 Whereas the LTTE cemeteries presenced (ontologised) absences (MIAs) (as they literally contained nothing), the SLA not only erased absences, but it erased the dead a second time. ${ }^{255}$ As elucidated in

\footnotetext{
252 Arulpragasam, M.I.A., 51.

253 Murari, The Prabhakaran Saga, 166.

254 Perera, Warzone Tourism, 77.

255 One could also question whether the SLA's erasure of the dead (absence) affirms the latter's presence, as erasure preconditions presence.
} 
Chapter 2.2, LTTE cemeteries claimed both Tamil memory and Tamil territory. M.I.A's stencil hence resurrects the dead fighter, killed in battle and in memory, and asserts memorial and onto-territorial claims. In the artist's own words, "each frame of [Nisa] is talking," in "a step further than Banksy," 256 which, like the lyrics and music video of "Bucky Done Gun," emphasises the insistence on speaking. The reproduction of and focalisation on Nisa's speaking face, resurrected from the dead as stencil, emphasises auto-narration and self-witnessing (the act of giving testimony, see Chapter 3.3). The stencil of Nisa documents and iterates the female militant's moment of speech and political self-positioning. Killed opposing the state's destructive thanatopolitics and protecting the borders of the envisioned independent state, Nisa documents female militancy and agency in the birth of the nation, her willingness to inscribe life (emancipation and liberation) with her death (Chapter 2.3). The stencil is a haunting memory of the militarisation of Jaffna and the demolition of cemeteries by the SLA. It is a memory of political erasure that privileges hauntology over ontology and appeals to recognise historical wounds. When recalling the absence of women in the very notion of absence or spectrality in Derrida (Chapter 3.4), it is noteworthy M.I.A's architrave, "the birth of M.I.A. as a concept," is not only a militant, but also female. If Hamlet is haunted by his father, then M.I.A is haunted by a "national mother.'

256 Arulpragasam, M.I.A., 51. 
The stencil captures different layers of spectrality: Nisa (as a subject and representation, or, to recall Spivak, as Vertretung and Darstellung) is an MIA or spectre (Chapter 3.4). Nisa is also spectralised by the medium of the photography-stencil. Yet, the stencil transcends the voicelessness of the medium of photography, as purported by Barthes (Chapter 3.5), resurrecting the subject's moment of self-testimonialisation. Nisa speaks from and against death, countering subalternity in and despite death. She iterates both state violence and resistance to it. While Nisa's black and white depiction emphasises its connection to photography and spectrality, the tiger's sanguine background signals violence and bloodshed. Nisa as an individual female LTTE militant is hence juxtaposed to the evoked collective (and masculine) eponymous tiger. M.I.A decisively eschews reproducing the frontal roaring tiger face of the LTTE iconography as a perhaps masculinist and exclusionary imagery. One may speculate the reason for the divergence: a deliberate play with the equation of Tamil and Tiger or the circumvention of censorship. Instead, she employs a specific face, like the Madres, to humanise the disappeared, counter erasure and effect witnessing (Chapter 3.5). The stencil of Nisa, resembling an ID photograph, not only documents the (speaking) dead, but also provides a counter-document for MIA who (as M.I.A stated in Chapter 4.1) are not only erased by the state, but also denied governmental documentation. But, at the same time, this stencil counterdocument is a work of constant iteration, which, by means of Nisa's frontal position, produces a sense of intimacy and immediacy. 


\section{This content is unavailable. Please consult the figure list for further details.}

Figure 4.5 M.I.A, “Nisa, Freedom Bird,” spray paint on canvas (animated), 2002

Nisa recurs twice in the music video of "Galang." In the first instance, multiple stencil inscriptions that read 'M.I.A.' are juxtaposed on and beside the stencil of Nisa, marking Nisa as an MIA, or, intriguingly, identifying M.I.A with Nisa (Figure 4.6). This is followed by a superimposition of a rebel who 'throws' blue and pink paint on the stencil of Nisa (Figure 4.7).257

\footnotetext{
257 The scene recalls Banksy's stencil "Rage, Flower Thrower" which depicts a rebel throwing a bouquet of flowers (also named "Flower Bomber," and reprinted in Banksy, Wall and Piece, 42.) The scene locates dissent and resistance within art. The dripping colours mediate the immediacy of stencil making. This act of throwing colours highlights the resistive nature of stencil art and the inherent performativity in its production. The act of stencilling is resistance and with each superseding stencil the camera trembles as if hit by a bomb.
} 
This content is unavailable. Please consult the figure list for further details.

Figure 4.6 Screenshot from "Galang.” Nisa 1

This content is unavailable. Please consult the figure list for further details.

Figure 4.7 Screenshot from "Galang." Nisa 2

In the second instance, Nisa is restencilled repeatedly to a haunting effect (Figure 4.8), only to be anew splashed over by pink spray paint (Figure 4.9). The Nisa stencils, as spectres, (re)enter and (re)exit, symbolising both destructive erasure and resistive resurrection. 


\section{This content is unavailable. Please consult the figure list for further details.}

Figure 4.8 Screenshot from "Galang." Nisa 3

\section{This content is unavailable. Please consult the figure list for further details.}

Figure 4.9 Screenshot from "Galang." Nisa 4

The stencil of Nisa markedly recurs again in "Bucky Done Gun," this time on flags (left) juxtaposed to flags depicting grenades (right) (Figure 4.10). 


\section{This content is unavailable. Please consult the figure list for further details.}

Figure 4.10 Screenshot from "Bucky Done Gun.” Nisa and grenade flags

The flag, social anthropologist Eriksen claims, quintessentially represents the state (not the nation) and produces unifying historical narratives. ${ }^{258}$ The flag of the state of Sri Lanka features a lion, while the LTTE flag prominently displays a roaring tiger. ${ }^{259}$ Both flags depict (masculine) predators notable for camouflage, and respectively inscribe Sinhala and Tamil as an ethno-national political identity. The flag, constructing state unity, is premised on the violent exclusion of the (gendered) ethno-

\footnotetext{
258 Eriksen, 'Some Questions about Flags', 2-4.

259 Hellmann-Rajanayagam states, “The name 'Tigers' were chosen for the group because the tiger was an integral part of the royal emblem of the Chola kings under whom Tamil language, Hinduism, Tamil culture, and the vast Tamil kingdom flourished. [...] [It hence refers to] the ancient glory of a people and a race" (Hellmann-Rajanayagam, "The "Groups", 173.) The LTTE flag draws on the royal emblem of the Chola kingdom, thereby tying in Tamil history and the tiger's "association with bravery, fearlessness, and heroism" (Jazeel, Sacred Modernity, 76.)
} 
national other. M.I.A's flag with Nisa's stencil prints crystallises the catenations between the female spectre and the nation-state. It critiques exclusionary national narratives that remove Tamils, places the erased female Tamil militant at the representational centre of the nation-state, thus sublimating the individual into a collective self. The resurrection of the erased female Tamil militant onto the flag transforms the latter into a haunting cemeterial site, invoking Nisa's death as a birth of national emancipation: Nisa is/as a spectre haunting the state.

The flag with the stencil prints of grenades, on the other hand, denotes state violence (similar to tanks in Chaper 4.3), or more specifically, the integrality of violence in the formation of the state. Both flags, the Nisas and grenades, form counter-narratives. ${ }^{260}$ Their juxtaposition places state violence and spectral resistance at the heart of the state. The grenade stencil flag represents state violence, while the Nisa stencil flag remembers state violence. The former centralises the state's destructive thanatopolitics, while the latter foregrounds the spectre's resistive thanatopolitics-one the killing, the other the symbolic birth of the nation.

260 National flags embody the state, whereas public stencils contest state narratives (Chapter 4.2). Stencils can be perceived of as a counter-medium to the flag. 


\subsection{Tigers}

A frequently recurring stencil motif in "Galang" is an animated tiger (Figure 4.11, Figure 4.12, and Figure 4.18). Wheaton submits the tiger stencil is either "a naïve gesture" or a critique of the LTTE, as the tiger's pervasiveness reflects the LTTE's "totalitarian hegemony" over Tamil nationalism. ${ }^{261}$ Canagarajah maintains it evokes the Tamil people's struggle for a separate state in Sri Lanka. ${ }^{262}$ The tiger, importantly, is sous rature. The Sri Lankan state media, postcolonial geographer Jazeel states, argues the tiger, "feline or otherwise," "is not, and never has been, a[n endemic] species," "it does not belong" and it violates "the rightful order." 263 The tiger is expelled and exterritorialised from nature and the nation. M.I.A's stencils iterate and resurrect the erased T/tiger symbolic of a people erased and allochthonised by the state's destructive thanatopolitics.

\footnotetext{
261 Wheaton, 'London Calling', 46.

${ }^{262}$ Canagarajah, Translingual Practice, 3.

263 Jazeel, Sacred Modernity, 77.
} 


\section{This content is unavailable. Please consult the figure list for further details.}

Figure 4.11 Screenshot from “Galang.” Animated tiger

\section{This content is unavailable. Please consult the figure list for further details.}

Figure 4.12 Screenshot from "Galang." Animated tiger 2

\subsection{PALM TREeS}

Its animated yellow-orange flames and black smoke indicative of burning, the palm tree stencil (Figure 4.13) is perhaps the most central image of "Galang" (Figure 4.14). Toward the end of the video, M.I.A dances and the screen fills with multiple M.I.A in mirror imaging (Figure 4.15). The 
background is subsequently replete with repeatedly bombed (Figure 4.16) and resurrected (Figure 4.17) palm trees. The army of M.I.A disappear except the frontal one, a tiger traverses the palm tree landscape (Figure 4.18), and the screen is once again filled with M.I.A iterations (Figure 4.19). After the ensuing removal of the palm trees, the array of M.I.A disappears and appears again, this time, against an 'M.I.A.' (and/or 'I.A.M. M.I.A.') stencil backdrop (Figure 4.20), which, once again, is supplanted by tanks amidst burning palm trees, and the M.I.A multiply and dematerialise anew (Figure 4.21). A collectivity of M.I.A and a palm trees landscape is resurrected and erased time after time (Figure 4.22). The palm trees (borassus flabellifer, also known as toddy palm or palmyra palm) not merely spatially replicate Jaffna, but are of mnemonic and ontoterritorial import. As M.I.A expounds,

The Toddy palm tree is the best thing in the world!! The first bit of alcohol I'd tasted was made from toddy [...]. The sweets I bought on the way to school were made out of the same stuff. All the roofs and walls of our houses were made from this tree. When the war started, the first thing the government did was burn down these specific trees because they were a representation of the way of life for the Tamils. ${ }^{264}$

The palm tree represents Tamil sustenance, Tamil homes, Tamil life itself. In other words, the tree is a geo-cultural signifier of Tamil ontology and epistemology. The annihilation of the trees betokens the annihilation of Tamil homes and Tamil lives. They evoke past injustices: the militarisation of Jaffna, the demolition of cemeteries by the SLA in 1995, and the 
burning of the Jaffna Public Library in 1981 by Sinhalese police and mobs. ${ }^{265}$ The library held ancient palm-leaf scrolls, and by implication evinced and legitimised Tamil mnemo-territorial claims on the island. The annihilation of the library and the palm-leaf manuscripts dematerialises and delegitimises Tamil claims to the ancestral homeland. The trees symbolise an onto-territorial claim. The image of scorched palm trees has become a Tamil trope of dispossession and displacement that foregrounds the materiality of war. ${ }^{266}$ M.I.A's palm tree stencils hence commemorate and mourn lost landscapes and lives.

M.I.A's palm tree stencil signify Tamil life and landscape (to be and to be there) sous rature. They are sites of the state's destructive thanatopolitics and the stencil's resistive thanatopolitics, of state erasure and spectral resurrection. As I have argued in Chapter 4.2, stencils are quintessential images sous rature. The music video of "Galang" in general, and this scene in particular, highlights erasure and resurrection. This scene crystallises the multiple erasures and resurrections of the palm trees and (the many personified) MIA/M.I.A. It captures the moment of both inscription and

\footnotetext{
265 As Tamil historian and critic Sivathamby explains, its burning, "[i]n the Tamil psyche, constitutes a major symbol of [...] the total annihilation of all [Tamil] intellectual resources" (Sivathamby, Being a Tamil and Sri Lankan, 17.) Knuth remarks, "the loss of the library, egregious to a group that treasured its literary heritage, shattered Tamil adults and radicalized Tamil youth" (Knuth, Burning Books, 80.) McDowell explains the library burning as "the obliteration of Tamil culture was at the crux of the Sinhalese doctrine [...] [which the LTTE interpreted] [...] as an act of cultural genocide" (McDowell, 'Symbolic Warfare in the Ethnocratic State', 28.)

266 For example, Jaffna Tamil artist Shanaathanan's painting "Home" (1997) portrays a green human figure holding a burning palm tree.
} 
its deletion, graffitiing and graffiticide, obliterations and resistance to it, the Derridean word and its crossing out (Chapter 3.1). Art historians Dubow and Rosengarten argue animations not only depict absences as traces, but also the very act of erasure, animation "renders the process of its own production materially evident, visible, factual [...] like a palimpsest or mystic writing pad, bears within it the time, the history-of its making.”267 Similarly, filmologist Haziza submits animation exposes the Derridean trace as an underlying structure. ${ }^{268}$ Underlining stencils as images sous rature, the music video of "Galang" visibilises both erasure and resistance by (re)inscriptions, it erases and simultaneously legibilises the erasure. The burning tree stencils concretise the state's destructive thanatopolitics, its stencil recurrence (resurrection) the stencil/spectre's resistive thanatopolitics. It hauntologises landscapes sous rature, the haunting effect occurs by constant (simultaneous) iterations. It is a landscape sous rature by dint of a medium sous rature (stencil), its iteration, and its repeated destruction and resurrection.

Like the palm tree stencils, an army of M.I.A/MIA is bombed and reincarnated. These multiple dancing and singing M.I.A/MIA echo a repetitious 'ya ya hey,' creating a caco- and polyphony of erased voices against a visual backdrop of war. Suvendrini Perera describes the moment

\footnotetext{
267 Dubow and Rosengarten, 'History as the Main Complaint', 682.

${ }^{268}$ Haziza states, "According to Derrida, the trace is that part of the sign that attests to an "other" which is forever absent [...] [and] ruptures traditional modes of representation $[\ldots]$ animation itself $[\ldots]$ exposes this trace structure” (Haziza, 'Under Erasure', 135.)
} 
as M.I.A "multiplying to fill the screen in formations that evoke guerrilla ranks as much as Disco or Bollywood.”269 More importantly, I proffer the army of dancing M.I.A amidst burning palm trees embodies a collectivity of MIA (Tamil absences and spectres) that performatively defy state violence, their visual iterations magnify the haunting.

\section{This content is unavailable. Please consult the figure list for further details.}

Figure 4.13 M.I.A, "Palm trees," spray paint on linoleum, 2004

269 Perera, 'Missing in Action', 10-11. 
This content is unavailable.

Please consult the figure list for further details.

Figure 4.14 Screenshot from "Galang." Burning palm trees

\section{This content is unavailable.} Please consult the figure list for further details. 
This content is unavailable.

Please consult the figure

list for further details.

Figure 4.16 Screenshot from "Galang." Palm trees bombed

This content is unavailable.

Please consult the figure

list for further details.

Figure 4.17 Screenshot from "Galang." Palm trees resurrected 
This content is unavailable.

Please consult the figure list for further details.

Figure 4.18 Screenshot from "Galang." Tiger traverses palm trees

\section{This content is unavailable.} Please consult the figure list for further details. 


\section{This content is unavailable. Please consult the figure list for further details.}

Figure 4.20 Screenshot from "Galang." M.I.As and M.I.A

\section{This content is unavailable. Please consult the figure list for further details.}




\section{This content is unavailable. Please consult the figure list for further details.}

Figure 4.22 Screenshot from "Galang." M.I.As, burning palm trees, tanks 2

\subsection{SUMMARY}

As discussed in Chapter 1 in broad terms and in Chapter 4.2 with reference to Arular, hegemonic readings render M.I.A's art as vacant of political specificity. In contrast, I located M.I.A's stencils within the Tamil liberation struggle and contend they, as collective autonarrations, contest the political erasure of Tamils in the act of stencilling. M.I.A's stencils resurrect cemeteries of Oliveechu, that, replicating the claims of the LTTE cemeteries, assert the right to remember, mourn, to be, and to be there. The 'source material' Oliveechu (architrave) is itself an illegalised copy (sous rature) whose spectral images of 'the MIA of the month' haunt(ed) the Tamil diasporic imaginary. The stencil mediatisation-a media sous rature par excellence-reflects (and resists) state erasures, enables haunting and camouflage. The aestheticisation of war images into 
"disposable fashion-y wallpaper and stencils," 270 the artist cogitates, is "[t]he only way to get away with this subject $[\ldots]$ I had to trick people into thinking I was as shallow as they were, using the right colours and print-making styles. ${ }^{271}$ M.I.A's minimalistic, bright, and iterative stencil stylisation ${ }^{272}$ deliberately conceals lived experiences of violence.

M.I.A's stencils not only document Oliveechu images, images of dead, cemeterially-absent subjects on criminalised tapes (doubly, triply absent), but haunt (multiply and de novo) to resist erasure. The stencils as spectral citations (Nisa, tigers, and palm trees) and M.I.A as an absenced collectivity of MIA haunt the state despite deliberate erasures (symbolised by tanks, grenades, and stealth bombers). The stencils-Nisa and the palm tree in particular-narrativise both Tamil destruction and resurrection, inscription and erasure. They are subjects and spaces sous rature. They are multiplied to be erased and re-instated again. They memorise and mourn the dead and by persevering recurrence, defy erasure.

In many ways, M.I.A's stencils contest Barthes' construal of photography as immobilising and incarcerating its subjects. Similar to the Madre de

270 M.I.A quoted in Orlov, 'Interview with M.I.A.'

${ }^{271}$ M.I.A quoted in Mugan, 'MIA'.

272 M.I.A's stencils, similar to Andy Warhol's photography-based silk-screen prints, constitute iterations of iterations. Whereas Warhol's art emphasises the similarities of the reproductions (Mattick, 'The Andy Warhol of Philosophy', 971.) and the machinisation of the artist who controls reproduction (Roof, Reproductions of Reproduction, 50-51.), M.I.A's stencil iterations archive erased war documents instead of celebrity portraits. 
Plaza de Mayo (Chapter 3.5), M.I.A mobilises photographs as documents of truth to counteract percepticide and "make[s] active spectators, or witnesses, of us all."273

273 Taylor, Disappearing Acts, xii. 



\section{Spectres of MulLivaikKal}

In the previous chapter I argued M.I.A's stencils rematerialise the cemetery of illegalised Oliveechu tapes-actual and symbolic images of MIA-which replicate the memorial and onto-territorial claims of LTTE cemeteries. This chapter, located in the central part of the study, looks back and forward, as I read M.I.A's "Born Free" as a call to not only remember and mourn, but importantly, witness the massacre against Tamils. "Born Free" is a single by M.I.A, released as part of her album Maya (stylised as $M \Lambda Y \Lambda$ ) in 2010 but recorded in 2009 when, towards the end of the Sri Lankan civil war, the Sri Lankan military slaughtered Tamils in an official No Fire Zone. The corresponding music video, directed by Romain Gavras in 2010, and its related artwork by M.I.A are the subject of my analysis. The music video depicts the abduction and execution of young, redheaded men to a desert by a US special weapons and tactics (SWAT) team. The persecuted can opt between two forms of deaths, shelling or landmine explosion. Critics either praise M.I.A's video for its critique of systematic violence 'around the world' (mentioning Sri Lanka in a long list of examples) or denounce it for its perceived trivialisation and desensitisation of violence. M.I.A's "Born Free" artwork iterates a soldier's trophy image and has not been thematised by media and academia alike. 
Marking the end of the civil war and denied by the GoSL, the Mullivaikkal massacre refers to the extrajudicial killing of Tamils by the SLA in May 2009. The GoSL opposed witnessing the event at the time and denied Tamils to remember and mourn the violence in its aftermath (Chapter 2.4). I contend that M.I.A's artwork and song remember the victims and defy the unwitnessing of the massacre by re-envisioning a soldier's trophy image of the atrocity.

\subsection{MAKING DIE AND UNWITNESSING}

Mullivaikkal is a predominantly Tamil-settled area in the north of Sri Lanka that saw heavy fighting between the SLA and the LTTE when the Sri Lankan civil war ended in May 2009. Despite the declaration of No Fire Zones (NFZs) in the area and despite the inevitable defeat of the LTTE, the SLA shelled and executed Tamils extrajudicially. Trapped in what was referred to The Cage, Tamil civilians were hunted by the SLA on the one hand and often forcibly held as human shields by the LTTE on the other. ${ }^{274}$ Cultural studies scholar Perera argues NFZs operated as 'killing zones' that retrospectively designated the dead as killable. ${ }^{275}$ Mullivaikkal is not only a space of deliberate slaughter or make die (Chapter 3.2), but also a space of unwitnessing.

\footnotetext{
274 Perera, 'Visibility', 6.

275 Perera, 17, 18.
} 
Journalists notably describe the war in general and the massacre in particular in scopic terms, in terms of unwitnessing and unseeing: a "hidden war," a "war without witnesses," a war in which "the world looked away." 276 Comprehending Mullivaikkal within discourses of visibility and technology, Perera argues it is a zone of unseeing despite securocractic monitoring technologies: a site of mass violence rendered invisible despite being "surveilled, recorded, archived." 277 As classified cables released by WikiLeaks in 2010 evince-to which M.I.A's mixtape Vicki Leekx (2010) pays homage-the international community remained cognisant of the killing and deliberately ignored the Mullivaikkal massacre.

Broadcasted by the British TV station Channel 4 in 2011, the graphic documentary Sri Lanka's Killing Fields depicts the final weeks of the war featuring videos of Tamil civilians and trophy videos of (Sinhalese) army soldiers. ${ }^{278}$ The videos document intense shellings of civilian targets

\footnotetext{
${ }^{276}$ Harrison, Still Counting the Dead. Harrison, "Journalists Failed to Tell the Story of War Crimes in Sri Lanka". Grant, Sri Lanka's Secrets, 133. Buncombe, 'Video That Reveals Truth of Sri Lankan "War Crimes". Macrae, 'Sri Lanka Massacred Tens of Thousands of Tamils While the World Looked Away'. Reporter and advocate for refugees Grant emphasises the GoSL's deliberate (and unsuccessful) attempt to hide acts of genocide, "[The GoSL] cannot hide $[\ldots]$ the emerging story of genocide $[\ldots]$ which continues to seep out from the $[\ldots]$ the dark, dark chambers of horror that are hidden away in its rehabilitation camps, military bases, civilian jails and police stations. The screams from the torture sessions $[\ldots]$ should be ringing around the world, yet $[\ldots]$ [we only hear] the occasional gentle admonishment at the UN" (Grant, Sri Lanka's Secrets, 23 emphasis mine.)

277 Perera, 'Visibility', 7, 10, 19.

278 This documentary is followed by Macrae, Sri Lanka's Killing Fields: War Crimes Unpunished. (2012) and Macrae, No Fire Zone: The Killing Fields of Sri Lanka. (2013)
} 
including hospitals, the execution of naked and blindfolded men and the heaving of denuded female dead bodies onto trucks. The trophy video was authenticated by the UN but the Sri Lankan government denies its truth value. ${ }^{279} \mathrm{UN}$ worker Weiss notes the Sri Lankan government removed aid agencies to remove international witnesses. ${ }^{280}$ The documentary depicts this moment poignantly: When the UN evacuated its staff from Kilinochchi in September 2008, Tamil civilians went to the UN office and appealed, in the words of a UN worker, "to have compassion, stay and watch." 281 A Hindu priest explicitly remarks, "We are begging you to stay and witness our suffering. If we allow you to leave the truth is that everyone here will die" (Figure 5.1). This moment

279 The Office of the High Commissioner for Human Rights Investigation on Sri Lanka (OISL)—which "investigated allegations of extrajudicial executions of identified LTTE cadres and unidentified individuals at the very end of the fighting on or around 18 May 2009 , some of whom were known to have surrendered to the Sri Lankan military"concludes, "based on witness testimony as well as photographic and video imagery, there appears to be sufficient information in several cases to indicate that they were killed after being taken into custody by the security forces. [...] many of the cases described in the report may amount to war crimes and/ or crimes against humanity" (Office of the High Commissioner for Human Rights, OHCHR Investigation on Sri Lanka, para. 1119.) However, the confirmation by a court of law is still outstanding and unlikely as "impunity is deeply entrenched throughout Sri Lankan institutions [...]. The majority of the many commissions of inquiry appear to have been designed to deflect criticism in high profile cases rather than as effective mechanisms to enable accountability" (Office of the High Commissioner for Human Rights, para. 1276.)

280 Weiss, The Cage, 155. Weiss makes this point in the documentary No Fire Zone as well.

${ }^{281}$ Kilinochchi is a town and at the time was an LTTE stronghold $60 \mathrm{~km}$ to the west of Mullivaikkal. As a UN worker recounts, “They were pleading with us, 'please don't leave.' There was one girl, she wasn't shouting and she wasn't chanting, she was just still but she had real sadness in her face. Her face just really captured this 'have compassion, stay and watch"” (Benjamin Dix, a British UN worker, in Macrae, Sri Lanka's Killing Fields.) 
emphasises the pivotal import of witnessing: Witnessing means survival (the prevention or deferral of death) and the recognition of injury (enabling the enactment of justice), unwitnessing is tantamount to death and the derealisation of violence. Unwitnessing also ensures the state's monopoly, its undisputed and absolute power, over the war narrative. Taylor, as outlined in Chapter 3.5, delineates percepticide as the systematic obstruction of witnessing violence or "seeing without witnessing.” 282 The Mullivaikkal massacre embodies a percepticide: It refers to both a denial of witnessing violence (the removal of external witnesses) and the deliberate ignorance and unseeing of violence (agnasia or 'the world looked away').

\section{This content is unavailable. Please consult the figure list for further details.}

Figure 5.1 Screenshot from Sri Lanka's Killing Fields. Witnessing

${ }^{282}$ Taylor, Disappearing Acts, 123-24. Percepticide, as outlined in Chapter 3.5, refers to an unmeant blindness (spectators who look but cannot see) and a willful blindness (spectators who choose not to look). 


\subsection{REINFLICTING OR WITNESSING VIOLENCE}

As M.I.A underscores, "[t]he No fire zone [sic] documentary has become our testimony," 283 "[i]t's not only the most important account of what happened to the Tamils, it's actually become part of the fabric of their history." ${ }^{84}$ M.I.A's artwork "Born Free" (Figure 5.4) and the music video of "Born Free" (Figure 5.7) iterate a soldier's trophy image of the documentary as 'our testimony.' Drawing on discourses on perpetrator images and the implications of their reproduction, I probe the trophy image of the Mullivaikkal massacre before examining its iteration in M.I.A's work.

One of the iconic images that came to synecdochally represent the Mullivaikkal massacre—also the film's frontispiece (Figure 5.2)—derives from an army soldier's trophy video and depicts a tied, naked, and blindfolded man at gunpoint (Figure 5.3). Perera observes the trophy video by the SLA soldiers restages the trophy photographs of Iraqi detainees by the US military of Abu Ghraib.285 Trophy photographs, communication scholar Jakob expounds, are staged to visually record dominance and enemy conquership as instances of "commemorative violence." 286 Butler similarly contends trophy photographs portend to "the bestialization" and the "derealization of the human $[\ldots]$ to make

\footnotetext{
283 Arulpragasam, 'M.I.A (@MIAuniverse) on Twitter'.

284 M.I.A quoted in BritDoc, 'Musician MIA on No Fire Zone'.

285 Perera, 'Visibility', 14.

${ }^{286}$ Jakob, 'Beyond Abu Ghraib', 88.
} 
known that a certain vanquishing had taken place."287 Similar to lynched body parts, ${ }^{288}$ the Mullivaikkal images are decorporealised souvenirs that remember and reperform the victim's subjugation. Integral to the war machinery, the perpetrators' self-portraitures with the (living) dead are literal thanatographs ${ }^{289}$ that entrench the (ethnocratic Sinhala Buddhist) state order. Sartre suggests nakedness objectifies the body (symbolising "our defenseless state as objects"), while clothes subjectivise the body as they "hide one's object-state" and "claim the right of seeing without being seen; that is, to be pure subject." 290 Philosopher Bergoffen similarly contends clothes afford protection, dignity, and even identity. ${ }^{291}$ The Mullivaikkal victim is not only stripped of his clothes, but also of his human and citizenship rights.

\footnotetext{
287 Butler, Precarious Life, 77-78.

288 Race scholar Young argues lynched body parts of African-Americans were not merely trophies and souvenirs, but dismembered fetish objects that signalled the removal of the sexual threat, remembered the dead, and reperformed the victim's own disappearance (Young, Embodying Black Experience, 179-86.)

289 Dubois, as outlined in Chapter 3.5, describes photography as a timeless death (an "achronic death") and an image of death (a "thanatography"). See Dubois, L'Acte photographique; van Gelder and Westgeest, Photography Theory, 106.

290 Sartre, Being and Nothingness, 289. The vulnerability attached to the naked body suggests power lies in the unseen.

${ }^{291}$ In the context of genocidal rape in Bosnia, Bergoffen submits, "Stripped of material and symbolic protection clothing offers, shamed in their nakedness and forced to violate cultural sexual taboos, prisoners are shorn of their cultural and linguistic identity" (Bergoffen, Contesting the Politics of Genocidal Rape, 39.)
} 
Photography scholar Struk opposes the iteration of perpetrator's trophy images, as they iterate the humiliation and degradation of the victims. ${ }^{292}$ This is exacerbated by the fact that "the act of looking [is] connected to the act of shooting," or, in other words, the immanent complicity of what memory studies critic Hirsch refers to as the embodied gaze of the photographer who is also a co-executioner. ${ }^{293}$ She submits, "[w]hen we confront perpetrator images [of executions], we cannot look independently of the look of the perpetrator [as they] are ruled by [...] a murderous National Socialist gaze." ${ }^{294}$ Unlike Struk who deems the viewer of perpetrator images as complicit in the deagentisation of the victims, Hirsch regards the viewer as retrospective witnesses and the iteration of these images as enabling (post-)memory and witnessing. ${ }^{295}$ Yet, she argues, the images must be recontextualised, as "[i]t is only when [perpetrator images] are redeployed [and translated into new graphic idioms $[\ldots]$ that they $[\ldots]$ enable a postmemorial working through $[\ldots]$ unhinge[d] from the effects of traumatic repetition."296 The translated

\footnotetext{
292 Struk poignantly appeals, "The Nazis took photographs of their victims to humiliate and degrade them. Are we not colluding with them by displaying them ourselves? [...] It seems time to call a halt to the repetitive [...] use of these photographs, out of respect for those who died" (Struk, Photographing the Holocaust, 215.)

293 Hirsch, 'Surviving Images', 26.

294 Hirsch, 26. Butler similarly stresses the Abu Ghraib photographers "were actively involved in the perspective of the war" (Butler, Frames of War, 65.)

295 Hirsch, 'Surviving Images', 22-23. This approximates international politologist Tétreault's argument that the Abu Ghraib images “document the crimes as well as the impunity with which they were committed" (Tétreault, "The Sexual Politics of Abu Ghraib', 34.) In other words, the perpetrator's trophy image also testifies to the wounds inflicted upon the victim.

296 Hirsch, 'Surviving Images', 29-31.
} 
iteration of the image also enables the visibilisation and agentisation of the dead. In forensic pathology, media studies scholar Pugliese states, the visibilisation of the victim's body is "tantamount to enabling the corpse to speak, to giving the dead a voice." 297

M.I.A's "Born Free" music video and artwork (Figure 5.4) are such iterative redeployment of the Mullivaikkal trophy image to defy the unwitnessing of the Mullivaikkal massacre. Both resituate the Mullivaikkal massacre and transform viewers into witnesses to recognise injury and counter silencing.

\section{This content is unavailable. Please consult the figure list for further details.}

Figure 5.2 Title image of Sri Lanka's Killing Fields

297 Pugliese, “"Super Visum Corporis”, 367. 


\section{This content is unavailable. Please consult the figure list for further details.}

Figure 5.3 Trophy image of the Mullivaikkal massacre

\section{3 “BORN FREE" ARTWORK}

Containing superimpositions, frames within frames, and image repetitions, M.I.A's "Born Free" artwork iterates the Mullivaikkal trophy image (Figure 5.4). It also cites images of the "Born Free" music video (Chapter 5.4): the bottom left depicts the SWAT team and the central right side depicts a (probably redhead) guerrilla fighter carrying an AK47. The backdrop on the left side is another artwork of M.I.A entitled "Burqa print" (Figure 5.5) which repeatedly features a woman in a burqa with a woman's face print, her fingers contouring the black outline of the word 'MIA.' At first glance, the woman of the "Burqa print" appears to speak, yet it is merely a mask. Suggesting the burqa signifies repression and silence, the image is admittedly problematic. Yet, I believe the burqa 
functions as a trope to refer to repressive states and expose the sham of free speech. It suggests that free speech is merely a façade. The artwork's juxtaposition of the Mullivaikkal victim with a woman in a burqa frames both subjects as censored: the man who cannot see, the woman who cannot speak; the 'verbal muteness' of the (immanent) dead trophy victim, the veiled muteness of the living to speak thereof (and to thereby remember, mourn, and witness). The artwork not only depicts both violence and its silencing, but also evokes Abu Ghraib and situates the Mullivaikkal massacre within the geopolitical context of the 'war on terror.' It challenges 'the war on terror' discourses that respectively criminalise Muslims and Tamils, that legitimise imperial conquest in order to 'save' Afghani or Iraqi women, that legitimise the killing of Tamils (and depoliticise the Tamil liberation struggle) to 'protect' the sovereignity of Sri Lanka. ${ }^{298}$ M.I.A's artwork not only iterates the trophy image, it also repeats it seven times, ${ }^{299}$ underlining its hauntedness. As a mnemonic

\footnotetext{
298 'The war on terror' discourses, Butler propounds, legitimise state violence, "The use of the term, 'terrorism,' thus works to delegitimate certain forms of violence committed by non-state-centered political entities at the same time that it sanctions a violent response by established states. [...] If this violence is terrorism rather than violence, it is conceived as an action with no political goal" (Butler, Precarious Life, 88-89.) Applying the term terrorism thus depoliticises (the use of violence by) non-state actors and dehistoricises the conflict. Perera makes a similar argument, "the perpetrators-the Israeli or Lankan states-represented themselves as extended fronts of the war on terror whose actions were vindicated by the ruthlessness of the terrorists they were facing" (Perera, 'Visibility', 4.)

299 According to Tamil Hindu Saivist belief, reincarnation occurs seven times, and a Tamil adage reads as 'in (my) seven lives' (ஏழேழு ஜென்மன்). The notion of Hindu reincarnation can be viewed as a form of hauntology, a concept M.I.A's album Matangi (2013) takes up.
} 
geography, the exposed bare skin of the Mullivaikkal victim in Figure 5.3 challenges 'verbal muteness,' poses truth claims, and (self-)witnesses the unwitnessed event. The iteration of the Mullivaikkal trophy image in M.I.A's artwork enables victims to haunt and viewers to remember, mourn, and witness.

\section{This content is unavailable. Please consult the figure list for further details.}

Figure 5.4 M.I.A, “Born Free” single artwork, 2010 


\section{This content is unavailable. Please consult the figure list for further details.}

Figure 5.5 M.I.A, "Burqa print," digital print on cotton, 2010

\section{4 "BORN FREE" MUSIC VIDEO}

Accompanied by an aggressive industrial punk soundscape, the video depicts a SWAT team singling out young, redheaded men who are dragged into a bus and driven to a remote field. On their way, the video intercuts to a mural and a keffiyeh-wearing petrol bomb throwers. 300 Upon arriving at their 'final' destination, two forms of death-land mine explosions or hunting SWAT teams-are inflicted upon them. The camera repeatedly focusses on two faces, a teenager in a tracksuit who stares at

\footnotetext{
300 Historically the Molotov cocktail (petrol bomb) is, as Hutnyk states, the "preferred weapon" of street confrontations and "a potent symbol of rebellious youth" (Hutnyk, Pantomime Terror, 80.) The keffiyeh, a symbol of Palestinian nationalism, is evoked to express solidarity.
} 
the perpetrator (Figure 5.8) and the youngest boy whose demise is graphically staged (Figure 5.9).

The industrial punk soundscape of "Born Free" is not coincidental. The song samples "Ghost Rider" by the American punk rock band Suicide. Reed understands industrial punk dimisses linear arrangements and logocentric norms,

The music was intended to be primal, visceral, and provocative. Noise $[\ldots]$ was the most effective tool [...] [and] a language of subversion. Noise defied order and control. It was a musical taboo. Sonic belligerence. It could destabilize. [...] [Industrial music shares] the belief that challenging and provoking an audience can be a productive goal rather than a failure of communication. 301

The noise in "Born Free," the song's deliberate disharmony, discord, and cacophony seeks to provoke the viewer. It is enhanced by the visual hyperviolence that destabilises distantiated viewing practices. The song also includes sounds of waterfalls, cracking ice, and the heartbeat of M.I.A's child who at the time was pregnant. ${ }^{302}$ The song hence inscribes the sound of life (M.I.A's child born during the war) into the 'deathly' soundscape.

Similar to the artwork, I contend the music video translates the Mullivaikkal massacre to oppose its unwitnessing and agentises its victims. For that I reflect upon the significations of depicting a 'ginger genocide,' illuminate two notable moments of visual resistance-a mural with the

\footnotetext{
${ }^{301}$ Reed, Assimilate, xi, 49.

302 Christopher 'Rusko' Mercer quoted in Hova, 'M.I.A.'
} 
caption "Our day will come" (Figure 5.6) and a teenager's oppositional gaze (Figure 5.8)—as well as the song's title.

Much of the media response circuits the video's dramatisation of hyperbolic and autotelic violence (violence for the sake of violence), denouncing M.I.A for sensationalism and violating social taboos. Some music critics remain ambivalent. Haddow for instance argues it 'parodies a genocide' for promotion, yet unlike Afghan and Iraq war films that are "too concerned with telling our side of the story," induces empathy for the victim rather than the aggressor. ${ }^{303}$ Henderson similarly dismisses the music video for aestheticising and anaesthetising violence, obfuscating "real political genocides," and "focus[sing] too much attention on the U.S. powers," but praises the anger and dignity of the prisoner who "dares to glare into the eyes of his attackers." 304 Another section of reviewers commends the video's depiction of violence-which, they argue, questions "the rounding-up of ethnic minorities, the trampling of personal liberties, the bullying of the powerless,"305 and "our desensitised attitude to violence"306 — and construes the "gingers [as] kind of anyone who's been oppressed," "a persecuted ethnic minority," a "target of a genocidal campaign," "the powerless." 307 Yet, some expressed the

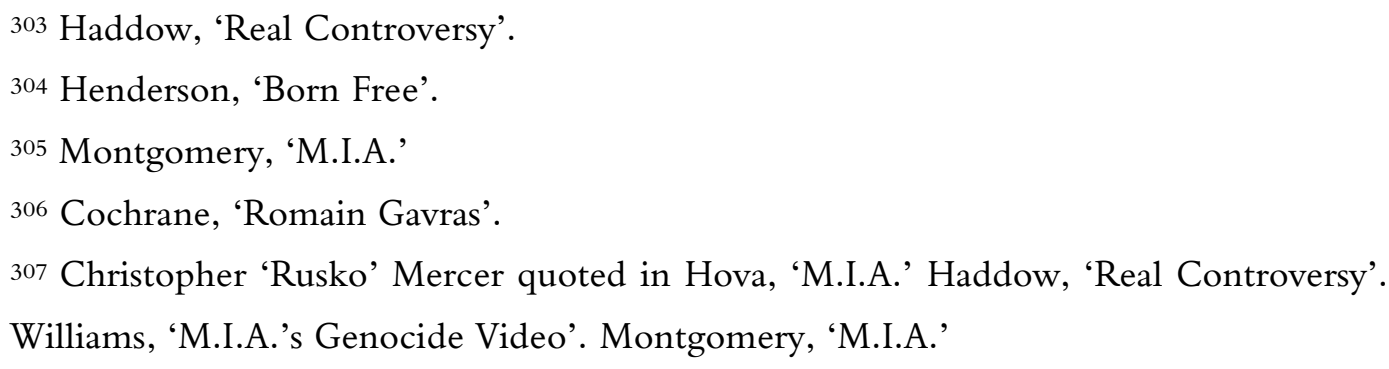


fallacies of this representational equation, calling it 'goofy'308 or 'comical,' as the "idea that redheads could stand in for 'anyone who's been oppressed' [...] is so far-fetched." 309 It, as Fogg highlights, equates individual bigotry and (anti-Celtic, specifically anti-Irish) prejudice with systematic oppressions such as racism, sexism, and homophobia. ${ }^{310}$ Even though I concur with Fogg's appraisal, I consider the 'ginger genocide' a meaningful allegory on the following grounds: It problematises the constructedness of race and recalls the historic negrification of the Irish. ${ }^{311}$ Redheads can fluctuate between deracialised (normative) whiteness and blackness ('the blacks amongst the whites' according to an internal white hierarchy). M.I.A's 'ginger genocide' and the absence of brown subjects is deliberate. Depicting the persecution of whites by whites reflects Sri

308 Zach, 'M.I.A.'s "Born Free Video"'.

309 Harris, 'Don't Call Me Ginger'.

310 Fogg, 'Gingerism'.

${ }^{311}$ Historian Roediger argues Irish immigrants were compared to and shared similarities with free African-Americans in antebellum northern cities, discriminated against by White (Anglo-Saxon) Protestants, "[African-Americans and the Irish] often lived side by side in the teeming slums of American cities of the 1830s. They both did Americas hard work, especially in domestic service and the transportation industry. Both groups were poor and often vilified. Both had experienced oppression and been wrenched from a homeland" (Roediger, Whiteness, 134.) Rendered as both white and black, Gerstle expounds the simianisation (monkeyfication), infantilisation, and dehumanisation of the Irish, "The Irish feared that they might be seen as black. This was no fantasy. The nativist press of the era frequently depicted the Irish as monkeys, an image also used to infantilize and dehumanize African Americans" (Gerstle, 'Liberty', 550.) In like manner, Curtis points to the simianisation of the Irish Celt in the caricatures of Victorian Britain (Curtis, Apes and Angels, 29-57.) McVeigh explicitly states "in these cartoons anti-Irishness becomes a racism" (McVeigh, 'Nick, Nack, Paddywhack', 140.) Sivanandan, a Tamil novelist and political scientist specialising on race, understands black "as a political colour” and includes the Irish as politically black (Sivanandan, 'Challenging Racism', 4.) 
Lanka's internal colonisation and the 'killing of one's own people.' The racial indeterminacy of redheads enables both white identificationcountering detachment for a white audience-and racial ambiguity. ${ }^{312}$ The international community exterritorialised, unsaw, and unwitnessed the violence of Mullivaikkal, as it concerned the (brown) other. By using red-heads, M.I.A internalises systematic state violence, transforming it into 'a white issue,' and implicating the viewers as complicit or witnessing subjects. It is, to recall Hirsch, a (post)memorial translation of the Mullivaikkal massacre. The transformation of Tamils into redheads in "Born Free" is not the only translational difference. M.I.A agentises the victims by means of the mural and the oppositional gaze of the persecuted.

The mural, cut in during the deportation of the victims to their execution site, depicts three red-headed guerrilla fighters raising assault rifles in the air, indicating armed resistance (Figure 5.6). Evoking murals in Belfast or Derry, the mural's caption replicates the IRA slogan 'Tiocfaidh ár lá' in English, 'Our Day Will Come.'313 Emphasising their memorial functions,

\footnotetext{
312 This of course is also problematic, as it reinforces the idea only white people are people (humans), and only the translation of the killing of brown people into the killing of white can effect justice (for brown people).

313 Although the mural explicitly refers to the Irish republican movement, "Born Free" also evokes and solidarises with the Palestinian movement, by means of the keffiyehwearing petrol bomb thrower (an animated stencil thrower juxtaposed to Nisa also appears in the music video of "Galang" (Chapter 4.4), yet instead of a Molotov cocktail, he 'throws' colours, symbolising resistance indwells in art). Notably, Irish murals themselves cite and solidarise with the Palestinian liberation struggle which finds
} 
Rodrigo surmises murals in Northern Ireland embody collective memories and constitute "the graphic voice of the region's turbulent history." 314 Subject to erasure, like stencils (Chapter 4), their political effectivity lies in claiming, contesting, and transforming public space, to testify to resistance. In this regard, murals are materialised sites of memory (similar to Auchter's notion of memorials in Chapter 3) that raise territorial claims and haunt the state. In a way, murals replicate the workings of LTTE cemeteries: They firstly remember and mourn, and they secondly assert the onto-territorial right to be and to be there. The mural in the music video not only reverberates the assertions of LTTE cemeteries, but also the horticultural symbolism of LTTE death. As argued before (in Chapter 2.3), the notion of elicci (arisal), symbolised by the vegetative imagery, indicates the overthrow of suppression: Resistance grows out of death, the poor will rise, and 'our day will come.' The mural threatens with resistance, it announces a haunting a priori even if the resisters are killed. This resistive mural is displayed prior to the slaughter scene. As such, the mural expresses the anticipation of (future) haunting. The victims' agency not only resides in the mural, but also in the returning gaze.

expression in mural proclamations such as 'One struggle: Palestine/Ireland,' 'Free Gaza/Derry' (See Chriost, Jailtacht, 143.) "Born Free" aligns the sectarian conflicts of the Irish, Palestinians and Tamils. Palestine, Sri Lanka, and Northern Ireland can be seen to share internal colonialism and (biopolitical/thanatopolitical) state violence. White for instance remarks Irish nationalism emerged first as an anticolonial movement (White, 'Nationalism', 26.) The work of Irish historians and cultural critics, Smyth states, (similar to or as postcolonial critics) seeks to "recover subjects from the past who did not find representation in the dominant narratives of nationalism and decolonisation" (Smyth, 'Irish Studies', 213.)

314 Aliaga Rodrigo, 'Painting History', 111. 


\section{This content is unavailable. Please consult the figure list for further details.}

Figure 5.6 Screenshot from "Born Free." Mural

Shot from the military view, the music video's execution scene (Figure 5.7) is the only image that directly quotes the Mullivaikkal trophy image (Figure 5.3). Fully exposed and kneeling with their hands behind their heads, the victims can neither see nor resist the perpetrators. A distinct difference between the Mullivaikkal image and the music video is the victim's scopic power. Unlike the Mullivaikkal victim, the redheads are not only free of blindfolds, they are clothed and counter the militarising gaze. In fact, looking is crucial in "Born Free." When forced to leave the bus at the destination site and run to the final site of execution, a tall teenager, who is focused throughout the video, twice stares at and looks down on the perpetrator (Figure 5.8). Black studies critic hooks states the repression of 
our/black people's right to gaze had produced in us an overwhelming longing to look, a rebellious desire, an oppositional gaze. By courage ously looking, we defiantly declared: 'Not only will I stare. I want my look to change reality.'315 M.I.A also changes reality, the blindfolded Mullivaikkal victim is translated into a redhead who opposes with an oppositional gaze, a resistive act, a willful transruption of the asymmetric scopic regime and the state's destructive politics of death.

\section{This content is unavailable. Please consult the figure list for further details.}

Figure 5.7 Screenshot from "Born Free.” Execution

315 hooks, 'The Oppositional Gaze', 208. A similar scopic notion is proposed by Hirsch who distinguishes between a resistive, agentic look and a deagentising gaze, "While the look is returned, the gaze turns the subject into a spectacle. [...] The gaze is mediated by the screen, contested and interrupted by the look" (Hirsch, 'Surviving Images', 2324.) Following Hirsch's terms, the look of the teenager contests and interrupts the gaze of the SWAT team member. 


\section{This content is unavailable. Please consult the figure list for further details.}

Figure 5.8 Screenshot from "Born Free.” Oppositional gaze

As discussed earlier, trophy images express the 'derealization of the human' and conquership over the victim. Scenes of "Born Free" replicate the 'bestialization' of the victims who are hunted down like animals, either exterminated by a SWAT weapon or killed in a minefield explosion (which symbolises the two forms of death-the SLA and the LTTETamils in Mullivaikkal faced). The scene of the young boy's execution from a close distance with a pistol (Figure 5.9) was much remarked upon as the killing of the "cherubic red-haired kid," 316 the "youngest and girliest of the lot." 317 The boy's facial reaction is of utmost (almost Edvard Munchian) anxiety. The boy's killing symbolises the killing of the innocent and perhaps refers to the killing of LTTE head Prabhakaran's son

\footnotetext{
316 Goodman, 'M.I.A.', 11 August 2016.

317 Cole, 'Track Review'.
} 
Balachandran. 318 The scene's slow-motion intensifies the moment of death and compels the viewer to witness this act of brutality. Another memorable scene of atrocity is the graphic depiction of exploding bodies that fills the screen with 'raining' severed body parts (Figure 5.10). Enhanced by the aggressive soundscape, the scene evokes war films and video games. Marking the ultimate moment of erasure, the corporeal dismememberment ensues within a single shot and encapsulates the disintegration of the body. It pictures state brutality that screens death as a spectacle. The emphasis is not on the act of killing or death itself, but the scarce remaining fragments. The victim is reduced to a combustible and pulverised body, indistinguishable from its surrounding desert landscape. The fragmentation destroys the sanctity, sovereignity, and the dignity of the body. It leaves not even 'intact' dead body behind to bury and mourn. ${ }^{319}$ Like Mullivaikkal, the sand of the landscape is saturated with blood (Figure 5.11).

M.I.A's depiction of the ultimate disintegration of the body (in both the artwork and the music video) is underpinned by her vocal and textual

318 On the image of Balachandran's dead body international relations scholar Kumarakulasingam states, "While it is unclear as to whether the images originated as trophy-photos or as indictments, they circulate globally as 'shock-pictures.' The text accompanying the image of the boy in the bunker is unequivocal about the meaning of the boy's death: He was not killed in battle, or in crossfire, it says. Instead, he was murdered in a deliberate manner. Ergo, it is an atrocity" (Kumarakulasingam, 'Bloody Translations', 61-62.)

319 The emphasis on human body parts again evokes lynching. As Harvey argues, parts of the lynched black body figured as souvenir, fetish, and 'a remain of the performance spectacle.' (Young, 'Black Body', 641.) 
insistence she "was born free." 320 Her repetitive proclamation refers to Article 1 of the Universal Declaration of Human Rights which states, "All human beings are born free and equal in dignity and rights." 321 Emphasising life and liberty, it asserts the right to live and the right to (corporeal) inviolability. Both the visual representation and lyrics seek to confront the audience ("I throw this shit in your face") and insists on the victims' voices and testimony ("I've got something to say").

\section{This content is unavailable. Please consult the figure list for further details.}

Figure 5.9 Screenshot from "Born Free." Execution of boy

\footnotetext{
320 The caption "Born Free" in the artwork is capitalised and printed in the font based on cursive handwriting with a brush (Brush Script M7) which emphasises humanity and the resistive power of art.

321 United Nations, Universal Declaration of Human Rights, 3.
} 


\section{This content is unavailable. Please consult the figure list for further details.}

Figure 5.10 Screenshot from "Born Free." Dismemberment

\section{This content is unavailable. Please consult the figure list for further details.}

Figure 5.11 Satellite image of The Cage

https://groundviews.org/wp-content/uploads/2012/09/Example-1-May-09.jpg

\subsection{SUMMARY}

The Mullivaikkal massacre is an unwitnessed injustice. M.I.A's "Born Free" artwork and music video resurrects the cemetery of Mullivaikkal and opposes the unwitnessing of violence against Tamils that render them 
killable and absent. Both the artwork and the music video iterate and translate the Mullivaikkal massacre to enable witnessing. In the photomontage artwork, M.I.A cites an image of the trophy video. By iterating the soldier's trophy image, it opposes the unwitnessing of the massacre. The artwork focusses on the invisibilisation of censorship. It juxtaposes the censorship of the dead and the living dead. The image of the burqa woman critiques the verbal muteness not only of the massacred body, but also of the living who are not allowed to talk, witness, remember, and mourn. The music video of "Born Free" counters the workings of trophy videos-the dehumanisation, deagentisation, and denudation-by enabling witnessing. The mural, the victim's oppositional gaze, and the insistence on being 'born free' subjectivise the victims. The mural replicates the workings of LTTE cemeteries, asserting to right to remember, mourn, to be and be there. M.I.A's translation of Mullivaikkal's mass violence into a different time-space transforms redheads into an ethno-racial, on biopolitical grounds killable population. Transposing the Mullivaikkal massacre into a grammar of white selfhood and familiarity not only internalises violence and enables witnessing, but also emphasise the killing of one's own people. In the Mullivaikkal trophy photograph, the blindfolded naked victim is utterly exposed and denied scopic power to return the (military) scopophilic gaze. Yet, a red-haired teenager resists with an oppositional gaze in the music video.

Both intervene in unseeing the massacre. Both demand the recognition of war crimes and justice for its victims. Both implicate the viewer as 
perpetrators and witnesses of violence. Both envision sites of hauntive resistance. The haunting quality resides in the iterations of the mass violence, both in the form of trophy images and the translation into a 'ginger genocide.' 


\section{SPectres of THE SeA}

The prior chapter illustrated the rehistoricisation of the Mullivaikkal massacre in M.I.A's "Born Free" to condemn the GoSL for making Tamils die, and the international community for letting Tamils die. M.I.A's single "Borders," I argue in this chapter, explicitly nullifies this porous border between making die and letting die (Chapter 3.2). The digital single release date, 27 November 2015, coincides with Maveerar Naal, the day of commemoration for LTTE fighters who died in the Sri Lankan civil war (Chapter 2.2). The corresponding music video, also released in November 2015 yet exclusively on Apple Music, was directed by M.I.A. The music video commences with a light blue screen intersected by a black line. The top of the black line reads 'BORDERS,' the bottom "Directed by MIA" (Figure 6.11). The camera pans down to a mid-shot of M.I.A's face (Figure 6.1), who, standing between two lines of running men in the background, utters the opening lyrics,

Freedom, 'I'dom, 'Me'dom

Where's your 'We'dom?

This world needs a brand new 'Re'dom

Repeating the line 'What's up with that?,' she gazes into the camera while a multitude of brown men lay on boats drifting on sea (Figure 6.7), climb over fences (Figure 6.12), and portray a ship (Figure 6.9 and Figure 6.10) and the word 'LIFE' with their bodies (Figure 6.13). 
While a minority of critics commend "Borders" for chastising governmental failure, ${ }^{322}$ the majority expresses unease or ambivalence with the music video for multiple reasons: the 'refugee commodification' for western audiences, the visual effacement of refugee women, a perceived inauthenticity (the mis/representation of the subaltern by a privileged star), and the song's exclusive release on Apple Music (the hypocrisy of operating within capitalist structures yet declaring a systematic overthrow). 323

Drawing on theorisations of the sea, the border, and the refugeeincluding cogitations on refugee iconologies, the slave ship, the Black Atlantic, and tidalectics-I contend the visual landscape of "Borders" exhumes a cemetery of refugees who died at sea. My contention is based on overlooked but eminent mise-en-scène-the overhead images of refugee boats (Figure 6.7), the human boat formation (Figure 6.10), and the 'LIFE' representation (Figure 6.13)—salient images that encapsulate death and life respectively. They evoke the sea as a space of obscured thanatopolitics and a border between life and death. They pose a cemeterial memory space of refugee spectres opposing with tidalectic haunting. Their overhead (imagery) is informed by a photograph underlying a white saviour complex, which itself retains an affinity with the slave ship. In "Borders," refugees as haunting subjects question the state's ontology and biopolitics.

\footnotetext{
322 Gibsone, 'MIA's Borders'.

323 McKinney, 'The Great Irony'.
} 


\section{This content is unavailable. Please consult the figure list for further details.}

Figure 6.1 Screenshot from "Borders.” M.I.A opening scene

\subsection{LetTing Refugees Die}

The refugee, "the ultimate bogeyman," 324 is subjected to a multitude of discursive-material practices: racialised (a racio-cultural incompatibility), pathologised (a sickness afflicting the purity and homogeneity of the nation-state), economised (either 'needed labour force' or 'job-stealers'), criminalised ('illegal,' 'welfare beneficiaries,' 'thiefs,' and 'rapists'), and passivated (vulnerable vicitims). ${ }^{325}$ As a strategy of exculpation, they are

\footnotetext{
324 Kornhaber, 'The Rapper of Refugees'.

325 The emphasis on the cultural and religious incompatability of 'refugees' with 'Europe' in media discourses seeks the externalisation of refugees. Cresswell observes news and media specifically deploy metaphors of flooding and swamping to describe the effects of immigration (Cresswell, 'Towards a Politics of Mobility', 19.) These renderings underlie an ethnic conception of citizenship which obscure (ethno)nationalism, systematic inequality, and racism. They frame refugee migration as an illegal act and assault on the body of the individual and the collective self. The illegalisation of the refugee is underpinned by gendered and racialised discourses. As Allsop points out, "[b]y virtue of their gender (and often religion), many male refugees have been cast as potential rapists
} 
exposable to death, externalised from ontology (de-ontologised), the state (denationalised), and the protections of citizenship (de-citizenised) and deprived of humanity, grievability, and mournability, or, to employ Butler's phrasing, placed outside the frame (Chapter 3.3). In Chapter 3.3, I elucidated Athanasiou and Butler's notion of dispossession as non-being and non-having which defines the dispossessed as quasi spectral. Butler defines dispossession as a political condition of impasse or aporia, in which "two modalities of colonial power (restricting a population to a land of which they have been dispossessed and refusing the entry into the European metropole) work together to produce the situation in which the targeted population belongs, finally, to no land." 326 The refugee condition not only epitomises non-being and non-having, but also dispossession as double expulsion. Postcolonial theorist Young refers to (and hence implicitly spectralises) refugees as the 'invisible visible' (diaspora) who are refused to be seen by 'those in power.'327 As such, Young connects the erasure of refugees with unseeing (a refusal to see), which, he contends, can be countered by visibilising invisibility. Sociologists and human geographers Davies et al. make a similar point,

and terrorists" (Allsop, 'Agent, Victim, Soldier, Son', 157.) On the other hand, as Athanasiou remarks, humanitarian discourses of (refugee) victimhood, including those against victimhood, erase the victims, conceal structural injustices and delegitimise demands for accountability and compensation (Athanasiou in Butler and Athanasiou, Dispossession, 112-14.)

326 Butler in Butler and Athanasiou, Dispossession, 23-24.

327 Young, 'Postcolonial Remains', 23, 26. 
calling attention to the unseeing, or to use their term, deliberate ignoring, of refugees in refugee camps, such as the one in Calais,

The continual disavowal of basic services [to refugees by French authorities] relied heavily on an agonotological [sic] approach-that of a willing ignorance to conditions in the camp, and "turning a blind eye". [...] the state's biopolitical activities have given way to calculated necropolitical inactions. 328

Associated with refugee sea deaths and a dominant refugee image in the West, this necropolitical inaction is most palpable in the image of the overcrowded and capsized refugee boat. Migration studies scholar Falk suggests dominant refugee iconographies either portray masses of people (evoking a refugee invasion) or an individual subject (victimising the refugee). 329 Similarly, anthropologist Malkki contends photographs arborise into a (depersonalising and anonymising) image of a miserable 'sea of humanity' and a (sentimentalising and muting) image of helpless 'women and children.'330 "Borders," as I will illustrate, both invokes and transrupts the former category of depicting (depersonalising and anonymising) overcrowded refugee boats. As M.I.A herself points out, the music video replicates a Time magazine cover image,

a photo of maybe 500 or 1,000 people in one boat, and it was an overhead shot of this boat in blue water. [...] [The 'refugee crisis' in media coverage depicts] this swarm of men in boats coming to wipe the west out. [...] Except it's not

\footnotetext{
328 Davies, Isakjee, and Dhesi, 'Violent Inaction', 1276, 1280. The authors adapt from Proctor and Schiebinger's work on agnotology, the making and unmaking of ignorance (Proctor and Schiebinger, Agnotology.)

329 Falk, 'Invasion, Infection, Invisibility', 96.

330 Malkki, 'Speechless Emissaries', 238-39.
} 
that. [...] I didn't want to go to the easiest source of empathy, which is to show a child dying on the shore. 331

Shot by the Italian photographer Sestini from an Italian navy helicopter in 2014, the image M.I.A refers to depicts an inflatable boat with 500 refugees off the coast of Libya, heading towards the Italian island of Lampedusa (Figure 6.2). It was selected in Time's Top 10 Photos of 2014 and "captured people's imagination." 332 Historians Kouremenos and Dierksmeier particularly note its aesthetic value, "[i]n the middle of the sea, the boat itself looks like an island, while the colourful clothing of the people in it gives it the appearance of a mosaic, an artwork in the middle of the blue Mediterranean." 333 Here is also where the image's problem lies: this particular aestheticisation mutes refugees into colourful blobs of an artwork. As legal theorist Manderson asserts, the Sestini photograph represents "the abject bodies of mainly unidentifiable refugees $[\ldots]$ as passive objects at the mercy of the natural world." 334 The black asylum seekers are not merely 'at the mercy of the natural world,' but specifically at the mercy of white saviours. The Sestini image underlies a white saviour complex, in which asylum seekers beseech compassion

\footnotetext{
${ }^{331}$ M.I.A quoted in Feeney, 'Borders'. M.I.A refers to the death of Alan Kurdi (Alan Shenu), a Syrian child who drowned in the Mediterranean Sea in 2015 when, with this parents, he tried to reach Europe in an inflatable boat. At the time a photograph of his dead body circulated widely in media reports and was taken up by activists and artists alike-such as Chinese artist Ai Weiwei and Indian artist Sudarsan Pattnaik-to protest the collective governmental and supra-national failure to protect refugee lives.

332 De Stefani, 'A Photographer's Search'.

333 Kouremenos and Dierksmeier, 'Teaching Insularity', 284.

334 Manderson, Danse Macabre, 118.
} 
and plead for generosity at the almighty (European) viewer. It enables what Tascon defines as the humanitarian gaze, a surveilling, panoptical gaze, informed by and reproducing the inequality of global-local power relations of looking. 335 The photographs' camera angle reflects and visualises the uncanny (scopic) power asymmetry in which black men look up to the proverbial 'rain and sunshine from above.' Similar to the news media discourses earlier, the overhead shot positions the (white) viewer as deific saviours and renders the black men surveilled and scrutinised as miniscule microscopic objects.

\section{This content is unavailable. Please consult the figure list for further details.}

Figure 6.2 Time Magazine cover, photograph by Sestini, 2014

Zenithal photograph from an Italian Navy helicopter published in Time, 28 July 2014.

335 Tascon, 'The Humanitarian Gaze', 75-76. 
A segment of Black-Italian artist Marboah's objet d'art "Echoes and Agreements" juxtaposes the Sestini photograph with the plan of the slave ship Brookes (Figure 6.3). Human rights and literary scholars Moore and Pinto note it "links not just the history of enslavement and the contemporary status of refugees in Fortress Europe, but [...] [also ties] statelessness and rightlessness [...] [focussing] on the life- and deathworlds of the ship and of the journey that often refuses to resolve into the teleology of national belonging." 336 The authors construe Marboah's pairing of the slave ship with the refugee ship as a critique and defiance of citizenship, state, and the national logic.

336 Moore and Pinto, ‘Beyond Sovereignty', 2-3. 


\section{This content is unavailable. Please consult the figure list for further details.}

Figure 6.3 Marboah, segment of "Echoes and Agreements," 201833

M.I.A's retranslation of the Sestini image in "Borders," like Marboah's art, cites the slave ship. The slave ship, historian Rediker argues, "was a strange and potent combination of war machine, mobile prison, and factory." 338 The plan of the slave ship Brookes emerged from measurements taken by the British Parliament, and included 470 men, women, and children packed together between the vessel's decks (Figure

337 "Plan of the Slave Ship Brookes," from Thomas Clarkson's The History of the Rise, Progress and Accomplishment of the Abolition of the African Slave-Trade, by the British Parliament (1808). Massimo Sestini, photograph of the migrant boat crossing (2014). Image taken from Moore and Pinto's article (Moore and Pinto, 3.) 338 Rediker, The Slave Ship, 9. 
6.4). 339 It certainly is striking that the number of asylum seekers in Sestini's boat image (and the number of Tamils in the ship MV Sun Sea as described later) corresponds to the numbers of slaves in the Brookes. The Brookes print, diaspora studies critic Wood notes, was "the most famous, widely-reproduced, and widely-adapted image representing slave conditions on the middle passage ever made," 340 to the extent, as historians Radburn and Eltis state, it " $\mathrm{c}[\mathrm{a}] \mathrm{me}$ to embody the African experience of the Middle Passage."341 Slave historian Hudson notes

the [Brookes] illustration is empty of everything apart from the bodies, prone and unresisting (Wood 2000:23) and the physical, material shell of the ship. This shell contains the boundaries and borders of the 'wooden life-world' of the slave-literally the wooden walls of the dark holds. ${ }^{342}$

The print only depicts the frame of the ship, and as the ship, its bodies are stripped, exposed, almost naked. The slave ship diagram deagentises its 'human cargo' and embodies confinement and incarceration. At the time, "many, on looking at the plate, considered the regulation itself as perfect barbarism." 343 Regarding this visual sanitisation, slavery scholar Trodd pronounces, "the diagram reinforced notions of black passivity $[\ldots]$; sterilised the journey $[\ldots]$ and denied individuation." 344 Yet, as

\footnotetext{
339 Radburn and Eltis, 'Visualizing the Middle Passage', 533.

340 Wood, 'Imaging the Unspeakable', 212.

${ }^{341}$ Radburn and Eltis, 'Visualizing the Middle Passage', 533.

342 Hudson, The Slave Ship, 91.

343 Clarkson, African Slave-Trade, 45.

344 Trodd, 'Am I Still Not a Man and a Brother?', 346. Interestingly, crowding in the slave image portends to inhuman conditions, while crowding in refugee discourses, as noted earlier, evokes swamping.
} 
Radburn and Eltis point out, "[t]he position of the African figures"supine" $[\ldots]$-implies a passivity that scholars have demonstrated to be patently false." 345 The print, they imply, obscures black African agency. Nevertheless, Trodd recognises slave ships are appropriated as antislavery tropes in Black visual culture. ${ }^{346}$ Connecting histories of violence and activating haunting maritime memories, M.I.A's "Borders" is informed by both (anti-)slavery and refugee images.

Both the slave ship and the sea have a relationship to memory. Black literary works expatiate upon the interlinkage of sea, slavery, and memory. British-Guyanese poet and novelist D'Aguiar writes, “The sea is slavery. [...] [bodies] are flung at this sea. Each [body] lands with a sound that the sea absorbs and silences." 347 Nigerian poet Osundare similarly evokes the notion of the sea as a cemetery of forgotten black bodies, stories, memories, and wounds. ${ }^{348}$ Art historian Finley deems the slave ship a central mnemonic space in the black psyche. ${ }^{349}$ The slave ship is both memory and a (haunting) cemetery. Slaves and slave ships are explicitly

\footnotetext{
345 Radburn and Eltis, 'Visualizing the Middle Passage', 535.

346 Trodd, 'Am I Still Not a Man and a Brother?', 346.

347 D'Aguiar, Feeding the Ghosts, 1.

348 "The Sea carries a story / Deeper than its glassy grin [...] / The Sea buries a million dreams / In its abysmal silence [...] / The Sea is Memory / The Sea is Oblivion / The Sea is salt / In a bleeding scar" (Osundare, 'The Atlantic Is a Bowl of Water', xiv.) Another famous example are the following lines from Saint Lucian poet Walcott, "Where are your monuments, your battles, martyrs? / Where is your tribal memory? Sirs, / in that grey vault. The sea. The sea / has locked them up. The sea is History." (Walcott, 'The Sea Is
} History', 237.) 349 Finley, Committed to Memory, 138. 
linked with haunting. Baucom refers to slaves as 'the specters of the Atlantic'350 and Rediker denotes the slave ship as 'a ghost ship.'351 Gilroy contends the ship articulates the "interfaces [of England's ports] with the wider world," "the middle passage," "the slave trade," and the place "where modernity might itself be thought to begin." 352 Black spectrality is constitutive of Western modernity and ontology. Black studies scholar Young constructs black (slave) bodies as 'haunted and haunting' by modernity, and locates the ghostliness of black bodies in their commoditisation,

Ghastly apparitions of violence testify to the largely untold history [..]. Theorizing the ghost uncouples the link between enslavement and an essential blackness $[\ldots]$ The haunted nature of the slave as commodity $[\ldots]$ enables us to speak about the effective imprints of violence, injury, and grief. 353

Questioning the terracentricity in narrating histories, Chambers suggests to view the sea as an ontological challenge to histories that "apparently require terrestrial ground in order to be narrated." 354 In other words, the sea enables narrating spectral histories. Haunting (as illuminated in Chapter 3.4) asserts claims of past injury in the present. As Young insinuates, it is critical to think of the slave as a spectre and the sea as a cemetery to foreground (past) violence. Unlike Tamil cemeteries that assert onto-territorial claims, slave ships embody deracination and

\footnotetext{
350 Baucom, 'Specters of the Atlantic', 80.

351 Rediker, The Slave Ship, 12-13.

352 Gilroy, The Black Atlantic, 16-17.

353 Young, Haunting Capital, 40, 47.

354 Chambers, 'Heterotopia', 116.
} 
dislocation. Yet, like LTTE cemeteries, the sea is a space of memory and history. Colonial discourses envision the sea as a liberal space of exploration, but for refugees and slaves, it is a cemetery and a prison. Current discourses on the 'refugee crisis' liken the Mediterranean Sea to an 'open-air,' 'live' or 'alive cemetery,' e.g. social scientist Vieira states, "This sea that gathers two margins with strong demographic and economic disparities" is a "Mediterranean cemetery." 355 Similarly, in postcolonial scholar Chambers' wording, it is a "marine cemetery of modern day migrant labour" and a "maritime archive."356 Edkins refers to refugees lost in the sea as MIA and a double absence (Chapter 3.4). The sea embodies what Agamben terms the moment in which biopolitics turns into thanatopolitics (Chapter 3.2), in which (refugee) let die is (refugee) make die. Mediterranean and migration studies scholar Abderrezak hypothesises the subjects in Mediterranean cinema are "[c]aught between two cemeteries, [they] are like disposable visitors not in lieux de mémoire (sites of memory), but in lieux sans mémoire (sites without memory) or lieux-mouroir (death sites)." 357 Yet, as expounded earlier, the sea for refugees and slaves, is both site of memory and death.

\footnotetext{
355 Vieira, 'Mediterranean Refugee', 17. Wolff, in this context, maintains Libyan refugees are more likely to die in the Mediterranean Sea than reach Europe (Wolff, 'Migration and Refugees', 439.)

356 Chambers, 'Heterotopia', 118.

357 Abderrezak, 'The Mediterranean Seametery and Cementery', 158.
} 


\section{This content is unavailable. Please consult the figure list for further details.}

Figure 6.4 Plan of the Slave Ship Brookes

\subsection{Spectres OF SLAVE AND REfUgeE SHIPS}

M.I.A's "Borders," similar to Sestini's photograph and Brookes print, is also characterised by the sanitisation of violence and deindividuation of passive bodies. The aestheticisation and ordered barbarity of "Borders" risks objectifying refugees and obscuring violence, yet, similar to "Born Free," I argue it critiques the images by replication and simultaneous uncanny transruption. The video of "Borders" depicts a staged, orchestrated, and sanitised tableau vivant. Both land (Figure 6.1 and Figure 6.5) and sea (Figure 6.6) environments are structured by geometric formations. The visual abundance of lines metaphorise the dominance of border regimes which structure and confine the mobility of refugees. The hyper-stylised, patterned, and meticulous compositions also emphasise the liminal state of refugees who linger on borders. The overhead shot of boats arranged flowerlike, each boat forming a petal, metaphorically centres M.I.A as MIA/refugee (Figure 6.6). 
This content is unavailable. Please consult the figure list for further details.

Figure 6.5 Screenshot from "Borders." Lines of men

\section{This content is unavailable. Please consult the figure list for further details.}

Figure 6.6 Screenshot from "Borders." Boat circle

"Borders" features a series of overhead shots of overcrowded boats floating in the sea (Figure 6.7). The men are shown to lie lethargically on the boats, passive and inert, and time seems to stand still. These images evoke what has earlier been referred to as 'perfect barbarism,' the aesthetic sanitisation of violence in both Sestini's refugee boat photograph and the Brookes slave ship diagram. Figure 6.7 highlights the passivity of refugees, that is, it cites and critiques the passivity of the subjects in dominant 
depictions of refugee- and slave ships. It reflects and emphasises the let die, the what Davies et al. describe as the state's biopolitical inaction which constitutes the state's destructive thanatopolitics, the 'agnotological approach' of deliberate ignorance. The inaction of letting (refugee) die is deliberate making (refugee) die, just as the lazing of anonymous, depersonalised brown men is a deliberate re-enactment of passivity. The sea here is a hyper-aestheticised space of tranquillity, passivity, and immobility. In proximity to the coast, the passengers float in a calm rather than stormy sea. The sea as a space of nothingness and an eternal limbo, is the paragon of a mare nullius and the colonial trope of absence. 358 M.I.A's depiction of the sea as a limbo and vast nothingness is deliberate, reflective of refugees who as (not bare, killable life but as) homo nullius or a corpus nullius find their end in a space of absence. The staging of stagnation also reflects refugee realities of protracted waiting. Connected to a history of violence and haunting, the overhead-shots in "Borders" recall and activate the haunting maritime cemeteries of supine slaves and standing refugees (Figure 6.8). M.I.A draws from, but also radically breaks the pictorial tradition of Brookes and Sestini. The transruption, as I will show in the following, indwell in the human boat, the LIFE representations, the lyrics, and sartorial politics.

\footnotetext{
358 The colonial erasure of maritime presences, such as islands, also 'empties' its people. Campbell and Wilson define mare nullius as a maritime equivalent of terra nullius, "a maritime form of the principle myth justifying European expansion on the Australian continent" that is defined by the same myths of emptiness (Campbell and Wilson, The Politics of Exclusion, 57-58.)
} 


\section{This content is unavailable. Please consult the figure list for further details.}

Figure 6.7 Screenshot from "Borders." Boat overhead shot

\begin{tabular}{|l|l|}
\hline $\begin{array}{l}\text { This content is unavailable. } \\
\text { Please consult the figure } \\
\text { list for further details. }\end{array}$ & $\begin{array}{l}\text { This content is unavailable. } \\
\text { Please consult the figure } \\
\text { list for further details. }\end{array}$ \\
\end{tabular}

This content is unavailable. Please consult the figure list for further details.

Figure 6.8: "Borders," Time image, and the Brookes

\subsection{NOAH'S ARK Illegal AS Tidalectic HaUNTING}

In a seminal and profoundly disturbing scene in "Borders," the men stand or kneel closely next to or above one another, their collective refugee body forming the shape of a ship (Figure 6.9 and Figure 6.10). With long brown identical raincoats or mariner's coats, they are positioned on the 
shoreline. M.I.A, wearing an orange overall, stands out as the ship's captain. This human boat-formation embodies the nexus of the slave ship and refugee ship as a cemetery. This performance art re-visualises the slave ship. The life-sized re-enactment produces a sense of confinement and suffocation. Body on body, the men evoke the claustrophobia of the slave ship, where bodies are pressed against each other. Like the Brookes image, it is stripped of the ship's surface to expose the materiality of the refugee bodies it contains. It foregrounds the vulnerability and hence grievability (see exposition of Butler in Chapter 3.5) of bodies exposed to violence and enables mournability. M.I.A's human ship conjoins the transatlantic slave trade with refugee flights in order to evoke past injustice to comment on present injustice. It parallelises the refugee- and slave ship as carceral and thanatotopic technologies that commoditise the dehumanisation of non-white bodies. Nonetheless, the anthromorphisation of the boat humanises the 'news' of yet another capsized refugee boat and corporealises histories of violence. The men's ghostly appearance arises from their demeanour, inactivity, and coats, the latter rendering the men indistinguishable, depersonalised, eerie, and corpselike. Resembling prisoners awaiting execution or lynching, they stare straight ahead with vacant expressions, their faces unfocussed. They are the (living) dead that haunt and challenge the biopolitics(-as-thanatopolitics) of the state. Confronting the complicity of the Global North in producing refugee sea deaths, the image poses a profound disturbance. It foregrounds the refugee bodies that are let die and evokes refugees as haunting spectral subjects. This key image in the visual narrative resurrects a refugee ship- 
cemetery in which refugees return to haunt the state. This image, the refugee ship as a 'cemetery-ship' also depicts a double heterotopia, a space of double spectrality (as alterity). 359

Against the previously outlined images of passivated refugees (Figure 6.7), this is a site of active haunting. M.I.A disturbs maritime sediments and brings forth the unseen and deliberately ignored refugee bodies of the carceral refugee ship in a tidalectic haunting.

359 Foucault apprehends heterotopia "suspect, neutralize, or invert the set of relations that they happen to designate, mirror, or reflect" (Foucault, 'Of Other Spaces', 24.) They are counter-sites that are "simultaneously represented, contested, and inverted." (Foucault, 24.) Foucault quotes the cemetery and the ship as instances of heterotopia. The cemetery, and in a way death itself, was historically exterritorialised from the city, "Until the end of the eighteenth century, the cemetery was placed at the heart of the city, next to the church. $[\ldots]$ it is only from $[\ldots]$ the nineteenth century that cemeteries began to be located at the outside border of cities [...] [as they] came to constitute [...] 'the other city,' where each family possesses its dark resting place" (Foucault, 25.) On the other hand, the ship, says Foucault, is "the heterotopia par excellence," "a floating piece of space, a place without a place" (Foucault, 27.) If Foucault fathoms the ship and cemetery as a heterotopia, M.I.A's human boat, which is also a cemetery, is a double heterotopia. The reception of Foucault's text illuminates the spectral quality of heterotopia. Johnson and Dehaene and Cauter respectively understand heterotopia as disturbing spaces of difference that evade power, interrupt ordinary everyday space, and inject alterity, plurality, and heterogeneity into sameness (Johnson, 'Unravelling Foucault', 84, 86. Johnson, 'The Geographies of Heterotopia', 790. Dehaene and Cauter, 'Heterotopia and the City', 3-4, 8.) Chambers, likewise, discerns heterotopia as unhomely counter-spaces that are "[a]lternative, subaltern, and subordinated to the rules that occlude their presence" (Chambers, 'Heterotopia', 113.) As spectrality epitomise alterity, spectral spaces constitute heterotopia. Both the ship and the cemetery are located outside ontology. The disturbing human boat is a counter-site that injects the notion of the sea as a cemetery. It also injects spectrality, the sea-cemetery of exterritorialised refugee bodies, into the land. 
Barbadian poet Brathwaite's concept of tidalectics can be understood as spectral iteration (haunting) or spectral time. Brathwaite conceptualises tidalectics as "the movement of the water backwards and forwards as a kind of cyclic, I suppose, motion, rather than linear [motion]."360 Literary comparatist Infante understands tidalectics as a challenge to the Hegelian dialectics of history and that counters "the teleological or progressive linearity of Western culture." 361 Island studies scholar DeLoughrey describes the concept regards "water as a shifting site of history." 362 Tidalectics, in DeLoughrey's words, explores the "complex and shifting entanglement between sea and land, diaspora and indigeneity, and routes and roots." 363 Perera remarks tidalectics denotes "contrapuntal' relations of land and ocean, understood as inextricably interconnected sociopolitical spaces." 364 Like the spectre, tidalectics not only challenges history (that is, the western notion of linear temporality), it also challenges ontology, the binaries of land and ocean, of absence and presence. Transnational studies scholar Hitchcock links tidalectics with the Black Atlantic, suggesting it represents "a conceptual space of identification that links blacks across the Atlantic by culture, politics, and history." 365

\footnotetext{
360 See Brathwaite, Third World Poems, 42. Mackey, Paracritical Hinge, 9-10, 14. Quoted in Torres-Saillant, 'The Trials of Authenticity in Kamau Brathwaite', 697.

361 Infante, After Translation, 151.

362 DeLoughrey, 'Routes and Roots', 2007, 163.

363 DeLoughrey, Routes and Roots, 2007, 2.

364 Perera, Australia, 4.

365 Hitchcock, Imaginary States, 69.
} 
Compton underscores the repeatability and palimpsestuality of tidalectics, which see[s] history as a palimpsest, where generations overlap generations [...] Repetition $[\ldots]$ informs black ontologies $[\ldots]$ In a European framework, the past is something to be gotten over, $[\ldots]$ in tidalectics, we $[\ldots]$ are ourselves versions of the past. 366

Iteration, the disruption of linear temporality as well as hauntology are central paradigms of tidalectics. Tidalectics (as spectrality) signifies iteration. If tidalectics refers to repetitions of water, ontology, history, bodies, (generationality), M.I.A's tides/ tidalectics bring(s) forth and washes up refugee bodies. M.I.A's human ship image encapsulates this tidalectic haunting. Refugees return to haunt, ask critical questions, and remind of the unwitnessing of their deaths.

\section{This content is unavailable. Please consult the figure list for further details.}

Figure 6.9 Screenshot from "Borders.” Human ship 1 frontal

366 Compton, Bluesprint, 17. 


\section{This content is unavailable. Please consult the figure list for further details.}

Figure 6.10 Screenshot from "Borders." Human ship 2 full shot

M.I.A's littoral human ship is in sharp contrast to the video's remaining depictions of ships floating in the sea. Deliberately positioning on the shoreline, it lingers in the liminal borderscape 367 between land and sea, life and death, ontology and spectrality, citizenship and statelessness. The men of the human ship inhabit the black line of credits in the introductory scene (Figure 6.11). This black line represents an actual and metaphoric

\footnotetext{
367 Rajaram and Grundy-Warr define borderscapes as an entry point "allowing for a study of the border as mobile, perspectival, and relational" (Rajaram and Grundy-Warr, 'Introduction', x.) In other words, borderscapes query notions of territoriality and conceive of borders in their constructedness. Reflecting this notion in a different context, Perera submits the beach represents multiple borders. On Hasan Elahi's installation FlowWet Feet (Dry Feet), which depicts waves repeatedly breaking on a shoreline, she writes, "In Flow the beach is the site of an invisible border: between land and sea, dry and wet, onshore and offshore, legal and illegal, freedom and unfreedom, asylum and detention, life and death. Yet Flow, by its rendering of the to and fro of waves on a beach, renders absurd the all-important demarcation, on the beach, between wet feet and dry feet, legal and illegal, law and violence. It mocks the belief in the neat divide, the line between this side and that side" (Perera, 'Oceanic Corpo-Graphies', 63.) This argument can of course be made in M.I.A's human boat image, too.
} 
border and indicates both sides of the partitioning: the border versus MIA (refugees), land versus sea, life versus death, mobility versus stasis. The light blue background connotes the sea and sky and connects to M.I.A's pirate-metaphor for refugees as boundary-transgressors.

The human ship recovers and transposes the dead bodies of refugees from the sea (a space of hauntology) to the land (a space of ontology) or, more specifically, the boundary site between life and death. The imagery resurrects a maritime refugee cemetery. By literally embodying a boat, the refugees constitute a haunting reminder of their let die. The human ship resurrects a double absence, as refugee sea deaths and refugees as such are invisibilised. "Born Free," as commented in the previous chapter, critiques the make die of Tamils by the GoSL and the unwitnessing (and hence let die) of the international community. "Borders" poignantly critiques that western refugee policies of let die are make die. The human ship synthesises the sea is a site of obscured thanatopolitics. Obscured thanatopolitics is, Agamben explicates, "the point at which the decision on life becomes a decision on death, and biopolitics can turn into thanatopolitics." 368 The sea is a thanatopolitical space outside bios (qualified life), in which refugees are (often invisibly) let die which constitutes a make die (Chapter 3.2). 
The human ship represents what M.I.A denotes as "Noah's ark illegal” in her song "Jump In” (2016). Deploying 'the master's tools,' M.I.A revisits the pericope of Noah's ark, a narrative that refers to the diluvian purging of evil and evokes collective punishment as well as rescue. Positioning refugees on the ark transforms refugees from rejected sinners to 'the chosen people.' The addendum 'illegal' to Noah's ark is a revisionist renarrativisation, in which illegality forms a counter-epistemology outside of citizenship and statehood.

\section{This content is unavailable. Please consult the figure list for further details.}

Figure 6.11 Screenshot from "Borders.” Title image

\subsection{LIFE}

One of the first images of "Borders" portrays the refugee men climbing over a fence in the background, separated by another border from M.I.A who sings in the foreground (Figure 6.12). This act of (literal and metaphorical) border transgression proceeds to a human artwork. Positioned on the fence, the men halt to depict the word 'LIFE' with their 
bodies (Figure 6.13). In a representation of a representation, lives represent 'LIFE.' Or, in Agamben's terms, bare lives represent qualified life (Chapter 3.2). This performative art illustrates and contests border regimes underpinned by the state's destructive thanatopolitics that hold power over life and death. It effects two things: Firstly, it demands (bare) refugee life to 'matter' and to 'count' as qualified life, and enabling grievability and mournability-effecting humanisation and the recognition of wounds. Secondly, it represents life at the border. The fence, resembling prison bars, is the border between life and death, between incarceration and liberation. Intersecting (and equating) prison and border regimes, the representation of life at the border recasts refugee life as incarceration. An act of self-humanisation, refugees deploy their bodies to embody 'LIFE' and point to the corporeality and thus mournability of their own bodies.

This scene (Figure 6.13) replicates M.I.A's chart artwork 'Design for Sum Life' (Figure 6.14) in which the outline of the word 'LIFE' is formed by horizontal bar charts. The image abstracts the biopolitical quantification and economisation of refugees. The abscissa-poverty, child labour, unemployment, and infant mortality-are markers of biopoliticality (see Chapter 3.2). Both the chart artwork and the body representation of 'LIFE,' in Butler's terminology, “'work within' and against normative matrices" that precondition life and death. As Butler pronounces, a political struggle [that determines who deserves a livable life, whose life counts] is one 'within and against' the normative matrices that condition who can 
become a 'who' in the domain of the livable. At least in English, to 'count' is both to matter and to be subject to an arithmetical calculus. [...] One might think that counting is among the easiest of ordering procedures, but it turns out that numbers are very controversial. 369

To contest categories of life and death, of bare and qualified life, one has to work within against normative matrices that determine whose lives count. Regimes of management, says Athenasiou, measure bodies through the governmentality of profitability. 370 The graph-artwork typifies and critiques 'to count' in the sense of 'to be subject to an arithmetical calculus' (that is, to be subject to regimes of management that operate under economic rationales), while the human LIFE-representation calls refugee lives 'to matter,' that is, to be grievable and mournable. Refugees 'represent' 'LIFE' to claim it. The chart condemns regimes of management, specifically regimes that manage borders and (the economisation of) life and death, and the removal of lived refugee experiences. The use of a chart illustrates the reduction of refugee lives to expendable numbers. M.I.A's images call for refugee lives to matter within and against normative matrices that determine which lives matter. To matter emphasises the body (the material wounds). The matter here, that is the refugee body in this tableau, is the very means in the struggle to matter. The very bodies which are declared expendable numbers are mobilised to inscribe life, in other words, de-ontologised bodies are used to claim life.

\footnotetext{
369 Butler in Butler and Athanasiou, Dispossession, 100.

370 Athanasiou in Butler and Athanasiou, 100.
} 
The fence is staged in another scene in which the men cling to it from behind it while M.I.A leans against it (Figure 6.15). The men are visible only as phantom-like prisoners, outlines, silhouettes, or spectres. M.I.A is outside the fence (similar to Figure 6.12) here. Throughout the video, she appears inside and outside the fence, with the refugee men and apart from them, reflecting her ambiguous positionality.

This content is unavailable. Please consult the figure list for further details.

Figure 6.12 Screenshot from "Borders." Fence climbing

This content is unavailable. Please consult the figure list for further details.

Figure 6.13 Screenshot from "Borders." LIFE 
This content is unavailable. Please consult the figure list for further details.

Figure 6.14 M.I.A, "Design for Sum Life painting,” 2007

\section{This content is unavailable. Please consult the figure list for further details.}

Figure 6.15 Screenshot from "Borders." Fence of spectres

\subsection{ClOTHING \& LYRICS}

people were like, 'Her fashion sense is really bad and her songs are terrible,' [...]

[but] you can be a Sri Lankan refugee and still be cool. ${ }^{371}$

Clothes are (surficial) extensions of the self and body. Throughout "Borders," textiles are sites of refugee resistance and agency. M.I.A aestheticises refugee clothes by resignifying sportswear. In a context in which refugees are either criminalised for wearing counterfeit or authentic (expensive) branded items, or deagentised as receivers of ill-fitting,

${ }^{371}$ M.I.A quoted in Robson, 'Globalist Rapper'. 
mismatched, and donated clothes, M.I.A uses self-designed clothes as resistance to oppose victimisation narratives and subjectivising refugees.

\section{This content is unavailable. Please consult the figure list for further details.}

Figure 6.16 Screenshot from "Borders.” 'Fly Pirates'

M.I.A's 'Fly Pirates' t-shirt (Figure 6.16) subverts the 'Fly Emirates' football jersey of Paris Saint-Germain. The football club threatened with legal proceedings, claims for compensation, and demanded the removal of the video, to which M.I.A responded,

[in] war zones or any slums [...] in the Third World, you would find sportswear. $[\ldots][$ F]ootball tops $[\ldots]$ [or] tracksuits $[\ldots]$ [are] the uniform of $[\ldots]$ underprivileged people $[\ldots]$, because that is the cheapest thing we can find. $[\ldots]$ We bootleg the biggest brands. [...] [F]or [the football team] to control that is a really stupid thing. 372

Refugees are re-interpreted as criminalised transgressors of the European colonial imagination. Yet, in the video they remain immobilised,

372 M.I.A. in Goodman, 'M.I.A.', 12 January 2016. 
representing the refugee condition. Linebaugh and Rediker describe some escaped slaves formed viable African and multi-racial seaborne piratical communities, "some slaves and free blacks found aboard the pirate ship freedom $[\ldots]$ pirate ships themselves might be considered multiracial maroon communities." 373 The production and availability of counterfeit (pirated) consumer goods in the third world resistivise the medium as a challenge to capitalism, corporatisation, and the racialised allocation of copyright laws. ${ }^{374}$ As such, M.I.A's resignified jersey is also an ambivalent iteration. The sly colonial's sartorial mimicry ('almost the same, but not quite') is a deliberate menace, a threat to and rupture of the civilising mission. ${ }^{375}$ The football club's desire for 'narcissistic authority' 376 is not merely 'stupid,' but seeks to effect the disciplining and dispossession of refugees.

Historically, pirates as dichotomised figures are deemed "a dangerous menace, an emblem of progress, or even a symbol of independence." 377 Thorup establishes commonalities in the construction of terrorists and pirates as 'enemies of humanity' who are situated outside of morality and legislative protection. ${ }^{378}$ In a similar vein, M.I.A. reframes refugees (who

\footnotetext{
373 Linebaugh and Rediker, The Many-Headed Hydra, 167.

374 It does not go unnoticed that the commodity value of luxury sportswear brands that connote exclusivity and elitism is achieved through the exploitation of third world subjects.

375 Bhabha, 'Of Mimicry and Man', 123.

376 Bhabha, 129.

377 Gerassi-Navarro, Pirate Novels, 5. See also Policante, The Pirate Myth.

378 Thorup, An Intellectual History of Terror, 156.
} 
are at times equated with 'terrorists') into pirates. Yet her analogy retains the ambivalences inherent in pirate discourses: It recalls their criminalisation, decitizenisation, and killability as bare lives (and male gendering), but also their empowerment, transgression, insurgency as anti-governmental subjects.

\section{This content is unavailable. Please consult the figure list for further details.}

Figure 6.17 Screenshot from "Borders.” 'Jesus sad'

M.I.A's t-shirt print 'Jesus said [...]' becomes 'Jesus Sad I am the way, the truth, and the life,' critiquing the lack of solidarity, Christian charity and ethical commitment (Figure 6.17). The music video embeds JudeoChristian references, including Noah's ark and a Biblical quote attributed to Jesus (Figure 6.17). The Judeo-Christian epistemological framework (used to justify the exclusion of refugees based on radical alterity of Islam in right-wing nationalist discourses) is evoked to pinpoint hypocrisy. 


\section{This content is unavailable. Please consult the figure list for further details.}

Figure 6.18 Screenshot from "Borders." Mylar blankets

The moment of rescue in "Borders" occurs at the border. The space blankets handed to the refugees portend vulnerability (Figure 6.18). For Butler, injurability comprises the "duality of being exposed to injury and, at the same time, refusing and resisting." 379 The stylised depiction of refugees in mylar blankets signify both the exposure and dissent to injury. It makes the spectator a witness and confronts their complicity. Kornhaber reads the gold blankets as "symbols of emergency $[\ldots]$ made couture," 380 a notion not dissimilar from what has been labelled 'refugee chic.' If fashion constitutes material memory, the space blankets, as the locus of memories of (near or living) death, express the vulnerability, grievability, and injurability of refugees. The imagery of this scene, once more, resembles Sestini's coverage of the Mediterranean Sea (Figure 6.19).

\footnotetext{
379 Judith Butler in Butler and Athanasiou, Dispossession, 111.

380 Kornhaber, 'The Rapper of Refugees'.
} 


\section{This content is unavailable. Please consult the figure list for further details.}

Figure 6.19 Sestini, Syrian refugees on an Italian navy ship

M.I.A's refugee spectres illuminate the hypocrisy of Western humanitarianism and their foundational role in marking the borders between life and death. The lyrics challenge the "apparatus of controlling [...] the spatiality, mobility, affectivity [...] of (neo-) colonized subjects" 381 and "contemporary multicultural liberalism [that] [...] reproduce[s] unequal liberal regimes of power and imaginaries of national cohesion.” 382

To iterate Butler's argument, violence against refugees can only be recognised as an assault if they are granted subject-status, which effect the derealisation of historical wounds. ${ }^{383}$

\footnotetext{
381 Butler and Athanasiou, Dispossession, 11.

382 Butler and Athanasiou, 75.

383 Athena Athanasiou in Butler and Athanasiou, 90.
} 
Recognition is an apparatus that discursively produces subjects as human (or inhuman, subhuman, less than human) $[\ldots]$. When a life that does not figure as normatively human is violated, this violation remains unrecognized $[\ldots]$ through terms that enable derealizing violence.

The larger objective of the song is to recognise that refugee deaths are violence. According to Betts and Collier, the media's proclamation of a 'global refugee crisis' from 2015 onwards was

a European crisis. And it was a crisis of politics rather than a crisis of numbers. [...] During [2015], over 3,000 people, including many children, drowned while trying to reach Europe [...] [the] policies [of European governments was] being shaped more by the domestic politics of the moment than the search for collective solutions. ${ }^{384}$

The lyrics of "Borders" foreground not the 'victim', but the 'perpetrator', asking questions directed at 'the West,'
Where's your 'We'dom? [...]
Borders (What's up with that?)
Politics (What's up with that?)
Police shots (What's up with that?)
Identities (What's up with that?)
Your privilege (What's up with that?)
Broke people (What's up with that?)
Boat people (What's up with that?)

They oppose European narratives of liberal democracy and interrogate the foundations of Eurocentric ontologies. Assuming the ignorant refugee identity and asking what appear to be infantile questions, the repeated question "what's up with that" critiques the trivialisation of 'the refugee 384 Betts and Collier, Refuge, 2. 
issue'. This achieves the opposite, it denounces the indifference to refugee deaths of the necrotising border effects and points to the hypocrisy.

They further censure the emptiness of Eurocentric ideoscapes ('ideology,' 'identities,' 'history') and humanitarian discourses ('discourses of pity' and white saviour narratives). Ideoscapes, Appadurai elucidates, consist of ideas, terms and images of the Enlightenment worldview, "including 'freedom', 'welfare', 'rights', 'sovereignty', 'representation' and the master-term 'democracy.'” 385 M.I.A's reference to the New World reminds of colonial subjugations, the "many, continuous displacements" 386 and decimations of indigenous people, justified and perpetuated by Enlightenment ideas. Similar to Hesse's claim that multicultural transruptions expose the 'promise of democracy' as a foundational ruse, ${ }^{387}$ Appadurai insinuates the challenge diasporas pose to European ideoscapes. M.I.A's iterative questions confront the thanatopolitical complicity of Western liberalism in refugee deaths, Enlightenment epistemologies, and immigration rhetorics. The lyrics demand political recognition and accountability for violence. They expose the gaps of Western liberalism. They conscientize the hypocrisy of Western liberal humanism and its production, seeing and unseeing of refugee deaths. It is not refugeecentric, but spectatorcentric. Refugees pose shaming questions and solicit witnessing. For Levinas, "[ $[\mathrm{t}] \mathrm{he}$

\footnotetext{
385 Appadurai, 'Disjuncture and Difference in the Global Cultural Economy', 9-10.

386 Hall, 'Cultural Identity and Diaspora', 234.

387 Hesse, 'Introduction', 19.
} 
spectator is an actor," 388 whose gaze implicates responsibility. When power turns a blind eye to the refugee sea deaths, they haunt, gaze, compel to take a positionality. By means of spectralising the refugee, their refugee gaze and iterative questions, "Borders" fixate the (Western) spectator to "dealing with, 'Are you in front of this fence? Are you a reporter on the fence? One of them? Are you with the people? Are you a pop star?"”389

The discrepancy between (the rhetorical questions of) the lyrics and the visual depiction is perceptible. The lyrics address Western humanist discourses of progress yet the visuals depict refugee limbo at sea.

\subsection{PRODUCTION AND RELEASE}

"Borders," as M.I.A, is set in the context of deaths in the Mediterranean Sea, yet its filming locale and release date point to a different form of death-camp. With 1,000 street-casted men, the video was shot in Pondicherry, the capital of the Union Territory of Puducherry, India (Figure 6.20).390 The coastal city, an enclave surrounded by the state of Tamil Nadu, is in close proximity to Northern Sri Lanka.

Additionally, the film set was also chosen to be close to the Tamil Nadu refugee camps of Sri Lankan Tamil refugees. As M.I.A explains,

\footnotetext{
388 Lévinas, Emmanuel Levinas, 39.

389 M.I.A quoted in Phillips, 'People Forget I'm Many Things'.

390 Feeney, 'Borders'.
} 
We built a 200-foot-long fence to replicate the Spanish one. ${ }^{391}[\ldots]$ we weren't allowed to build this fence in the state [Tamil Nadu] I had permission to film the boats in. We got kicked out and had to go to the next state [the Union Territory of Puducherry] [...] we built [the fence] on the border itself between two states. 392

The material realities of border effects is reflected in the production of the music video itself, as M.I.A was necessitated to construct her fictional border at an actual border. It is no coincidence that "Borders" was released on Maaveerar Naal (மாவீரர் நாள்), the remembrance day that commemorates the deaths of LTTE militants. The filming location, the brown subjects, and the release date of "Borders" are indicative of Tamil histories. The song remembers and resurrects Tamil militants and refugees as haunting subjects. It juxtaposes (the remembrance of) Tamil fighters and (the remembrance of) Tamil refugees. By extension, it remembers the hardships and demonisation of Tamil refugees at sea such as the incident of the MV Sun Sea in Canada 393 or the deportation and deaths of Tamil refugees in Australia and Manus Island. Kingsbury synopsises the Tamil refugee condition as follows,

after the war [in 2009], Tamils continued to flee Sri Lanka, in substantial fear of their lives. Despite the clear grounds $[\ldots]$ for seeking refugee status, receiving countries such as Australia and Canada treated them $[\ldots]$ as $[\ldots]$ criminals $[\ldots]$. The government of Sri Lanka meanwhile continued its shrill calls for Tamil

\footnotetext{
391 This refers to the Melilla border fence between Morocco and Spain.

392 M.I.A quoted in Feeney, 'Borders'.

393 The vessel arrived in Canada in August 2010 carrying nearly 500 Tamil refugees. The Canadian government's reaction led to the deportation and subsequent torture of at least one individual (refer Woodward, 'Canada Deported Man to Torture in Sri Lanka'.)
} 
asylum seekers to be returned to Sri Lanka, employing the logic that if they fled they necessarily $[\ldots]$ were members or sympathisers of the LTTE. Apart from the obvious fact that many were just ethnic Tamils wishing to espace persecution, many LTTE sympathisers simply sought equity under the state. ${ }^{394}$

To question M.I.A's 'inauthenticity' for representing Tamil refugees, to accuse her of hypocrisy, is to discredit the artist, depoliticise the larger issue, mute refugee voices and preclude the possibility of working within and against systems of oppression, "within and against" the normative matrices that condition who can become a "who" in the domain of the livable." 395 It evokes the arrival of Tamil refugees to Canadian shores between 2009 and 2010. Thurairajah describes the political climate as follows,

While these refugees gained much media attention, the focus was on the criminality of illegal migrants, rather than on the plight of the Tamils in Sri Lanka. ${ }^{396}$

Bradimore and Bauder find the Canadian press "emphasized issues of criminality and terrorism, and constructed the refugees as risk."397 Ellis' article describes the complicity of the Australian government with the oppression and injustice towards Tamils in Sri Lanka, as boat convoys are used to "[to] send a back-off message to Australia should it dare criticise Colombo." 398 Billboards and the "no-visa" campaigns by the Australian governments aim "to discourage (Tamil) asylum-seeker departures, and

\footnotetext{
394 Kingsbury, Sri Lanka, 10.

395 Judith Butler in Butler and Athanasiou, Dispossession, 100.

396 Thurairajah, 'Shadow', 146.

397 Bradimore and Bauder, 'Mystery Ships'. 5

398 Ellis, 'The Smugglers' Prey'.
} 
to break the smugglers." 399 The Australian administration therefore backs the Sri Lankan government for its own purposes.

\section{This content is unavailable. Please consult the figure list for further details.}

Figure 6.20 Screenshot from Matangi / Maya / M.I.A. "Borders" set

\subsection{SUMMARY}

M.I.A's "Borders" resurrects a refugee sea-cemetery to oppose the unwitnessing of refugee sea deaths. Refugees who died at sea haunt as spectres. It emphasises refugee let die is make die, staging (visual) borders as borders in which, to recall Agamben (Chapter 3.2), "the decision on life becomes a decision on death, $[\ldots]$ this line $[$ is $]$ no longer $[\ldots]$ a stable border dividing two clearly distinct zones." 400 It insists on the complicity of unseeing refugee deaths in the production of refugee deaths.

\footnotetext{
399 Ellis.

400 Agamben, Homo Sacer, 72.
} 
"Borders" was released on the day that commemorates and mourns the deaths of LTTE militants (Maaveerar NaaI). This day of commemoration, as enunciated earlier (Chapter 2.2), was staged on LTTE cemeteries. The refugee cemetery in "Borders" is implicitly linked to the LTTE cemetery. Both cemeteries assert onto-territorial and memorial claims. The release date evokes and implicitly apposes dead Tamil fighters and (living) dead Tamil refugees who are both criminalised. Tamils fleeing the island postwar as refugees encounter demonisation and deportation, particularly in countries such as Canada and Australia. The MV Sun Sea incident illustrates the vilification of Tamil refugees as terrorists in Canada. The Canadian press and politicians, in "a campaign of fear-mongering," linked the ship of Tamil refugees, intercepted by the Canadian navy, to 'smugglers and terrorists.' ${ }^{\prime} 01$ The ship contained 493 lives-the number of lives in Sestini's refugee boat photograph and the number of slaves on the Brookes-lives detained, some imprisoned, deported, one at least "brutally tortured," "held for a year without charge in a Sri Lankan prison, beaten with plastic pipes, and forced to go without food and water." 402 Tamils in the island are made die, Tamils fleeing (as living dead) are let die (which, M.I.A's work insinuates, is a make die, too). The dead (of

\footnotetext{
401 The Canadian federal Safety Minister at the time termed some of the passengers "suspected human smugglers and terrorists" and warned it was "imperative that we prevent supporters and members of a criminal or terrorist organization from abusing Canada's refugee system” (Anonymous, '10 Years'.) 402 Woodward, 'Canada Deported Man to Torture in Sri Lanka'.
} 
Mullivaikkal) are denied memory and mourning, the living (dead) denied witnessing. 



\section{RE-EXIT MIA}

I set out to identify the specific cemeteries of M.I.A's work, inquiring into their visual translations, functions, objectives, and larger political significance. The relevance of my treatise lies in my methodology, which, informed by my proximate relationship to Tamil histories, reveals M.I.A's political and ideological work. The artist's work and my reading thereof draw from familiar collective narratives and images circulated amongst the Tamil diaspora, including Oliveechu tapes, war trophy images, and news feed of intercepted refugee boats. In other words, they emerge from the constant absence-presences of the war in Tamil diasporic lives and media. The key contribution of my study is uncovering the absence-presences and locating MIA in M.I.A's output, thereby revealing its raison d'être.

Imperceptible are not only the spectres of the war in M.I.A's work, but also the multiple challenges in writing this thesis, which, for a plethora of reasons, was an arduous exercise. This study on Tamil erasures was shaped by retraumatising pangs of personal and collective losses. The taxing psychosomatic labours of my scholarly praxis entailed quotidian intellectual returns to Sri Lanka's killing fields, the impossibility of representing genocide coupled with the burden of representation, and outright reluctance on account of self-protection. Against incapacitation and paralysis to write the unwriteable, that too as the problematic 'native 
informant,' my only driving force was, to evoke an M.I.A song, the need to tell this story.

This story/study is informed by witnessing the continuation of the conflict post-war first-hand and on the ground. In the context of a research stay I travelled to the north and northeast of Sri Lanka in 2018/2019. Despite being born in Jaffna amidst internal (Sri Lankan) and external (Indian) military occupation, the visit marked my first 'homecoming' as I spent the entirety of my life in Germany. My own journey meant documenting Tamil absences under a de facto embargo of narrative (including photographic) memorisation. It was punctuated by sexual harassment from the Sri Lankan military, the racial animosity of busloads of Sinhalese 'tourists,' and a continued refusal of access to warzone sites. My research in a way fleshes out ways to make Tamil absences present, that is, to mediatise the hauntings of MIA by a/my living self from the sites that killed the already dead. In this respect, the chief lesson for future projects I draw from this intellectual and physical journey is to bear in mind the corpo-affective impacts of emotionally volatile research subjects, despite the fruits of research outcomes, like the following ones.

The chronology of M.I.A's work reflects the history of multiple Tamil erasures in the Sri Lankan civil war. Each of my case studies is a body of evidence that testifies to my wider claim that M.I.A's output forms a Tamil counter-narrative to the political erasures of Tamils by the GoSL and the Global North. The selected case studies recirculate historical wounds as 
Tamil sites of death: the LTTE and Oliveechu cemetery ("Galang" and "Bucky Done Gun"), the cemetery of the Mullivaikkal massacre ("Born Free"), and the refugee sea-cemetery ("Borders"). In the mid-1990s the GoSL demolished Tamil cemeteries and post-9/11 western nation-states criminalised the LTTE tape series of Oliveechu. M.I.A's stencils in "Galang" and "Bucky Done Gun" embody and contest the erasure of the LTTE and Oliveechu cemeteries. The Mullivaikkal massacre, the extrajudicial killing of Tamils in a No Fire Zone in 2009, is restaged in the music video of "Born Free." "Borders" implicitly critiques western demonisations and deportations of Tamil asylum-seekers fleeing Sri Lanka post-war by envisaging boat people as a haunting cemetery who unmask the hypocrisy of European narratives of liberal democracy vis-à-vis refugee deaths. My reading of M.I.A's aesthetic praxis through this chronological structure exposes the reverberations and recitations of the war in Sri Lanka as absent presences in diasporic artistic productions.

M.I.A's aesthetic techniques interact with and convert sites of death in a remarkable way. In western historical contexts, cemeteries were relocated from urban centres to the peripheries, often in the form of tranquil landscaped gardens. In my selected case studies the artist recartographises Tamil cemeteries into ubiquitous popcultural expressions: animated stencils, flags, murals, photo montages, and performative bodies. The LTTE cemeteries videoised into Oliveechu tapes are re-videoised as stencil backgrounds and stencil flags in "Galang" and "Bucky Done Gun." The stencil medium is strategically employed to embody transience, while the 
stencil animation visibilises the very act of erasure. In other words, the aesthetic praxis of sous rature (stencil) represent the politics of sous rature (political effacement). The stencil motifs and animations of erased and recurrent LTTE militants, tigers, and palm trees signify Tamil obliteration and resistance. Situating the cemeterial stencils as music video backdrops literalises the idea that the war dead continually loom in the background. The stencil flags in "Bucky Done Gun" place the Tamil MIA of the effaced cemetery in the heart of the state as a haunting reminder of state violence. The mural in "Born Free" announces the future hauntings of the immanent dead and mobilises the vegetative imagery of the Tamil resistance movement in which the dead are metaphorically planted as seeds from which national emancipation emerges. All case studies express haunting by means of the physical body: an army of dancing M.I.A/MIA ("Galang"), a persecuted community of redhead men ("Born Free”), a corporealised refugee ship-cemetery and 'LIFE' enactment (“Borders”). The iteration of M.I.A's performative body against stencil reproductions are spectral recurrences which defy the demolition of LTTE cemeteries as part of the Sri Lankan state's politics of death. Likewise, the 'ginger genocide' deploys redheads (who are both white and politically black) as bodies of racial and power-political ambiguity to reflect 'the killing of one's own people' and compel the international community to witness the unwitnessed massacre of Tamils by the SLA in Mullivaikkal. The excavation and the powerful staging of the bodies of the sea as a sculptural refugee-ship and 'LIFE' enactment haunt the Global North for its deliberate inaction. In all four songs, bodies are instrumentalised as sites 
of haunting to physicalise the materiality of violence enacted upon Tamils. M.I.A's spectres deploy their bodies, the very bodies marked as absences, as a means to resist the political erasure inscribed upon them. Stencil, mural, body, conceptual, and performance art as politico-aesthetic praxes reinscribe Tamil cemeteries as ideological means and surfaces to activate Tamil hauntings.

M.I.A's topographies of death rematerialise the architecture of cemeteries even in a step further than aforementioned stencil, flag, mural, and body locales. The materialised sites of memory are embedded in music videos as replayable media in digital domains. Enabling iterability, the digitalisation of cemeteries evince a shift in memory and funerary praxes. This media shift implies the digital dissemination of memory sites to a diverse and uncertain audience. Considering the covertness of M.I.A's aesthetic tools (as for instance stencils are deliberately mobilised to feign shallowness), this shift marks a simultaneous ubiquitisation and obscuration of cemeterial landscapes. My historicised readings rethink the artist's work as acts of tending to Tamil graves through encoded popculturalisation. Indeed, M.I.A's work revisualises cemeteries as inconspicuous yet omnipresent sites of absence.

M.I.A's artistic production not only translates but also extends the funerary work of LTTE cemeteries. Cemeteries chiefly serve to remember and mourn the dead. LTTE cemeteries, additionally, stake ontological and territorial claims. M.I.A's stencils in "Galang" and "Bucky Done Gun" 
replicate the memorial and onto-territorial claims of the LTTE cemeteries, remembering and mourning Tamil subjects and landscapes sous rature. By means of a deliberately recondite visual register to circumvent censorship, they also obscure eulogies for the dead into covert expressions of loss and defiance. The music video of "Born Free" resurrects the cemetery of the Mullivaikkal massacre by translating it into a visual grammar of white familiarity to compel its (western) spectators to witness the unwitnessed Tamil killing. Unlike the Mullivaikkal trophy image that perpetuates the dehumanisation and subjugation of the blindfolded victims, M.I.A's rendition of the killing in the 'ginger genocide' agentises the persecuted by their retuning gaze and the cautionary mural pronouncement of impending hauntings. M.I.A's artwork "Born Free" reproduces the Mullivaikkal trophy image to expose Tamil truth claims and to let the dead speak with and through their brutalised bodies. It also situates the war in Sri Lanka within the larger geopolitical context of the 'war against terror' to expose that the criminalisation of Tamils and Muslims as 'terrorists' only serve to depoliticise the use of violence by non-state actors and legitimise violence by state (the GoSL) and imperial powers (USA) respectively. Turning (genocidal) evidence to art and art to evidence, both "Born Free"-cemeteries make it a point to historicise the depicted violence and identify the agents of brutality. In "Borders" refugee bodies corporealise (in conceptual and literal terms) 'LIFE' and a ship-cemetery, exhumed from the sea to the land, to condemn the hypocrisy of Western liberal humanism in its production of refugee deaths and denounce its regimes of management that frame refugee lives as 
expendable numbers. Evoking the intercepted vessel MV Sun Sea that carried Tamil refugees and released on Maveerar Naal, the LTTE's official day of commemoration for its dead, the song juxtaposes Tamil militants with Tamil refugees. M.I.A's memorial landscapes extend the funerary work of the LTTE cemeteries by activating spectral hauntings: stencil iterations of MIA that haunt to resist the prohibition of videoised obituaries in "Galang," a trophy image that haunts to identify the perpetrators of state violence and that elicits audience-witnessing in "Born Free," an excavated ship that haunts to demand accountability for refugee deaths in "Borders."

M.I.A's spectres oppose the state's destructive politics of death. Founded upon dead militant actors, LTTE cemeteries biopoliticise Tamil deaths, that is, they are comprehended as sites which give birth to the envisioned independent state of Eelam. Underlying a resistive thanatopolitics, M.I.A's work, in a way, biopoliticises haunting. Haunting in the selected works is instrumentalised as a means to defy biopolitical make-die and let-die: palm tree stencils and the performative bodies of M.I.A in "Galang" contest the destruction of LTTE cemeteries and Oliveechu tapes (makedie); the re-enactment of a redhead slaughter in "Born Free" condemns the deliberate massacre of Tamils (make-die) and its unseeing (let-die); the revisioning of the refugee cemetery-ship in "Borders" castigates that to let refugees die is make refugees die. M.I.A's spectres propound unmournable and unrecognised Tamil lives as 'politically qualified life.' 
M.I.A's output defies the state's politics of death by translating an image of death. Each of the case study is based on a thanatography of sorts: a quasi-obituary image of an Oliveechu tape erased by censorship, a perpetrator trophy image whose truth value is contested, and a refugee boat image underlying a white-saviour complex. The Oliveechu images are translated into stencils in "Galang," the trophy image of the Mullivaikkal massacre by the SLA into a revisionist 'ginger genocide' in "Born Free," and Sestini's eminent photograph of a refugee ship into a refugee sea-cemetery ship in "Borders." Transfiguring images of death (of MIA, make-die and let-die), they epitomise and contest the state's politics of death.

The thanatopolitical sites of M.I.A's presented work lay claims to justice for the dead. The artist is acutely aware of the significance of materiality the limits of discursivity, 403 yet, as Parry admonishes (Chapter 3.4), cultural restitution is necessary for material justice. M.I.A exhumes and reconceptualises Tamil cemeteries as evidence to prosecute the responsible. Centralising political erasure, the cemeterial landscapes activate past and present injustices towards Tamils as sites of witnessing. M.I.A's cemeteries foreground obscured sites of erased graveyards, no fire zones, and borders. Urging a responsibility for the (living) dead, they challenge the state's control over ontology and visibility that renders Tamil lives unlivable and absent. Situated in the Tamil struggle for self-

\footnotetext{
403 Her (now defunct) website's name is informative in that regard (Arulpragasam, 'Yesthelittlepeoplewillneverwinbuttheycanfuckshitup.Com'.)
} 
determination, M.I.A's visual cemeteries iterate a series of unrecognised Tamil historical wounds-the militarisation(s) of Jaffna, the Mullivaikkal massacre, and sea deaths-to restore Tamil memory, mourning, and witnessing. Haunting, by means of recurrence and the recirculation of historical wounds, defies closure and the impunity of the state's politics of death.

Inscribed on murals, stencils, bodies, flags, and textiles, M.I.A's spectres are synechdochal and collective. M.I.A's MIA are politically erased subjects who defy state erasure from a state of absence (as MIA) and who, by iteration, craftily alternate between an individual and a collective Tamil identity. MIA, inscribed into the artist's stage persona, signify Tamils as subjects of erasure and resistance. M.I.A's archival opus reflects a collective Tamil memory and its self-references of MIA read like a manifesto on resistance to state violence. The evoked spectres and cemeteries have a synecdochal (part-whole) relationship, and the individual self (M.I.A) is symbolic of a collective identity (MIA). In other words, M.I.A is a proxy for MIA. M.I.A's individual history is what Jameson (admittedly problematically terms) a national allegory, "where the telling of the individual story [...] cannot but ultimately involve the whole laborious telling of the collectivity itself." 404 As the the spectres of M.I.A are MIA, the title of my study is iterative and self-referential: the 
spectres of M.I.A, the MIA of M.I.A, the MIA of MIA, a Tamil collectivity whose recurring re-exit is a re-entrance.

M.I.A's memory locales, although renarrativising collective Tamil histories, establish affiliative ties with colonial, class, and racial histories of violence. They solidarise with blacks (by means of a black fist animation in "Galang" and the slave ship evocation in "Borders"), Palestinians (by means of a petrol bomber animation in "Galang" and a keffiyeh-wearing petrol bomber in "Born Free"), Muslims (by means of stealth bomber stencils and Muslim women animations in "Galang," the burqa print in the artwork "Born Free," and the evoked Syrian refugee crisis in "Borders"), the Irish (by means of a 'ginger genocide' in "Born Free”), and Brazilian favela dwellers (by means of funk carioca in "Bucky Done Gun”). M.I.A's work resists the occupation of Palestine, the war on terror, and socio-economic marginalisation.

M.I.A's productions implicate the audience as witnesses and agents of state violence. Confronting and engaging the listenership, the lyrical selves demand to be heard ("quieten down") and pose critical questions ("what's up with that?"). The visual implications of the music videos interpellate its spectators as political witnesses or complicit bystanders, dark tourists, so to speak, to expose their apathy regarding the state's obscured thanatopolitics. 
The interpretative intersections between M.I.A/MIA and hauntology is only nascent. While my own study ensconces itself in the spectral Tamilcentric war revisualisations within M.I.A's work, a hauntological lens upon other facets might not only be feasible, but also fecund. The extendibility of hauntology as a framework for future research to decipher M.I.A's productions reaches into the domain of auditive and conceptual strategies. Hauntology indeed paves the way to illuminate M.I.A's soundpolitics. Samples in particular lend themselves to examine the significance of iteration as an underlying tactic in M.I.A's work. Samples as recontextualised sounds are iterations and alterations. Spectres of sorts, they carry memories and express lingering presences of the past. A hauntological reading of M.I.A's use of samples as spectral sounds brings to light another underresearched facet, namely, subaltern politics. However, the importance of grounding the objects of enquiry in their localised histories in these proposed research undertakings cannot be overstated. To quote a specific instance, examining the use of Dalit samples in M.I.A's Kala (2007) buttresses a subaltern reading in specific Indian Tamil Dalit histories. Even though, as I have illustrated, hauntology as a framework underscores the centrality of MIA in M.I.A's work, it also captures the notion of iteration as resistance in more general terms. For instance, M.I.A's album Matangi (2013) can be read to re-interpret Hindu notions of karmic reincarnation as forms of secular and resistive haunting of 'this exodus.' 
In the documentary Matangi / Maya / M.I.A., M.I.A asks, "If you come from the struggle how the fuck can you talk about the struggle without talking about the struggle?" 405 This, I have argued, is what M.I.A's work achieves: to speak of and oppose absence through absence.

405 M.I.A quoted in Loveridge, Matangi / Maya / M.I.A. 


\section{Bibliography}

Abderrezak, Hakim. 'The Mediterranean Seametery and Cementery in Leila Kilani's and Tariq Teguia's Filmic Works'. In Critically Mediterranean: Temporalities, Aesthetics, and Deployments of a Sea in Crisis, edited by yasser elhariry and Edwige Tamalet Talbayev, 147-61. Mediterranean Perspectives. Cham: Springer International Publishing, 2018. https://doi.org/10.1007/978-3-31971764-7_8.

Abraham, Nicolas. 'Notes on the Phantom: A Complement to Freud's Metapsychology'. In The Shell and the Kernel: Renewals of Psychoanalysis, by Nicolas Abraham and Maria Torok, 171-76.

Edited and translated by Nicholas T. Rand. Chicago: University of Chicago Press, 1994.

Agamben, Giorgio. Homo Sacer: Sovereign Power and Bare Life.

Translated by Daniel Heller-Roazen. Homo Sacer 1. Stanford: Stanford University Press, 1998.

Remnants of Auschwitz: The Witness and the Archive. Translated by Daniel Heller-Roazen. New York: Zone Books, 2000.

Aliaga Rodrigo, Esther. 'Painting History: Murals in Northern Ireland'. In

'To Banish Ghost and Goblin': New Essays on Irish Culture, edited by David Clark and Rubén Jarazo Álvarez, 111-22. Oleiros: Netbiblo, 2010.

Alison, Miranda. 'Cogs in the Wheel? Women in the Liberation Tigers of Tamil Eelam'. Civil Wars 6, no. 4 (2003): 37-54. https://doi.org/10.1080/13698240308402554.

Allsop, Jenifer. 'Agent, Victim, Soldier, Son: Intersecting Masculinities in the European "Refugee Crisis." In A Gendered Approach to the Syrian Refugee Crisis, edited by Jane Freedman, Zeynep Kivilcim, and Nurcan Özgür Baklacığlu, 1st ed., 157-58. Abingdon, Oxon: Routledge, 2017. https://doi.org/10.4324/9781315529653.

Anderson, Benedict. Imagined Communities: Reflections on the Origin and Spread of Nationalism. New York: Verso, 2006.

Anderson, Nicole. Derrida: Ethics Under Erasure. Continuum Studies in Continental Philosophy. London; New York: Continuum, 2012. 
Anonymous. '10 Years Later MV Sun Sea's Tamil Refugees Continue to Be Failed by Canada'. Tamil Guardian. Accessed 24 September 2020. https://www.tamilguardian.com/content/10-years-later-mvsun-sea $\%$ E2\%80\%99s-tamil-refugees-continue-be-failedcanada $\% \mathrm{C} 2 \% \mathrm{AO}$.

Appadurai, Arjun. 'Disjuncture and Difference in the Global Cultural Economy'. Theory, Culture \& Society 7, no. 2-3 (June 1990): 295310. https://doi.org/10.1177/026327690007002017.

Arulpragasam, Mathangi. 'M.I.A (@MIAuniverse) on Twitter'. M.I.A. P.O.W.A, 18 May 2016. https://twitter.com/miauniverse.

- _ 'Yesthelittlepeoplewillneverwinbuttheycanfuckshitup.Com', 2010.

https://web.archive.org/web/20101005065114/http://yesthelittlepe oplewillneverwinbuttheycanfuckshitup.com/.

Arulpragasam, Maya. 'Arular'. In M.I.A., 16-18. New York: Rizzoli, 2012.

—_. 'Introduction'. In M.I.A., 13-15. New York: Rizzoli, 2012.

- M.I.A. New York: Rizzoli, 2012.

—_. 'Vicki Leekx'. In M.I.A. New York: Rizzoli, 2012.

Ashworth, Gregory J. 'Holocaust Tourism and Jewish Culture: The Lessons of Krakow-Kazimierz'. In Tourism and Cultural Change, edited by Paul Callaghan, Mike Robinson, and Nigel Evans, 1-12. Tourism and Culture. Newcastle: University of Northumbria, 1996. Assmann, Jan. Moses the Egyptian: The Memory of Egypt in Western Monotheism. Cambridge, Mass: Harvard University Press, 1997.

Atkinson, Meera. The Poetics of Transgenerational Trauma. New York: Bloomsbury Academic, 2017.

Atluri, Tara. “"Like PLO I Don't Surrender”: Genealogies of Feminine "Terror" and the Evils of Orientalist Desire'. In Gender and the Representation of Evil, edited by Lynne Fallwell and Keira V. Williams, 177-96. Routledge Research in Gender and History. New York; London: Routledge, 2016.

Auchter, Jessica. The Politics of Haunting and Memory in International Relations. Interventions. London; New York: Routledge, 2014.

Banksy. Wall and Piece. London: Century, 2005.

Bargu, Banu. 'Another Necropolitics'. Theory \& Event 19, no. 1 (2016). Barry, Ellen. 'Postwar Sri Lanka's Awkward Peace'. The New York Times, 
https://www.nytimes.com/2014/12/29/world/postwar-sri-lankasawkward-peace.html.

Barthes, Roland. Camera Lucida: Reflections on Photography. New York: Hill and Wang, 1981.

Baucom, Ian. 'Specters of the Atlantic'. South Atlantic Quarterly100, no. 1 (2001): 61-82. https://doi.org/10.1215/00382876-100-1-61.

Bazin, André. 'The Ontology of the Photographic Image'. Translated by Hugh Gray. Film Quarterly 13, no. 4 (July 1960): 4-9. https://doi.org/10.2307/1210183.

Bergoffen, Debra B. Contesting the Politics of Genocidal Rape: Affirming the Dignity of the Vulnerable Body. New York: Routledge, 2013.

Betts, Alexander, and Paul Collier. Refuge: Rethinking Refugee Policy in a Changing World. New York: Oxford University Press, 2017.

Bevernage, Berber, and Koen Aerts. 'Haunting Pasts: Time and Historicity as Constructed by the Argentine Madres de Plaza de Mayo and Radical Flemish Nationalists'. Social History 34, no. 4 (November 2009): 391-408. https://doi.org/10.1080/03071020903256986.

Bhabha, Homi. 'DissemiNation'. In The Location of Culture, 199-244. London; New York: Routledge, 2004.

. 'Of Mimicry and Man: The Ambivalence of Colonial Discourse'. In The Location of Culture, edited by Homi Bhabha, 121-31. London: Routledge, 2004.

Binelli, Mark. 'M.I.A: Guerilla Goddess'. Rolling Stone, 29 December 2005. https://www.rollingstone.com/music/music-news/m-i-aguerilla-goddess-73924/.

Blanco, María del Pilar, and Esther Peeren. 'Introduction: Conceptualizing Spectralities'. In The Spectralities Reader: Ghosts and Haunting in Contemporary Cultural Theory, 1-28. New York: Bloomsbury Academic, 2013.

Bradimore, Ashley, and Harald Bauder. 'Mystery Ships and Risky Boat People: Tamil Refugee Migration in the Newsprint Media'. Canadian Journal of Communication 36, no. 4 (2011): 637-61.

Brathwaite, Kamau. Third World Poems. Harlow: Longman, 1991.

Breihan, Tom. 'M.I.A. and the Double Standard of MTV Censorship'. The $\begin{array}{llll}\text { Village } & \text { Voice, } & 18 & \text { December }\end{array}$ https://www.villagevoice.com/2007/12/18/m-i-a-and-the-doublestandard-of-mtv-censorship/. 
BritDoc. 'Musician MIA on No Fire Zone'. BritDoc Impact Award, n.d. https://docimpacthi5.org/films/nofirezone.

Buncombe, Andrew. 'Video That Reveals Truth of Sri Lankan "War Crimes". The Independent, 27 August 2009. http://www.independent.co.uk/news/world/asia/video-thatreveals-truth-of-sri-lankan-war-crimes-1777746.html.

Buse, Peter, and Andrew Stott. 'Introduction: A Future for Haunting'. In Ghosts: Deconstruction, Psychoanalysis, History, edited by Peter Buse and Andrew Stott, 1-20. Basingstoke: Palgrave Macmillan, 2002.

Butler, Judith. Frames of War: When Is Life Grievable? London: Verso, 2009.

- Precarious Life: The Powers of Mourning and Violence. London: Verso, 2004.

Butler, Judith, and Athena Athanasiou. Dispossession: The Performative in the Political. Malden, MA: Polity, 2013.

Campbell, Bruce C., and $\mathrm{Bu}$ V. E. Wilson. The Politics of Exclusion: Indonesian Fishing in the Australian Fishing Zone. Perth, W.A.: Indian Ocean Centre for Peace Studies and the Australian Centre for International Agricultural Research, 1993.

Canagarajah, A. Suresh. Translingual Practice: Global Englishes and Cosmopolitan Relations. Milton Park, Abingdon, Oxon; New York: Routledge, 2013.

Carman, John Braisted, and Vasudha Narayanan. The Tamil Veda: Pillān's Interpretation of the Tiruvāymoli. Chicago: University of Chicago Press, 1989.

Carrington, Victoria. 'I Write, Therefore I Am: Texts in the City'. Visual Communication 8, no. 4 (November 2009): 409-25. https://doi.org/10.1177/1470357209343356.

Chakrabarty, Dipesh. 'History and the Politics of Recognition'. In Manifestos for History, edited by Keith Jenkins, Sue Morgan, and Alun Munslow, 77-87. London: Routledge, 2007.

- _ 'Postcoloniality and the Artifice of History: Who Speaks for “Indian” Pasts?' Representations, no. 37 (January 1992): 1-26. https://doi.org/10.2307/2928652. 
Chambers, Iain. 'Heterotopia and the Critical Cut'. In The Globalization of Space: Foucault and Heterotopia, edited by Mariangela Palladino and John Miller, 111-26. London: Pickering \& Chatto, 2015.

Chambers-Letson, Joshua. 'Reparative Feminisms, Repairing FeminismReparation, Postcolonial Violence, and Feminism'. Women \& Performance: A Journal of Feminist Theory 16, no. 2 (July 2006): 169-89. https://doi.org/10.1080/07407700600744287.

Chandrakanthan, A. J. V. 'Eelam Tamil Nationalism: An Inside View'. In Sri Lankan Tamil Nationalism: Its Origins and Development in the Nineteenth and Twentieth Centuries, edited by A. Jeyaratnam Wilson, 157-73. Vancouver: UBC Press, 2000.

Chattopadhyay, Swati. 'Visualizing the Body Politic'. In Making Place: Space and Embodiment in the City, edited by Arijit Sen and Lisa Silverman, 44-68. 21st Century Studies. Bloomington: Indiana University Press, 2014.

Cheran, R. 'Citizen of Many Worlds: Theorizing Tamil DiasporiCity'. In History and Imagination: Tamil Culture in the Global Context, edited by Darshan Ambalavanar and C. Kanaganayakam, 150-68. Toronto: TSAR Publications, 2007.

—_ The Sixth Genre: Memory, History, and the Tamil Diaspora Imagination. A History of Ethnic Conflict in Sri Lanka 7. Colombo: Marga Institute, 2001.

Chia, Robert C. H., and Jannis Kallinikos. 'Epilogue: Interview with Robert Cooper'. In Organized Worlds: Explorations in Technology and Organization with Robert Cooper, 121-65. London; New York: Routledge, 1998.

Chow, Rey. Ethics after Idealism: Theory, Culture, Ethnicity, Reading. Theories of Contemporary Culture 20. Bloomington: Indiana University Press, 1998.

Chriost, Diarmait Mac Giolla. Jailtacht: The Irish Laguage, Symbolic Power and Political Violence in Northern Ireland, 1972-2008. Cardiff: University of Wales Press, 2012.

Clark, Laurie. 'Coming to Terms with Trauma Tourism'. Performance Paradigm 5, no. 2 (October 2009): 1-31.

Clarkson, Thomas. The History of the Rise, Progress and Accomplishment of the Abolition of the African Slave-Trade, by the British 
Parliament (1808): Volume II. Frankfurt am Main: Outlook Verlag, 2018.

Cochrane, Lauren. 'Romain Gavras: Born Free Director Is No Stranger to Stress'. The Guardian, 24 September 2010, sec. Music. https://www.theguardian.com/music/2010/sep/25/romain-gavrasborn-free.

Cole, Matthew. 'Track Review: M.I.A.'s “Born Free”'. Slant, 24 April 2010. https://www.slantmagazine.com/music/track-review-miasborn-free/.

Compton, Wayde, ed. Bluesprint: Black British Columbian Literature and Orature. Vancouver: Arsenal Pulp Press, 2003.

Creech, Brian. 'Refugee Status: Tracing the Global Flows of M.I.A.: Refugee Status'. Communication, Culture \& Critique 7, no. 3 (September 2014): 267-82. https://doi.org/10.1111/cccr.12051.

Cresswell, Tim. 'Towards a Politics of Mobility'. Environment and Planning D: Society and Space 28, no. 1 (February 2010): 17-31. https://doi.org/10.1068/d11407.

Cuder, Eva Gil. 'More than Words: Drama and Spectrality for the Articulation of Trauma'. Journal of English Studies 10, no. 0 (29 May 2012): 65-80. https://doi.org/10.18172/jes.181.

Curtis, L. Perry. Apes and Angels: The Irishman in Victorian Caricature. Washington, D.C.: Smithsonian Institution Press, 1997.

Dabashi, Hamid. Can Non-Europeans Think? London: Zed Books, 2015.

D’Aguiar, Fred. Feeding the Ghosts. London: Granta, 2014.

Davies, Thom, Arshad Isakjee, and Surindar Dhesi. 'Violent Inaction: The Necropolitical Experience of Refugees in Europe'. Antipode 49, no. 5 (2017): 1263-84. https://doi.org/10.1111/anti.12325.

Davis, Colin. 'Hauntology, Spectres and Phantoms'. French Studies 59, no. 3 (1 July 2005): 373-79. https://doi.org/10.1093/fs/kni143.

De Stefani, Lucia. 'A Photographer's Search for the Migrants Shown in This Iconic Image'. Time, 7 October 2015. https://time.com/4063972/refugee-crisis-massimo-sestini/.

Debrix, François. Global Powers of Horror: Security, Politics, and the Body in Pieces. Interventions. London: Routledge, 2017.

Dehaene, Michiel, and Lieven de Cauter. 'Heterotopia in a Postcivil Society'. In Heterotopia and the City: Public Space in a Postcivil Society, 3-10. London: Routledge, 2008. 
DeLoughrey, Elizabeth. 'Routes and Roots: Tidalectics in Caribbean Literature'. In Caribbean Culture: Soundings On Kamau Brathwaite, edited by Annie Paul and Kamau Brathwaite, 163-75. Kingston, Jamaica: University of the West Indies Press, 2007.

DeLoughrey, Elizabeth M. Routes and Roots: Navigating Caribbean and Pacific Island Literatures. Honolulu: University of Hawai'i Press, 2007.

Derrida, Jacques. 'Deconstruction Engaged'. In The Sydney Seminars, 1999.

. 'Différance'. In Literary Theory: An Anthology, edited by Julie Rivkin and Michael Ryan, 2nd ed., 278-99. Malden, Mass.: Blackwell, 2004.

- _. Memoires for Paul de Man. Translated by Cecile Lindsay, Jonathan Culler, and Eduardo Cadava. Revised. The Wellek Library Lectures at the University of California, Irvine. New York: Columbia University Press, 1989.

. Of Grammatology. Translated by Gayatri Chakravorty Spivak. Corrected ed.. Baltimore: Johns Hopkins University Press, 1997.

___ 'Sign, Structure, and Play in Human Sciences'. In The Languages of Criticism and The Sciences of Man: The Struralist Controversy, edited by Richard Macksey and Eugenio Donato, 147-64. Baltimore: Johns Hopkins Press, 1970.

- - Specters of Marx: The State of the Debt, The Work of Mourning and the New International. Translated by Peggy Kamuf. New York: Routledge, 2006.

- - 'Spectrographies'. In Echographies of Television: Filmed Interviews, edited by Bernard Stiegler, 113-34. Cambridge, UK: Polity Press, 2002.

___ Speech and Phenomena: And Other Essays on Husserl's Theory of Signs. Northwestern University Studies in Phenomenology \& Existential Philosophy. Evanston: Northwestern University Press, 1973.

Deutscher, Penelope. Foucault's Futures: A Critique of Reproductive Reason. Critical Life Studies. New York: Columbia University Press, 2017.

DeVotta, Neil. 'Ethnolinguistic Nationalism and Ethnic Conflict in Sri Lanka'. In Fighting Words: Language Policy and Ethnic Relations 
in Asia, edited by Michael Edward Brown and Šumit Ganguly, 10539. Cambridge, London: MIT Press, 2003.

Diack, Heather. 'Clouded Judgment: Conceptual Art, Photography and the Discourse of Doubt'. In Photography and Doubt, edited by Sabine T. Kriebel and Andrés Mario Zervigón. London: Routledge, 2016.

Dillon, Michael. Biopolitics of Security: A Political Analytic of Finitude. London: Routledge, 2015.

Dubois, Philippe. L'Acte photographique et autres essais. Collection Nathan-Université Série 'Cinéma et image'. Paris: Nathan, 1992.

Dubow, Jessica, and Ruth Rosengarten. 'History as the Main Complaint: William Kentridge and the Making of Post-apartheid South Africa'. Art History 27, no. 4 (2004): 695-96. https://doi.org/10.1111/j.01416790.2004.444_10_10.x.

Dubreuil, Laurent. 'The Presences of Deconstruction'. New Literary History 37, no. 1 (2006): 107-17.

Eckstein, Lars. 'Sound Matters: Postcolonial Critique for a Viral Age'. Atlantic Studies 13, no. 4 (October 2016): 445-56. https://doi.org/10.1080/14788810.2016.1216222.

Edkins, Jenny. 'Missing Migrants and the Politics of Naming: Names Without Bodies, Bodies Without Names'. Social Research 83, no. 2 (Summer 2016): 359-89, 535.

Ellis, Eric. 'The Smugglers' Prey'. The Global Mail, n.d. https://markfinger.github.io/recent-work/sri-lanka/smugglersprey.html.

Emig, Rainer. 'Missing in Act(i)on: Asian-British Pop Music Between Resistance and Commercialization'. In Word \& Image: In Colonial and Postcolonial Literatures and Cultures, edited by Michael Meyer, 261-78. Cross/Cultures 116. Amsterdam: Rodopi, 2009.

Eriksen, Thomas Hylland. 'Some Questions about Flags'. In Flag, Nation and Symbolism in Europe and America, edited by Thomas Hylland Eriksen and Richard Jenkins, 1-13. London: Routledge, 2007.

Falk, Francesca. 'Invasion, Infection, Invisibility: An Iconology of Illegalized Immigration'. In Images of Illegalized Immigration: Towards a Critical Iconology of Politics, edited by Christine Bischoff, Francesca Falk, and Sylvia Kafehsy, 83-100. Bielefeld: 
Transcript, 2010

http://public.eblib.com/choice/publicfullrecord.aspx?p=1914779.

Feeney, Nolan. 'Why M.I.A. Put Her “Borders” Video on Apple Music'.

Time, 24 December 2015. https://time.com/4160294/mia-bordersapple-music-migrant-crisis-interview/.

Finley, Cheryl. Committed to Memory: The Art of the Slave Ship Icon. Princeton: Princeton University Press, 2018.

Fleischer, Ruben. 'The 50 Best Music Videos of the Aughts'. Slant $\begin{array}{llll}\text { Magazine, } & 20 & \text { January }\end{array}$ https://www.slantmagazine.com/music/best-of-the-aughts-musicvideos/.

Fogg, Ally. 'Gingerism Is Real, but Not All Prejudices Are Equal to One Another'. The Guardian, 15 January 2013, sec. Opinion. https://www.theguardian.com/commentisfree/2013/jan/15/ginger ism-prejudice-bullying.

Foucault, Michel. 'La Naissance de La Médecine Sociale'. Revistacentroamericana de Ciencias de La Salud 6 (January 1977): 89-108.

—_. 'Of Other Spaces'. Translated by Jay Miskowiec. Diacritics 16, no. 1 (1986): 22-27. https://doi.org/10.2307/464648.

- _ 'Society Must Be Defended': Lectures at the Collège de France, 1975-1976. Edited by Mauro Bertani, Alessandro Fontana, and François Ewald. Translated by David Macey. 1st ed. New York: Picador, 2003.

Fraser, Nancy, and Axel Honneth. Redistribution or Recognition?: A Political-Philosophical Exchange. London: Verso, 2003.

Fuglerud, Øivind. 'Aesthetics of Martyrdom: The Celebration of Violent Death among the Liberation Tigers of Tamil Eelam'. In Violence Expressed: An Anthropological Approach, edited by Maria SixHohenbalken and Nerina Weiss, 71-88. Farnham: Ashgate, 2011.

Ganeshananthan, V. V. Love Marriage. London: Phoenix, 2009.

Gelder, Hilde van, and Helen Westgeest. Photography Theory in Historical Perspective. Chichester: Wiley-Blackwell, 2011.

Gerassi-Navarro, Nina. Pirate Novels: Fictions of Nation Building in Spanish America. Durham: Duke University Press, 1999. 
Gere, Charlie. 'The Hauntology of the Digital Image'. In A Companion to Digital Art, edited by Christiane Paul, 203-25. Malden, MA: Wiley Blackwell, 2016.

Gerstle, Gary. 'Liberty, Coercion, and the Making of Americans'. The Journal of American History 84, no. 2 (September 1997): 524-58. https://doi.org/10.2307/2952569.

Gibsone, Harriet. 'MIA's Borders: Artist Braves Boats and Barbed Wire in Video Crusade for Refugees'. The Guardian, 27 November 2015, sec.

Music. https://www.theguardian.com/music/2015/nov/27/mia-bordersvideo-refugee-crisis-europe.

Gilroy, Paul. The Black Atlantic: Modernity and Double Consciousness. London: Verso, 1993.

Goodman, Amy. 'M.I.A. Responds to French Soccer Team Demanding Takedown of “Borders” Video About Refugees'. Democracy Now!, 12 January 2016. http://www.democracynow.org/2016/1/12/exclusive_mia_respond s_to_french_soccer.

Goodman, Lizzy. 'M.I.A.: The Permanent Revolution of Pop's Most Fascinating Radical'. Rolling Stone, 11 August 2016. https://www.rollingstone.com/music/music-features/m-i-a-thepermanent-revolution-of-pops-most-fascinating-radical-248355/.

Grant, Trevor. Sri Lanka's Secrets: How the Rajapaksa Regime Gets Away With Murder. Clayton: Monash University Publishing, 2014.

Haddad, Candice. 'Immigration, Authorship, Censorship, and Terrorism: The Politics of M.I.A.'s US Crossover'. In In the Limelight and Under the Microscope: Forms and Functions of Female Celebrity, edited by Diane Negra and Su Holmes, 280-302. London: Bloomsbury, 2011.

Haddow, Douglas. 'The Real Controversy of MIA's Video'. The Guardian, 1 May 2010, sec. Opinion. https://www.theguardian.com/commentisfree/2010/may/01/miavideo-real-controversy.

Hall, Stuart. 'Cultural Identity and Diaspora'. In Identity: Community, Culture, Difference, edited by Jonathan Rutherford. London: Lawrence \& Wishart, 1990. 
Hardt, Michael, and Antonio Negri. Empire. Cambridge, Mass.: Harvard University Press, 2000.

Harris, Malcolm. 'Don't Call Me Ginger'. Al Jazeera America, 13 July 2014. http://america.aljazeera.com/opinions/2014/7/don-t-call-meginger.html.

Harrison, Frances. "Journalists Failed to Tell the Story of War Crimes in Sri Lanka”. Journalism, $17 \quad$ May 2012. https://www.journalism.co.uk/news-commentary/francesharrison-sri-lanka-journalists-failed-to-tell-the-story-of-warcrimes/s6/a549285/.

—_ Still Counting the Dead: Survivors of Sri Lanka's Hidden War. London: Portobello, 2012.

Haziza, Natalie. 'Under Erasure: William Kentridge, Derrida, and PostApartheid South Africa'. Studies in Gender and Sexuality 19, no. 2 (2018): 133-44. https://doi.org/10.1080/15240657.2018.1456019.

Hellmann-Rajanayagam, Dagmar. 'And Heroes Die: Poetry of the Tamil Liberation Movement in Northern Sri Lanka'. South Asia: Journal of South Asian Studies 28, no. 1 (2005): 112-53. https://doi.org/10.1080/00856400500056236.

—_ 'Female Warriors, Martyrs and Suicide Attackers: Women in the LTTE'. International Review of Modern Sociology 34, no. 1 (2008): $1-25$.

Hellmann-Rajanayagam, Dagmar. 'Tamils and the Meaning of History'. Contemporary South Asia 3, no. 1 (1994): 3-23. https://doi.org/10.1080/09584939408719724.

Hellmann-Rajanayagam, Dagmar. 'The "Groups" and the Rise of Militant Secessionism'. In The Sri Lankan Tamils: Ethnicity and Identity, edited by Chelvadurai Manogaran and Bryan Pfaffenberger, 169207. London: $\quad 2019$. https://public.ebookcentral.proquest.com/choice/publicfullrecord .aspx?p=5789326.

- - 'The Politics of the Tamil Past'. In Sri Lanka: History and the Roots of Conflict, edited by Jonathan Spencer, 107-24. New York: Routledge, 1990.

- - The Tamil Tigers: Armed Struggle for Identity. Beiträge Zur Südasienforschung, Band 157. Stuttgart: F. Steiner, 1994. 
Henderson, Eric. 'Music Video: M.I.A.'s “Born Free”'. Slant, 29 April 2010. https://www.slantmagazine.com/music/music-video-miasborn-free/.

Hermes, Will. 'Artist of the Year: M.I.A.: The Sri Lankan-Born, LondonBred MC with the Freshest Playground Sound Around'. SPIN, January 2006.

Hesse, Barnor. 'Introduction: Un/Settled Multiculturalisms'. In Un/Settled Multiculturalisms: Diasporas, Entanglement, Transruptions, edited by Barnor Hesse, 1-30. London: Zed, 2000.

Hirsch, Marianne. 'Surviving Images: Holocaust Photographs and the Work of Postmemory'. The Yale Journal of Criticism 14, no. 1 (1 April 2001): 5-37. https://doi.org/10.1353/yale.2001.0008.

Hitchcock, Peter. Imaginary States: Studies in Cultural Transnationalism. Transnational Cultural Studies. Urbana: University of Illinois, 2003. hooks, bell. 'The Oppositional Gaze: Black Female Spectators'. In Feminist Postcolonial Theory: A Reader, edited by Reina Lewis and Sara Mills, 207-21. Hoboken, N.J.: Taylor and Francis, 2003. https://public.ebookcentral.proquest.com/choice/publicfullrecord .aspx?p=1144713.

Hoole, Rajan, and Daya Sosasundaram, eds. The Broken Palmyra: The Tamil Crisis in Sri Lanka: An Inside Account. Claremont, Calif.: Sri Lanka Studies Institute, 1992. https://web.archive.org/web/20201003021442/http://uthr.org/BP /Content.htm.

Hova, Tray. 'M.I.A. Producer: "Born Free" Video Started As Joke; New Album Will "Scare People". Vibe, 28 April 2010. https://www.vibe.com/2010/04/mia-producer-born-free-videostarted-joke-new-album-will-scare-people.

Howze, Russell. Stencil Nation: Graffiti, Community, and Art. San Francisco: Manic D Press, 2008.

Hudson, Martyn. The Slave Ship, Memory and the Origin of Modernity. London: Routledge, 2017.

Hutnyk, John. Pantomime Terror: Music and Politics. Winchester: Zero Books, 2014.

——_ 'Poetry after Guantanamo: M.I.A'. Social Identities 18, no. 5 (1 September 2012): 555-72. https://doi.org/10.1080/13504630.2012.692893. 
Infante, Ignacio. After Translation: The Transfer and Circulation of Modern Poetics Across the Atlantic. New York: Fordham UP, 2013.

Jakob, Joey Brooke. 'Beyond Abu Ghraib: War Trophy Photography and Commemorative Violence'. Media, War \& Conflict 10, no. 1 (1 April 2017): 87-104. https://doi.org/10.1177/1750635216636136.

Jameson, Frederic. 'Marx's Purloined Letter'. In Ghostly Demarcations: $A$ Symposium on Jacques Derrida's Specters of Marx, edited by Michael Sprinker, 26-67. Radical Thinkers 33. London: Verso, 2008.

Jazeel, Tariq. Sacred Modernity: Nature, Environment and the Postcolonial Geographies of Sri Lankan Nationhood. Postcolonialism across the Disciplines 12. Liverpool: Liverpool University Press, 2013.

Jemima, Repo. 'Thanatopolitics or Biopolitics? Diagnosing the Racial and Sexual Politics of the European Far Right'. Contemporary Political Theory15, no. 1 (2016): 110-18.

Johnson, Peter. 'The Geographies of Heterotopia': Geography Compass 7, no. 11 (November 2013): 790-803. https://doi.org/10.1111/gec3.12079.

___ 'Unravelling Foucault's "Different Spaces"'. History of the Human Sciences 19, no. 4 (November 2006): 75-90. https://doi.org/10.1177/0952695106069669.

Jones, Demelza. Superdiverse Diaspora: Everyday Identifications of Tamil Migrants in Britain. Cham: Palgrave Macmillan, 2020. https://doi.org/10.1007/978-3-030-28388-9.

Jones, Rhys Dafydd, James Robinson, and Jennifer Turner. 'Introduction: Between Absence and Presence: Geographies of Hiding, Invisibility and Silence'. Space and Polity 16, no. 3 (December 2012): 257-63. https://doi.org/10.1080/13562576.2012.733567.

Kanaganayakam, Chelva. 'Configuring Spaces and Constructing Nations in Sri Lankan Tamil Literature'. In Pathways of Dissent: Tamil Nationalism in Sri Lanka, edited by R. Cheran, 83-92. New Delhi: SAGE, 2009.

Kandasamy, Niro. 'Home, Continuities and Resistance: Memory Activism in the Aftermath of Sri Lanka's Civil War'. In A Sense of Viidu: The (Re)Creation of Home by the Sri Lankan Tamil Diaspora in 
Australia, edited by Niro Kandasamy, Nirukshi Perera, and Charishma Ratnam, 53-69. Singapore: Springer, 2020.

Kingsbury, Damien. Sri Lanka and the Responsibility to Protect: Politics, Ethnicity and Genocide. Milton Park: Routledge, 2012.

Knuth, Rebecca. Burning Books and Leveling Libraries: Extremist Violence and Cultural Destruction. Westport, Conn: Praeger, 2006.

Kornhaber, Spencer. 'The Rapper of Refugees: What's M.I.A.'s “Borders” Video Really About?' The Atlantic, 30 November 2015. https://www.theatlantic.com/entertainment/archive/2015/11/miaborders-video-refugees-migration-appropriation/418017/.

Kössler, Reinhard. Namibia and Germany: Negotiating the Past. Windhoek, Namibia: University of Namibia Press, 2015.

Kouremenos, Anna, and Laura Dierksmeier. 'Teaching Insularity: Archaeological and Historical Perspectives'. Shima 14, no. 1 (January 2020): 284-97. https://doi.org/10.21463/shima.14.1.18.

Kumarakulasingam, Narendran. 'Bloody Translations: The Politics of International Compassion and Horror'. Journal of Narrative Politics 1, no. 1 (2014): 61-75.

Kurian, Alka. Narratives of Gendered Dissent in South Asian Cinemas. New York: Routledge, 2012.

Laouyene, Atef. 'Canadian Gothic and the Work of Ghosting in AnnMarie MacDonald's Fall on Your Knees'. In Unsettled Remains: Canadian Literature and the Postcolonial Gothic, edited by Gerry Turcotte and Cynthia Conchita Sugars, 125-54. Waterloo, Ontario: Wilfrid Laurier University Press, 2009.

Laub, Dori. 'An Event without a Witness: Truth, Testimony, and Survival'. In Testimony: Crises of Witnessing in Literature, Psychoanalysis, and History, edited by Shoshana Felman, 75-92. New York: Routledge, 1991.

. 'Bearing Witness, or the Vicissitudes of Listening'. In Testimony: Crises of Witnessing in Literature, Psychoanalysis, and History, edited by Shoshana Felman, 57-74. New York: Routledge, 1991.

Leeder, Murray. 'Introduction'. In Cinematic Ghosts: Haunting and Spectrality from Silent Cinema to the Digital Era,1-14. New York: Bloomsbury Academic, 2015. 
Lévinas, Emmanuel. Emmanuel Levinas: Basic Philosophical Writings. Edited by Adriaan Theodoor Peperzak, Simon Critchley, and Robert Bernasconi. Studies in Continental Thought. Bloomington: Indiana University Press, 1996.

Linebaugh, Peter, and Marcus Rediker. The Many-Headed Hydra: Sailors, Slaves, Commoners, and the Hidden History of the Revolutionary Atlantic. Boston: Beacon Press, 2000.

Loveridge, Steve. 'Foreword'. In M.I.A, Hardcover ed., 6-11. New York: Rizzoli International Publications, 2012.

—_. Matangi / Maya / M.I.A. Color, NTSC, Widescreen, Documentary. Giant Interactive, 2018.

Luckhurst, Roger. "“Something Tremendous, Something Elemental”: On the Ghostly Origins of Psychoanalysis'. In Ghosts: Deconstruction, Psychoanalysis, History, edited by Peter Buse and Andrew Stott, 50-71. Basingstoke: Palgrave Macmillan, 2002.

- - 'The Contemporary London Gothic and the Limits of the “Spectral Turn"'. Textual Practice 16, no. 3 (January 2002): 52746. https://doi.org/10.1080/09502360210163336.

Mackey, Nathaniel. Paracritical Hinge: Essay, Talks, Notes, Interviews. Contemporary North American Poetry. Madison, Wis: University of Wisconsin Press, 2005.

Mackey, Robert. 'Outside Sri Lanka, Tamil Diaspora Not Ready to Surrender'. The Lede, 18 May 2009. https://thelede.blogs.nytimes.com/2009/05/18/outside-sri-lankatamil-diaspora-not-ready-to-surrender/.

Macrae, Callum. No Fire Zone: The Killing Fields of Sri Lanka. CinePhil, 2013.

- _ 'Sri Lanka Massacred Tens of Thousands of Tamils While the World Looked Away'. Vice, 5 August 2015. https://www.vice.com/en_uk/article/kwxz4m/death-of-a-tiger$0000710-\mathrm{v} 22 \mathrm{n} 8$.

—_. Sri Lanka's Killing Fields. ITN Productions, 2011.

—_. Sri Lanka's Killing Fields: War Crimes Unpunished. ITN Productions, 2012.

Maier, Carla J. Transcultural Sound Practices: British Asian Dance Music as Cultural Transformation. London: Bloomsbury, 2020. 
Malkki, Liisa. 'Speechless Emissaries: Refugees, Humanitarianism and Dehistoricization'. In Siting Culture: The Shifting Anthropological Object, edited by Karen Fog Olwig and Kirsten Hastrup, 227-58. London: Routledge, 1997.

Mamdani, Mahmood. 'The Truth According to the TRC'. In The Politics of Memory: Truth, Healing and Social Justice, edited by Ifi Amadiume and 'Abd Allāh Aḥmad Na'īm. London: Zed Books, 2000.

Manderson, Desmond. Danse Macabre: Temporalities of Law in the Visual Arts. Cambridge: Cambridge University Press, 2019.

Manogaran, Chelvadurai. 'Colonization as Politics: Political Use of Space in Sri Lanka's Ethnic Conflict'. In The Sri Lankan Tamils: Ethnicity and Identity, edited by Chelvadurai Manogaran and Bryan Pfaffenberger, 84-125. London: Routledge, 2019. https://public.ebookcentral.proquest.com/choice/publicfullrecord $. \operatorname{aspx} ? \mathrm{p}=5789326$.

Marway, Herjeet. 'Scandalous Subwomen and Sublime Superwomen: Exploring Portrayals of Female Suicide Bombers' Agency'. Journal of Global Ethics 7, no. 3 (2011): 221-40. https://doi.org/10.1080/17449626.2011.635677.

Mattick, Paul. 'The Andy Warhol of Philosophy and the Philosophy of Andy Warhol'. Critical Inquiry 24, no. 4 (July 1998): 965-87. https://doi.org/10.1086/448903.

Mbembe, A. 'Necropolitics'. Public Culture 15, no. 1 (1 January 2003): 1140. https://doi.org/10.1215/08992363-15-1-11.

Mbembe, Achille. On the Postcolony. Studies on the History of Society and Culture 41. Berkeley: University of California Press, 2001.

McDowell, Chris. A Tamil Asylum Diaspora: Sri Lankan Migration, Settlement and Politics in Switzerland. Vol. 1. Refugee and Forced Migration Studies. Providence: Berghahn Books, 1996.

McDowell, Sara. 'Symbolic Warfare in the Ethnocratic State: Conceptualising Memorialisation and Territoriality in Sri Lanka'. Terrorism and Political Violence 24, no. 1 (January 2012): 22-37. https://doi.org/10.1080/09546553.2011.598196.

McGonegal, Julie. Imagining Justice: The Politics of Postcolonial Forgiveness and Reconciliation. Montreal: McGill-Queen's University Press, 2009. 
McKinney, Kelsey. 'The Great Irony of M.I.A.'s New Refugee-Centric Music Video'. Splinter, 12 December 2017. https://splinternews.com/the-great-irony-of-m-i-a-s-new-refugeecentric-music-vi-1793853294.

McMullen, Ken. Ghost Dance. The Other Cinema, 1983. https://www.youtube.com/watch?v=0nmu3uwqzbI.

McVeigh, Robbie. 'Nick, Nack, Paddywhack: Anti-Irish Racism and the Racialization of Irishnes'. In Racism and Anti-Racism in Ireland, edited by Ronit Lențin and Robbie McVeigh, 136-52. Belfast: Beyond the Pale, 2002.

'M.I.A. Arular. XL/Interscope'. SPIN, January 2006.

Michelsen, Nicholas. Politics and Suicide. Interventions. Abingdon, Oxon: Routledge, 2016.

Mohanty, Chandra Talpade. 'Under Western Eyes: Feminist Scholarschip and Colonial Discourses'. In Feminist Postcolonial Theory: A Reader, edited by Reina Lewis and Sara Mills, 49-74. Hoboken, N.J.: Taylor and 2003. https://public.ebookcentral.proquest.com/choice/publicfullrecord .aspx?p=1144713.

Montgomery, James. 'M.I.A. Releases Brutally Graphic Video For "Born Free". $\quad M T V \quad$ News, $26 \quad$ April 2010. http://www.mtv.com/news/1637769/mia-releases-brutallygraphic-video-for-born-free/.

Moore, Alexandra S., and Samantha Pinto. 'Beyond Sovereignty: New Cultural Imaginaries of Human Rights'. In Writing Beyond the State: Post-Sovereign Approaches to Human Rights in Literary Studies, edited by Alexandra S. Moore and Samantha Pinto, 1-18. Palgrave Studies in Literature, Culture and Human Rights. Cham: Springer International Publishing, 2020. https://doi.org/10.1007/978-3-030-34456-6_1.

Morton, Stephen. 'Postcolonialism and Spectrality: Political Deferral and Ethical Singularity in the Writing of Gayatri Chakravorty Spivak'. Interventions 1, no. 4 (January 1999): 605-20. https://doi.org/10.1080/13698019900510851.

Mugan, Chris. 'Mia: Learning to Speak Guerrilla Language'. The Independent, 1 October 2004. http://www.independent.co.uk/arts- 
entertainment/music/features/mia-learning-to-speak-guerrillalanguage-8691894.html.

Müller, Friedrich Max. Anthropological Religion: The Gifford Lectures Delivered Before the University of Glasgow in 1891. London: Longmans, Green, and Co., 1892.

Murari, S. The Prabhakaran Saga: The Rise and Fall of an Eelam Warrior. New Delhi: Sage Publications India, 2012.

Murray, Stuart J. 'Thanatopolitics: Reading in Agamben a Rejoinder to Biopolitical Life'. Communication and Critical/Cultural Studies 5, no. 2 (June 2008): 203-7. https://doi.org/10.1080/14791420802024350.

Nair, Sreenath. Restoration of Breath. Consciousness and Performance. Consciousness, Literature \& the Arts 9. Amsterdam: Rodopi, 2007. Nand, Ashlene. 'MIA Madness with Ashlene Nand! \#Flashback'. Brown By Ashlene (blog), $25 \quad$ July 2012. https://brownbyashlene.blogspot.com/2012/07/mia-madnesswith-ashlene-nand-flashback.html.

Nayar, Pramod K. Human Rights and Literature: Writing Rights. New York: Palgrave Macmillan, 2016.

Newman, Michael. 'Suffering from Reminiscences'. In Postmodernism and the Re-Reading of Modernity, edited by Francis Barker, Peter Hulme, and Margaret Iversen, 84-114. Essex Symposia, Literature, Politics, Theory. Manchester: Manchester University Press, 1992.

Nora, Pierre. 'Between Memory and History: Les Lieux de Mémoire'. Representations, no. 26 (April 1989): 7-24. https://doi.org/10.2307/2928520.

Office of the High Commissioner for Human Rights. Report of the OHCHR Investigation on Sri Lanka (OISL). Geneva, 2015.

Orlov, Piotr. 'Interview with M.I.A. from Arthur No. 16 (May 2005)'. $\begin{array}{lllll}\text { Arthur } & \text { Magazine, } & 11 & \text { February }\end{array}$ https://arthurmag.com/2007/02/11/interview-with-mia-fromarthur-magazine/.

O'Rourke, Lindsey A. 'What's Special about Female Suicide Terrorism?' Security Studies 18, no. 4 (2009): 681-718. https://doi.org/10.1080/09636410903369084.

Osundare, Niyi. 'The Atlantic Is a Bowl of Water'. In Atlantic CrossCurrents: Transatlantiques, edited by Susan Z. Andrade, Eileen 
Julien, Micheline Rice-Maximin, and Aliko Songolo, xiii-xv. Trenton, NJ: Africa World Press, 2001.

Parris, Matthew. 'Absolute Power Corrupts One's Dress Sense Absolutely'. The Spectator 317, no. 9551 (2011): 37.

Parry, Benita. Postcolonial Studies: A Materialist Critique. Postcolonial Literatures. London: Routledge, 2004.

—_. 'Reconciliation and Remembrance'. Pretexts 5, no. 1-2 (1995): 84-96.

Perera, Sasanka. Warzone Tourism in Sri Lanka: Tales from Darker Places in Paradise. New Delhi: SAGE, 2016.

Perera, Suvendrini. Australia and the Insular Imagination: Beaches, Borders, Boats, and Bodies. 1st ed. New York: Palgrave Macmillan, 2009.

——. 'Missing in Action: By All Media Necessary'. Borderlands EJournal 11, no. 1 (2012): 81-100.

-_ 'Oceanic Corpo-Graphies, Refugee Bodies and the Making and Unmaking of Waters'. Feminist Review, no. 103 (2013): 58-79.

- ' 'Visibility, Atrocity and the Subject of Postcolonial Justice'. Borderlands 14, no. 1 (2015): 1-27.

Pfaffenberger, Bryan. 'Introduction: The Sri Lankan Tamils'. In The Sri Lankan Tamils: Ethnicity and Identity, edited by Chelvadurai Manogaran and Bryan Pfaffenberger, 1-27. London: Routledge, 2019.

https://public.ebookcentral.proquest.com/choice/publicfullrecord $. \operatorname{aspx} ? \mathrm{p}=5789326$.

—_ 'The Political Construction of Defensive Nationalism: The 1968 Temple Entry Crisis in Sri Lanka'. In The Sri Lankan Tamils: Ethnicity and Identity, edited by Chelvadurai Manogaran and Bryan Pfaffenberger, 143-62. London: Routledge, 2019. https://public.ebookcentral.proquest.com/choice/publicfullrecord .aspx? $\mathrm{p}=5789326$.

Phillips, Lior. 'People Forget I'm Many Things: M.I.A. on Identity, Politics, and Being Understood'. Consequence of Sound, 9 September 2016. https://consequenceofsound.net/2016/09/people-forget-im-manythings-m-i-a-on-identity-politics-and-being-understood/. 
Policante, Amedeo. The Pirate Myth: Genealogies of an Imperial Concept. Law and the Postcolonial: Ethics, Politics, \& Economy. Milton Park: Routledge, 2015.

Ponnambalam, Satchi. Sri Lanka: National Conflict and the Tamil Liberation Struggle. Thornton Heath, Surrey: Tamil Information Centre, 1983.

Proctor, Robert, and Londa L. Schiebinger. Agnotology: The Making and Unmaking of Ignorance. Stanford: Stanford University Press, 2008. Pugliese, Joseph. 'Assimilation, Unspeakable Traces, and the Ontologies of Nation'. In Asian \& Pacific Inscriptions: Identities, Ethnicities, Nationalities, edited by Suvendrini Perera. Bundoora, Vic., Australia: Meridian, 1995.

—_. "Super Visum Corporis": Visuality, Race, Narrativity and the Body of Forensic Pathology'. Law and Literature 14, no. 2 (July 2002): 367-96. https://doi.org/10.1525/lal.2002.14.2.367.

Radburn, Nicholas, and David Eltis. 'Visualizing the Middle Passage: The Brooks and the Reality of Ship Crowding in the Transatlantic Slave Trade'. The Journal of Interdisciplinary History 49, no. 4 (2019): 533-65. https://doi.org/10.1162/jinh_a_01337.

Rajaram, Prem Kumar, and Carl Grundy-Warr. 'Introduction'. In Borderscapes: Hidden Geographies and Politics at Territory's Edge, edited by Prem Kumar Rajaram and Carl Grundy-Warr, 29:ix-xl. Borderlines. Minneapolis; London: University of Minnesota Press, 2007.

Ramesh, Randeep. 'MIA Accused of Supporting Terrorism by Speaking out for Tamil Tigers'. The Guardian, 11 February 2009, sec. Music. http://www.theguardian.com/music/2009/feb/11/mia-sri-lankatamil-tigers.

Ranganathan, Maya. Eelam Online: The Tamil Diaspora and War in Sri Lanka. Newcastle upon Tyne: Cambridge Scholars, 2010.

Rediker, Marcus. The Slave Ship: A Human History. New York: Viking, 2007.

Reed, S. Alexander. Assimilate: A Critical History of Industrial Music. Oxford, New York: Oxford University Press, 2013.

Roberts, Michael. 'Pragmatic Action and Enchanted Worlds: A Black Tiger Rite of Commemoration'. Social Analysis: The International Journal of Cultural and Social Practice 50, no. 1 (2006): 73-102. 
Robson, Daniel. 'A Globalist Rapper Pauses for Breath'. The Japan Times Online, 5 October 2007. http://archive.is/Qqx0.

Roediger, David R. The Wages of Whiteness: Race and the Making of the American Working Class. Revised. The Haymarket Series. London, New York: Verso, 2007.

Rollefson, J. Griffith. Flip the Script: European Hip Hop and the Politics of Postcoloniality. Chicago Studies in Ethnomusicology. Chicago: University of Chicago Press, 2017.

Roof, Judith. Reproductions of Reproduction. New York: Routledge, 1996.

Salgado, Minoli. 'Writing Sri Lanka, Reading Resistance: Shyam Selvadurai's Funny Boy and A. Sivanandan's When Memory Dies'. Journal of Commonwealth Literature 39, no. 1 (2004): 5-18. https://doi.org/10.1177/002198904043283.

Sangarasivam, Yamuna. 'Militarizing the Femine Body: Women's Participation in the Tamil Nationalist Struggle'. In Violence and the Body: Race, Gender, and the State, edited by Arturo J. Aldama, 59-76. Bloomington: Indiana University Press, 2003.

Sartre, Jean-Paul. Being and Nothingness: An Essay in Phenomenological Ontology. Translated by Hazel Estella Barnes. New York: Citadel Press, 2001.

Sawyer, Miranda. 'MIA: "I'm Here for the People". The Guardian, 12 June 2010, sec. Music. https://www.theguardian.com/music/2010/jun/13/mia-featuremiranda-sawyer.

Schalk, Peter. 'Historisation of the Martial Ideology of the Liberation Tigers of Tamil Ealam (LTTE)'. South Asia: Journal of South Asian Studies 20, no. 2 (December 1997): 35-72. https://doi.org/10.1080/00856409708723295.

___. 'Ilattamils' Defying GoSL's Disenfranchisement Of Mourning After May 2009'. Colombo Telegraph, 3 July 2015. https://www.colombotelegraph.com/index.php/ilattamilsdefying-gosls-disenfranchisement-of-mourning-after-may-2009/.

Seaton, A. V. 'Guided by the Dark: From Thanatopsis to Thanatourism'. International Journal of Heritage Studies 2, no. 4 (1996): 234-44.

Sedgwick, Peter. Descartes to Derrida: An Introduction to European Philosophy. Malden, MA: Blackwell, 2001. 
Sekula, Allan. 'On the Invention of Photographic Meaning'. In Thinking Photography, edited by Victor Burgin, 84-109. Communications and Culture. London: Macmillan, 1982.

Shanaathanan, Thamotharampillai. 'Commemorating Home: Art as Place Making, an Artist's Narration'. Journal of Material Culture 20, no. 4 (2015): 415-28. https://doi.org/10.1177/1359183515605858.

—_. 'Painting the Artist's Self: Location, Relocation and the Metamorphosis'. In Pathways of Dissent: Tamil Nationalism in Sri Lanka, edited by R. Cheran, 93-106. New Delhi, India ; Thousand Oaks, Calif: SAGE, 2009.

Sharpley, Richard. 'Shedding Light on Dark Tourism: An Introduction'. In The Darker Side of Travel: The Theory and Practice of Dark Tourism, edited by Philip R. Stone, 3-22. Aspects of Tourism. Bristol, UK: Channel View Publications, 2009.

Sivamohan, Sumathy. 'The Rise of Militant Tamil Nationalism, Its Assumptions and the Cultural Production of Tamil Women'. In Sri Lankan Society in an Era of Globalization: Struggling To Create A New Social Order, edited by S. H Hasbullah and Barrie M Morrison, 126-49. New Delhi: Sage Publications, 2004. http://site.ebrary.com/id/10354913.

Sivanandan, Ambalavaner. 'Challenging Racism: Strategies for the '80s'. Race \& Class 25, no. 2 (1983): 1-11. https://doi.org/10.1177/030639688302500202.

—_. When Memory Dies. London: Arcadia Books, 1997.

Sivathamby, Kārttikēcu. Being a Tamil and Sri Lankan. Colombo: Aivakam, 2005.

Smiley, Tavis. M.I.A Tells of Sri Lanka Genocide to US-World Fans 2, 2009. https://www.youtube.com/watch?v=J2Tf6ItheO4.

- - 'My Conversations with M.I.A. and the Sri Lankan Foreign Secretary'. The Huffington Post, 21 March 2009. https://www.huffpost.com/entry/my-conversations-withmia_b_168093.

Smyth, Gerry. "Irish Studies, Postcolonial Theory and the "new" Essentialism'. Irish Studies Review: Irish Studies and Postcolonial Theory 7, no. 2 (1999): https://doi.org/10.1080/09670889908455635. 
Sontag, Susan. On Photography. New York: Farrar, Straus and Giroux, 1977.

—_ Regarding the Pain of Others. 1st ed. New York: Farrar, Straus and Giroux, 2003.

Sosa, Cecilia. Queering Acts of Mourning in the Aftermath of Argentina's Dictatorship: The Performances of Blood. Suffolk: Boydell \& Brewer, 2014.

Spivak, Gayatri Chakravorty. 'Can the Subaltern Speak?' In Marxism and the Interpretation of Culture, edited by Cary Nelson and Lawrence Grossberg, 271-316. Urbana: University of Illinois Press, 1988.

—_. 'Ghostwriting'. Diacritics 25, no. 2 (1995): 64-84. https://doi.org/10.2307/465145.

___. 'Translator's Preface'. In Of Grammatology, by Jacques Derrida, ix-xc. Baltimore: Johns Hopkins University Press, 1997.

'Sri Lanka Civil War: Rajapaksa Says Thousands Missing Are Dead'. $B B C$ News, 20 January 2020, sec. Asia. https://www.bbc.com/news/world-asia-51184085.

Sriskanda Rajah, A. R. Government and Politics in Sri Lanka: Biopolitics and Security. Routledge Studies in South Asian Politics 11. Milton Park: Routledge, 2017.

Stack-O'Connor, Alisa. 'Lions, Tigers, and Freedom Birds: How and Why the Liberation Tigers of Tamil Eelam Employs Women'. Terrorism and Political Violence 19, no. 1 (2007): 43-63. https://doi.org/10.1080/09546550601054642.

'Star Rapper's War Views Turn off Sri Lankan Youth'. Agence France$\begin{array}{llll}\text { Presse, } & 23 & \text { February } & 2009 .\end{array}$ https://web.archive.org/web/20090223171743/https://www.googl e.com/hostednews/afp/article/ALeqM5i2oo26yLuFQIDBkJBm6C mQjeEEjA.

Stewart, James. 'War Tourism in the North of Sri Lanka'. Overland: $\begin{array}{llll}\text { Literary Journal, } & 18 & \text { June }\end{array}$ https://overland.org.au/2013/06/war-tourism-in-the-north-of-srilanka/.

Stokke, Kristian, and Anne Kirsti Ryntveit. 'The Struggle for Tamil Eelam in Sri Lanka'. Growth and Change 31, no. 2 (January 2000): 285304. https://doi.org/10.1111/0017-4815.00129. 
Struk, Janina. Photographing the Holocaust: Interpretations of the Evidence. London: IB Tauris, 2004.

Subramanian, Samanth. This Divided Island: Stories from the Sri Lankan War. London: Atlantic Books, 2015.

Tascon, Sonia. 'The Humanitarian Gaze'. In Social Work in a Glocalised World, edited by Mona Livholts and Lia Bryant, 1st ed., 71-86. London: Routledge, 2017.

Taylor, Diana. Disappearing Acts: Spectacles of Gender and Nationalism in Argentina's 'Dirty War'. Durham: Duke University Press, 1997.

the Americas. Durham: Duke University Press, 2003.

Tétreault, Mary Ann. 'The Sexual Politics of Abu Ghraib: Hegemony, Spectacle, and the Global War on Terror'. NWSA Journal 18, no. 3 (2006): 33-50. https://doi.org/10.1353/nwsa.2006.0064.

Thorup, Mikkel. An Intellectual History of Terror: War, Violence and the State. Critical Terrorism Studies. London: Routledge, 2010.

Thurairajah, Kalyani. 'The Shadow of Terrorism: Competing Identities and Loyalties among Tamil Canadians'. Canadian Ethnic Studies/Etudes Ethniques Au Canada 43, no. 1-2 (2011): 129-52.

Torres-Saillant, Silvio. 'The Trials of Authenticity in Kamau Brathwaite'. World Literature Today 68, no. 4 (1994): 697-707. https://doi.org/10.2307/40150612.

Touré. 'M.I.A. Goes to War'. The Daily Beast, 30 January 2009. https://www.thedailybeast.com/articles/2009/01/30/mia-goes-towar.

Trawick, Margaret. 'Reasons for Violence: A Preliminary Ethnographic Account of the LTTE'. South Asia 20 (1997): 153-80. https://doi.org/10.1080/00856409708723308.

Trilling, Daniel. 'New World Order: M.I.A. Adopts the Feisty Sound of the Slums, but She Is Strongest When Closer to Home'. New $\begin{array}{llll}\text { Statesman, } & 23 & \text { August }\end{array}$ https://www.newstatesman.com/music/2007/08/british-poparulpragasam-world.

Trodd, Zoe. 'Am I Still Not a Man and a Brother? Protest Memory in Contemporary Antislavery Visual Culture'. Slavery \& Abolition: Slavery and Memory in Black Visual Culture 34, no. 2 (2013): 33852. https://doi.org/10.1080/0144039X.2013.791172. 
Truman, Emily. 'The (In)Visible Artist: Stencil Graffiti, Activist Art, and the Value of Visual Public Space'. Shift: Queen's Journal of Visual and Material Culture, no. 3 (2010): 1-15.

Turcotte, Gerry, and Gaetano Rando. 'Diasporic Spectrality: Minorities \& Cultural Assertions in Canada, Australia and Beyond'. Australasian Canadian Studies 23, no. 2 (2005).

United Nations. Universal Declaration of Human Rights. New York: United Nations, 1964.

University Teachers for Human Rights, ed. A Sovereign Will to SelfDestruct: The Continuing Saga Of Dislocation \& Disintegration. Report 12. Thirunelvely: University Teachers for Human Rights, University of Jaffna, 1993. https://web.archive.org/web/20201003040529/http://uthr.org/Re ports/Report12/Report12.htm.

—_ ed. Land, Human Rights \& The Eastern Predicament. Report 11. Thirunelvely: University Teachers for Human Rights, University of Jaffna, 1993. https://web.archive.org/web/20201003040452/http://uthr.org/Re ports/Report11/Report11.htm.

—_ ed. Let Them Speak: Truth about Sri Lanka's Victims of War. Special Report 34. Thirunelvely: University Teachers for Human Rights, University of Jaffna, 2009. https://web.archive.org/web/20201003172818/http://uthr.org/Spe cialReports/Special\%20rep34/Special_Report_34\%20Full.pdf. , ed. The Politics of Destruction \& the Human Tragedy. Report 6. Thirunelvely: University Teachers for Human Rights, University of Jaffna, 1991. https://web.archive.org/web/20201003040215/http://uthr.org/Re ports/Report6/Report6.htm.

, ed. The Trapped People Among Peace Makers and War Mongers. Report 9. Thirunelvely: University Teachers for Human Rights, University of Jaffna, 1992. https://web.archive.org/web/20201003040415/http://uthr.org/Re ports/Report9/Report9.htm.

University Teachers for Human Rights, Rajan Hoole, and Rajani Thiranagama, eds. Sri Lanka: The Arrogance of Power: Myths, 
Decadence \& Murder. Colombo: University Teachers for Human Rights, University of Jaffna, 2001.

Vaitheespara, Ravi. "Beyond "Benign" and "Fascist" Nationalisms: Interrogating the Historiography of Sri Lankan Tamil Nationalism'. South Asia: Journal of South Asian Studies 29, no. 3 (2006): 43558. https://doi.org/10.1080/00856400601032003.

Van De Voorde, Cécile. 'Sri Lankan Terrorism: Assessing and Responding to the Threat of the Liberation Tigers of Tamil Eelam (LTTE)'. Police Practice and Research 6, no. 2 (2005): 181-99. https://doi.org/10.1080/15614260500121195.

Vatter, Miguel. 'Eternal Life and Biopower'. CR: The New Centennial $\begin{array}{lllll}\text { Review } & 10, & \text { no. } & 3 & \text { (2010): }\end{array}$ https://doi.org/10.1353/ncr.2010.0035.

Vieira, Inês. 'The Construction of the Mediterranean Refugee Problem from the Italian Digital Press (2013-2015): Emergencies in a Territory of Mobility'. Networking Knowledge: Journal of the MeCCSA Postgraduate Network 9, no. 4 (24 May 2016). https://doi.org/10.31165/nk.2016.94.448.

Walcott, Derek. 'The Sea Is History'. In Poems 1965-1980, 237-40. London: Cape, 1993.

Wayland, Sarah. 'Ethnonationalist Networks and Transnational Opportunities: The Sri Lankan Tamil Diaspora'. Review of International Studies 30, no. 3 (2004): 405-26. https://doi.org/10.1017/S0260210504006138.

Weems, Lisa. 'Border Crossing with M.I.A. and Transnational Girlhood Studies'. In Postcolonial Challenges in Education, edited by Roland Sintos Coloma, 369:180-81. Counterpoints. New York: Peter Lang, 2009.

'M.I.A. in the Global Youthscape: Rethinking Girls' Resistance and Agency in Postcolonial Contexts'. Girlhood Studies 2, no. 2 (1 December 2009): $55-75$. https://doi.org/10.3167/ghs.2009.020205.

—_. 'Refuting "Refugee Chic": Transnational Girl(Hood)s and the Guerilla Pedagogy of M.I.A.' Feminist Formations 26, no. 1 (17 April 2014): 115-42. https://doi.org/10.1353/ff.2014.0010.

Weiss, Gordon. The Cage: The Fight for Sri Lanka and the Last Days of the Tamil Tigers. 1st ed. New York: Bellevue Literary Press, 2012. 
Wheaton, Robert. 'London Calling-For Congo, Colombo, Sri Lanka...' In Da Capo Best Music Writing 2006: The Year's Finest Writing on Rock, Hip-Hop, Jazz, Pop, Country, \& More, edited by Mary Gaitskill and Daphne Carr, 36-49. Cambridge, Mass.: Da Capo, 2006.

White, Timothy J. 'Nationalism vs. Liberalism in the Irish Context: From a Postcolonial Past to a Postmodern Future'. Ére-Ireland 37, no. 3 (2002): 25-38. https://doi.org/10.1353/eir.2002.0016.

Williams, Mary Elizabeth. 'Does M.I.A.'s Genocide Video Go Too Far?' Salon, 27 April 2010, sec. Culture. https://www.salon.com/2010/04/27/mia_born_free_video/.

Wilson, A. Jeyaratnam. Sri Lankan Tamil Nationalism: Its Origins and Development in the Nineteenth and Twentieth Centuries. Vancouver: UBC Press, 2000.

_- 'The Colombo Man, the Jaffna Man, and the Batticaloa Man: Regional Identities and the Rise of the Federal Party'. In The Sri Lankan Tamils: Ethnicity and Identity, edited by Chelvadurai Manogaran and Bryan Pfaffenberger, 126-42. London: Routledge, 2019.

Wolff, Sarah. 'Migration and Refugees in the Mediterranean: Rethinking Geopolitical Constraints, Western-Centric Policies and Mobility's Precariousness'. Mediterranean Politics 20, no. 3 (2015): 439-44. https://doi.org/10.1080/13629395.2015.1087106.

Wood, Marcus. 'Imaging the Unspeakable and Speaking the Unimaginable: The "Description" of the Slave Ship Brookes and the Visual Interpretation of the Middle Passage'. Lumen: Selected Proceedings from the Canadian Society for Eighteenth-Century Studies 16 (1997): 211-45. https://doi.org/10.7202/1012450ar.

Woodward, Jon. 'Canada Deported Man to Torture in Sri Lanka: Affidavit'. CTV British Columbia, 8 October 2013. https://bc.ctvnews.ca/canada-deported-man-to-torture-in-srilanka-affidavit-1.1489741.

Yiftachel, Oren, and As'ad Ghanem. "Understanding "Ethnocratic" Regimes: The Politics of Seizing Contested Territories'. Political Geography 23, no. 6 (August 2004): 647-76. https://doi.org/10.1016/j.polgeo.2004.04.003. 
Young, Harvey. Embodying Black Experience: Stillness, Critical Memory, and the Black Body. Theater: Theory/Text/Performance. Ann Arbor: University of Michigan Press, 2010.

—_. 'The Black Body as Souvenir in American Lynching'. Theatre Journal 57, no. 4 (2005): 639-57. https://doi.org/10.1353/tj.2006.0054.

Young, Hershini Bhana. Haunting Capital: Memory, Text and the Black Diasporic Body. Hanover, New Hampshire: University Press of New England, 2006.

Young, Robert JC. 'Postcolonial Remains'. New Literary History 43, no. 1 (25 May 2012): 19-42. https://doi.org/10.1353/nlh.2012.0009.

Zach, Baron. 'M.I.A.'s “Born Free Video": Police Brutality, Mass Redhead Genocide, and Exploding Humans'. The Village Voice, 26 April 2010. https://www.villagevoice.com/2010/04/26/m-i-a-s-bornfree-video-police-brutality-mass-redhead-genocide-and-explodinghumans/. 